التوزيع الجغرافي الحالي والأمثل لواردات مصر من بعض الزيوت التباتية

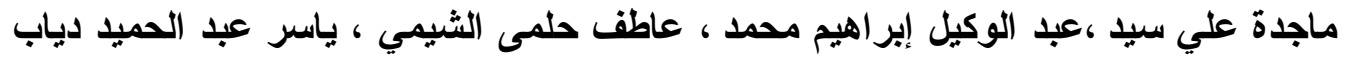

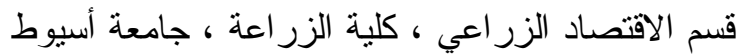

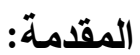

تشخل المحاصيل الزيتية مكانة هامة في الاقتصاد الزر اعي المصري، وتأتي أهميتها مــن

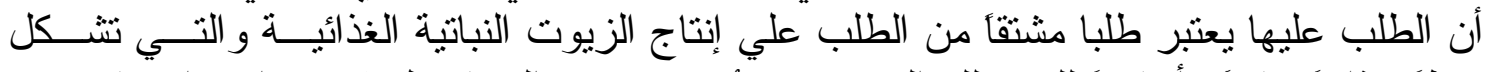

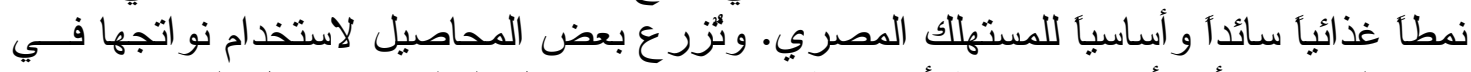

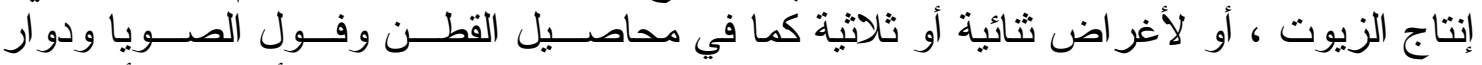

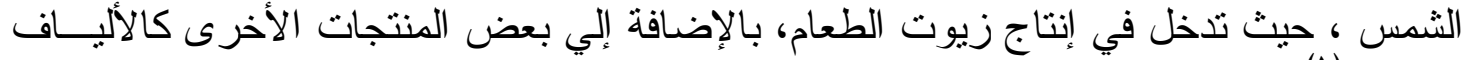

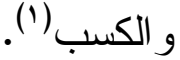

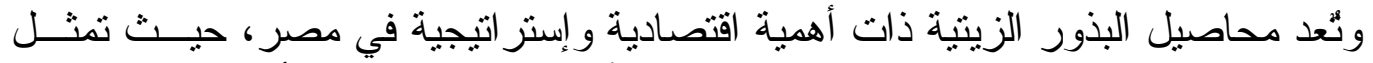

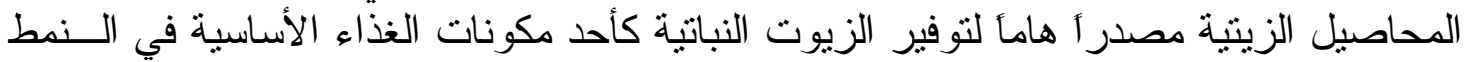

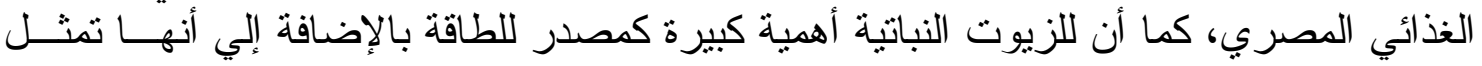

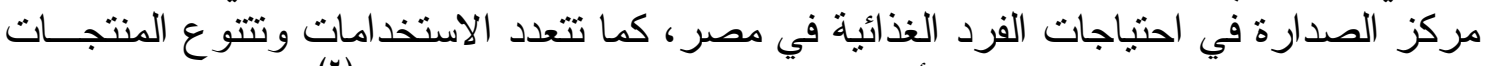

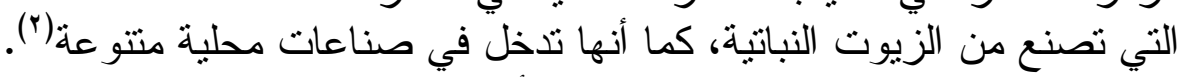

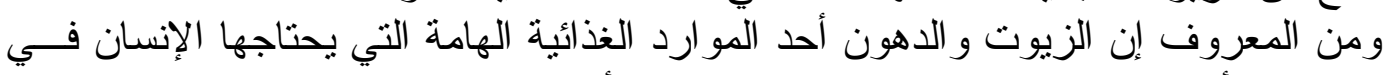

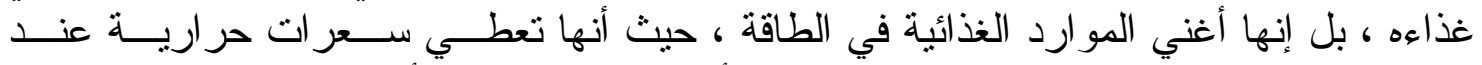

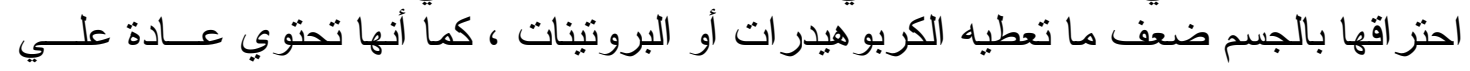

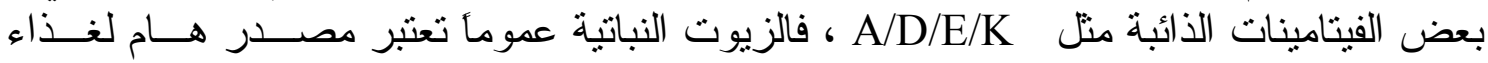

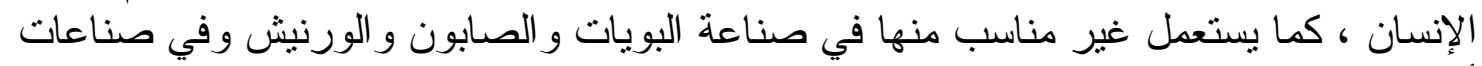

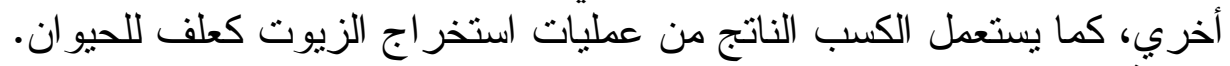
مشكلة البحث:

تأتي الزيوت النباتية الغذائية في مقدمة السلع التي تتز ايد فيها الفجوة الغذائية فــي مصـــر

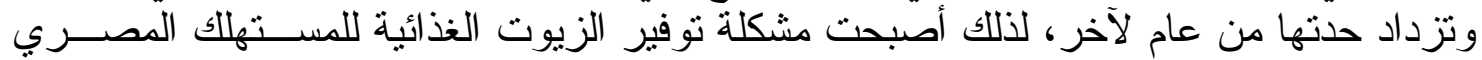

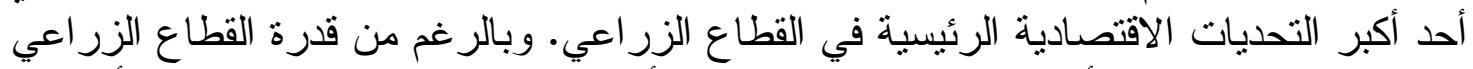

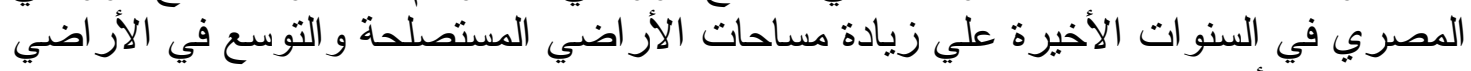

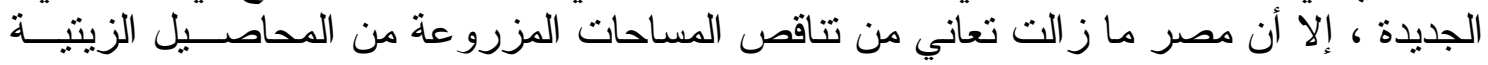

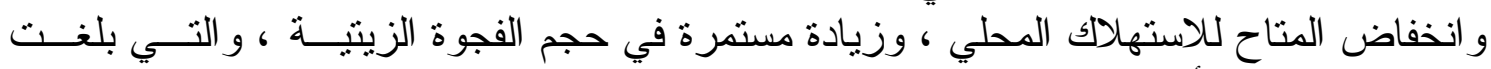

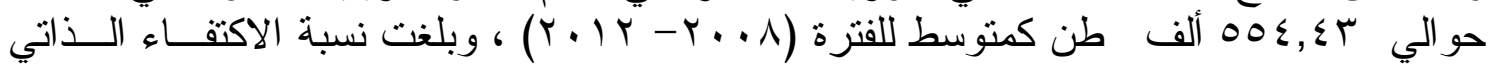

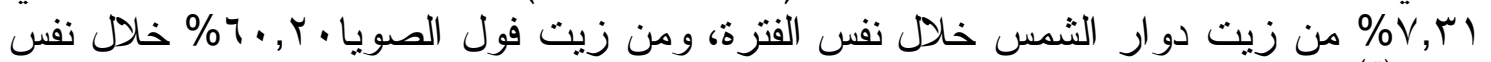

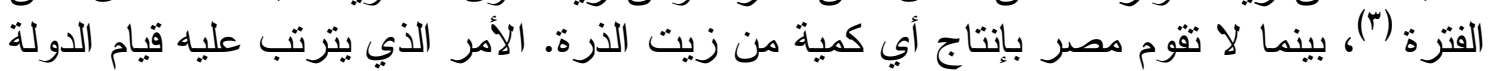

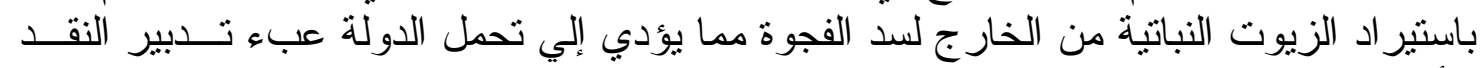

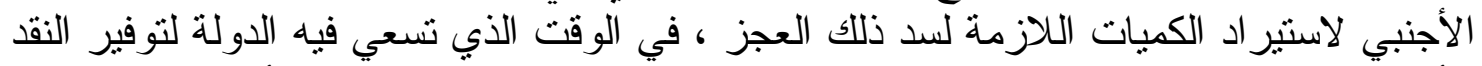

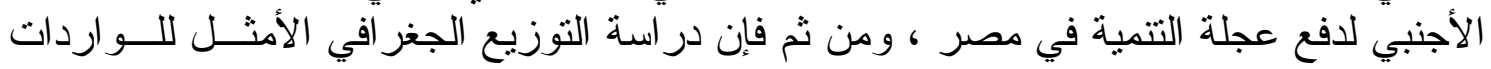

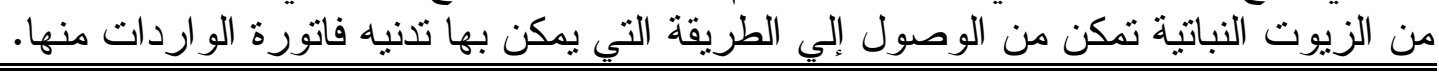

Received on: 12/11/2014

Accepted for publication on: 30/11/2014

Referees: Prof. Galal A. El-sagheer

Prof. Metwally S. Elzanaty

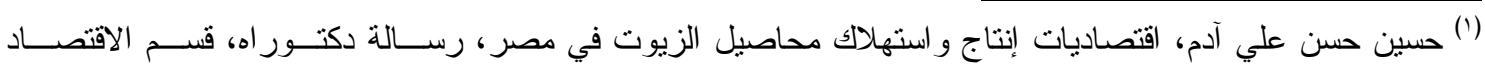

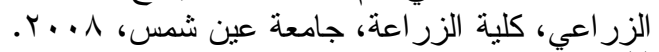
www.aiu.edu/University ${ }^{(r)}$ (r) (") 


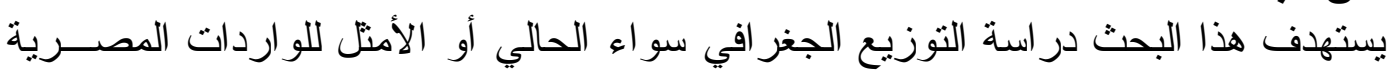
الكهدف من البحث:

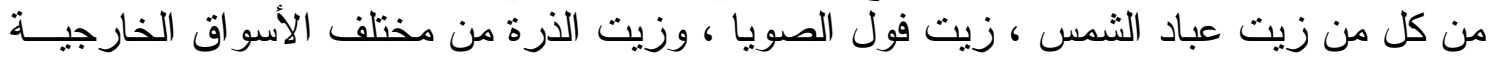

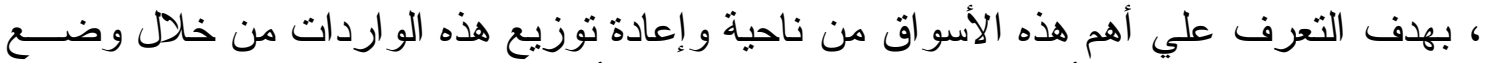

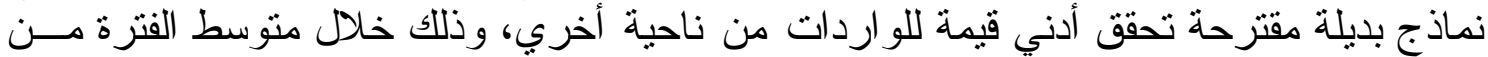

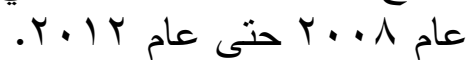
الأسلوب البحثي ومصادر البيانات:

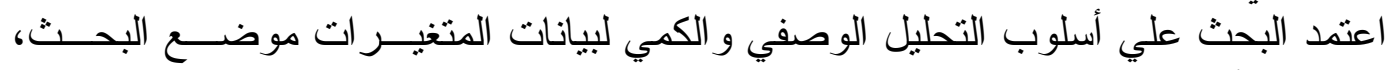

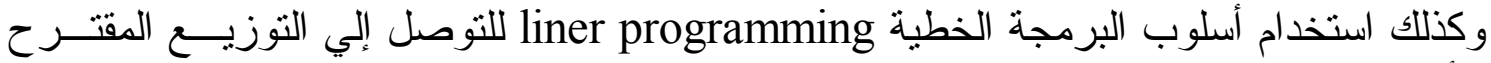

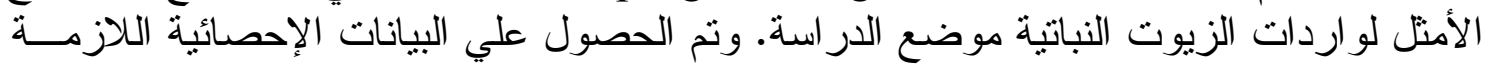

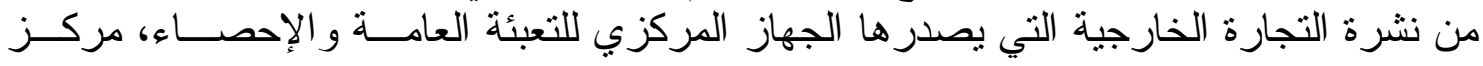

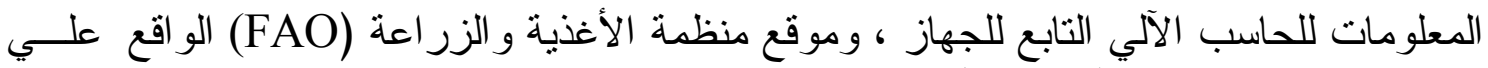

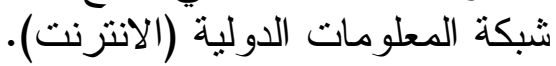

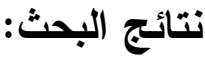

أولاً: التوزيع الجغرافي الحالي لواردات مصر من بعض الزيوت النباتية :

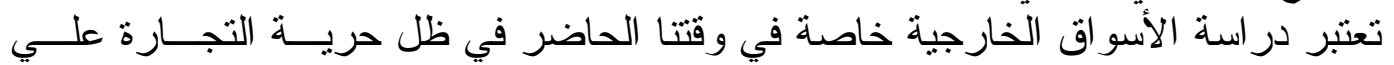

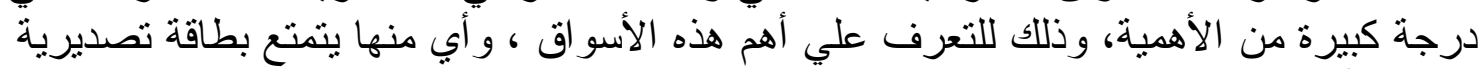

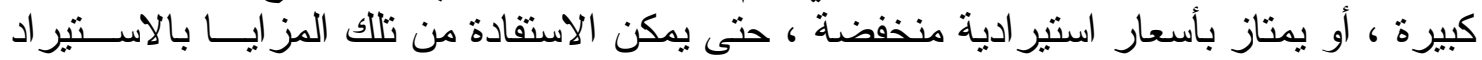

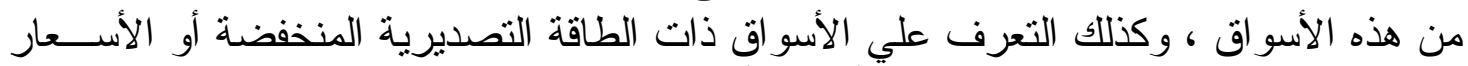

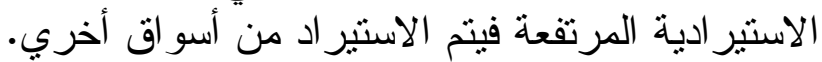

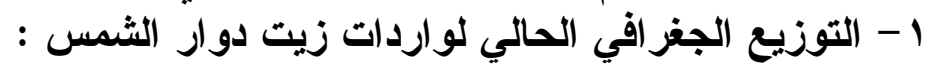

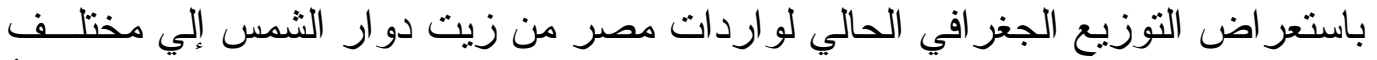

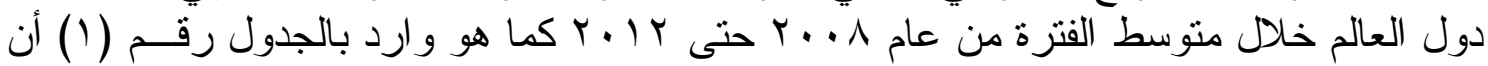

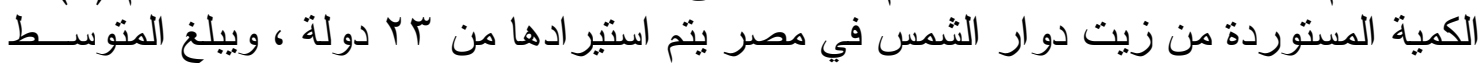

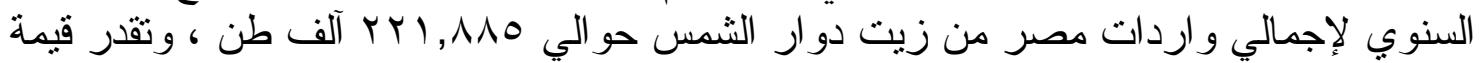

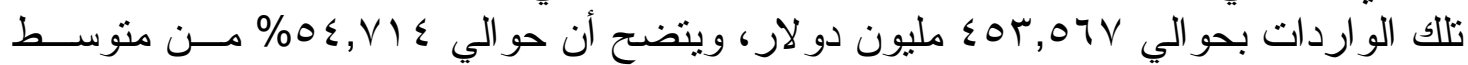

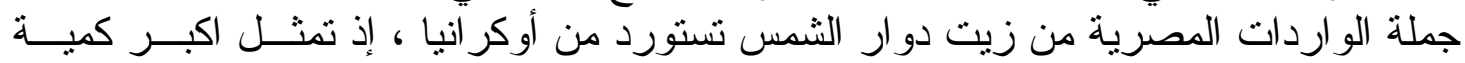

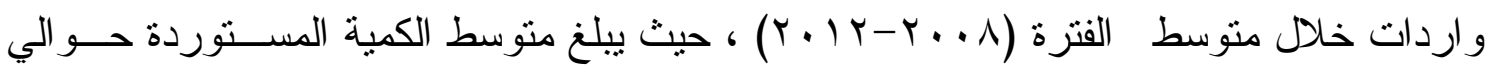

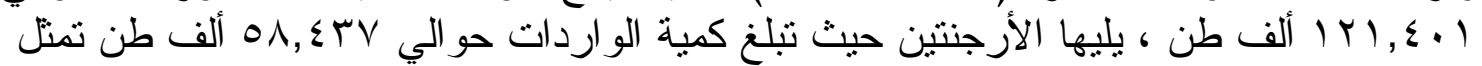

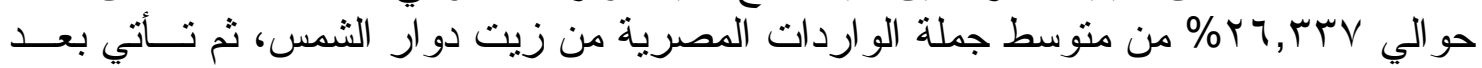

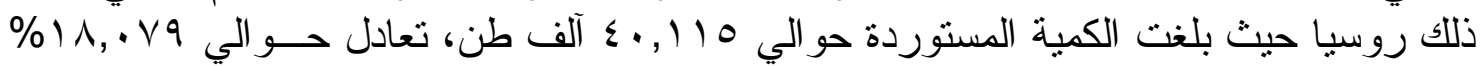

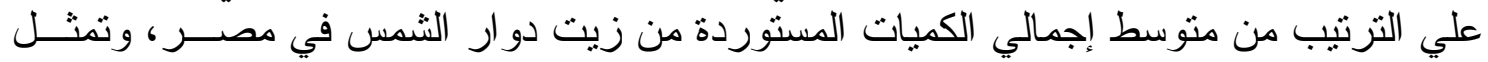

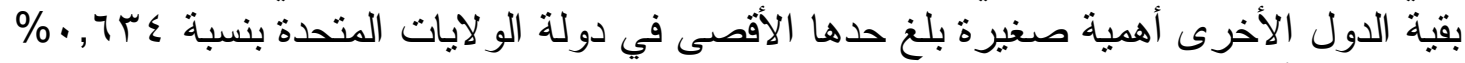

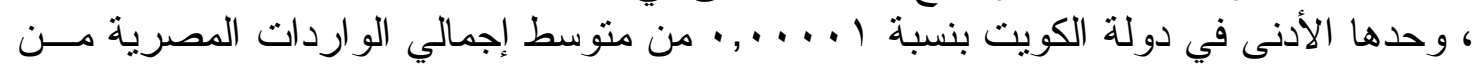

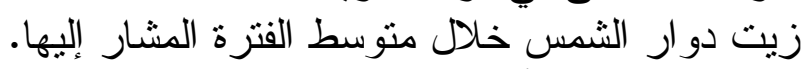

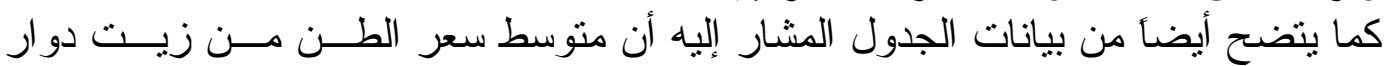

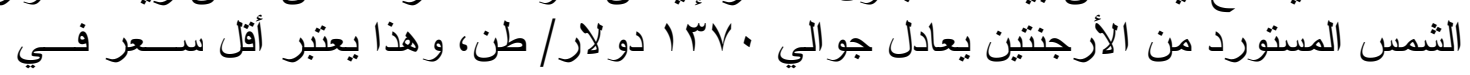

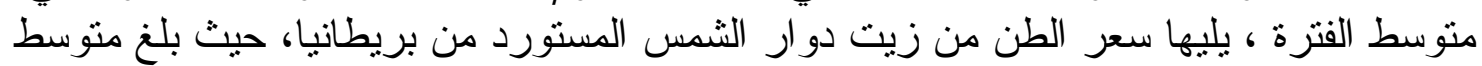

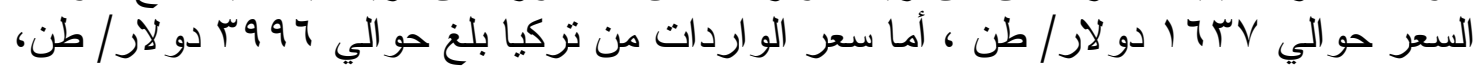

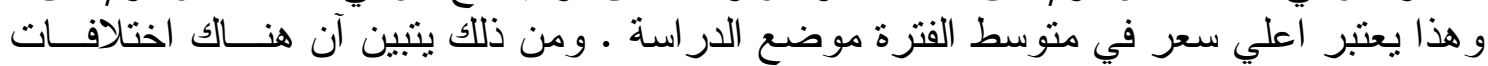

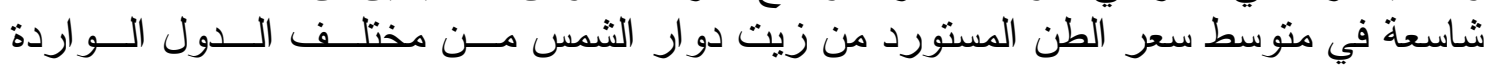

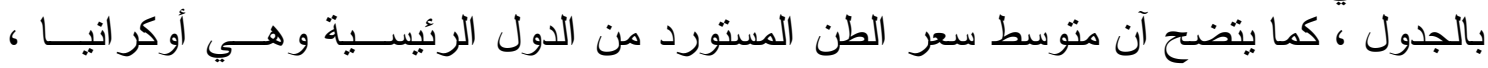




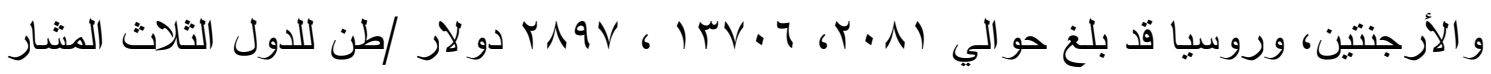

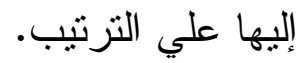




\begin{tabular}{|c|c|c|c|c|c|c|c|}
\hline \multicolumn{2}{|c|}{ الطاقة التصديرية } & \multirow{2}{*}{ 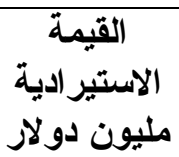 } & \multirow{2}{*}{ متوسط السعر } & \multicolumn{2}{|c|}{ الكمية المستوردة } & \multirow{2}{*}{ السنو ات } & \multirow{2}{*}{ الدولة } \\
\hline$* \%$ & ألف طن & & & $\%$ & ألف طن & & \\
\hline$\cdot, \cdot \leq 9$ & $r \varepsilon, \wedge l$. & $\cdot, \cdot r q$ & YMOV & $\cdot, \ldots$ & $\cdot, \cdot 1 r$ & $r$ & الإمار ات \\
\hline $1, .77$ &., $07 \mathrm{~V}$ & $\cdot, \cdot 11$ & $1 \wedge 11$ & r., & $\cdot, \cdots 7$ & 1 & الأردن \\
\hline$\cdot, \vee \vee T$. & $1,1 \wedge V$ & r & אזםr & $\cdot, \cdots \varepsilon$ & $\cdot, \cdots 9$ & 1 & الصبن \\
\hline & דזי, • & $\cdot, \ldots \varepsilon$ & rqY & $\cdot, \ldots, 1$ &,$\ldots \ldots 1$ & 1 & الكويت \\
\hline$\cdot, \cdots \varepsilon$ & $17 \pi, .91$ & $\cdot, \cdots 9$ & $100 \leqslant$ & r., r & $\cdot, \cdots 7$ & 1 & المجر \\
\hline$\cdot, \ldots 1$ & YI,VAะ & $\cdot, \ldots 1$ & Y^OV & $\cdot, \cdots \cdot q$ & $\cdot, \cdots r$ & 1 & المكسيك \\
\hline $1, \wedge \leqslant \wedge$ & שTו & $r, \cdot \wedge \varepsilon$ & r19r & ع & $1, \varepsilon \cdot V$ & $\varepsilon$ & الو لايات \\
\hline$\cdot, 0 \wedge 7$ & $r, \cdot r \wedge$ & rr., & 1909 & $\cdot, \ldots$ & $\cdot, \cdot 1 r$ & r & المتحدة \\
\hline$\cdot, \ldots$ & rq,oV^ & $\cdot, \cdot Y_{1}$ & $1 \leqslant 14$ & $\cdot, \cdots 1$ & $\cdot, \cdots$ & r & اليونان \\
\hline 7,071 & 19.,7זะ & $1 \cdot, \cdot 77$ & ITV. & rq,rس & 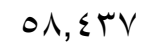 & 0 & إيطاليا \\
\hline$, \ldots, \cdots$ & $10, .0$. & سו . ., & TMVT & $, \ldots, r$ & $\cdot, \cdots \varepsilon$ & 1 & الأرجنتين \\
\hline$\cdot, \cdot 1$ & $\wedge \varepsilon, \wedge Y \varepsilon$ & $\cdot, \cdot r$. & TYVE & $\cdot, \cdots \varepsilon$ & $\cdot, \cdots 9$ & r & أسبانبا \\
\hline 0, VYO & rדוצ', & YOY, $T \leqslant \wedge$ & $r \cdot \Lambda l$ & $0 \leq, V) \leq$ & $|Y|, \Sigma \cdot \mid$ & 0 & ألمانيا \\
\hline., 04 & $17,7.0$ & $\cdot, \cdot 10$ & ITV & $\cdot, \cdots \varepsilon$ & $\cdot, \cdots 9$ & r & أوكر انيا \\
\hline$\cdot, \ldots$ & $\wedge q, \leqslant \vee 7$ & $\cdot, \cdots V$ & IVAT & $\cdot, \cdot r$ & $\cdot, \cdots \varepsilon$ & 1 & بريطانيا \\
\hline$\cdot, 19 \varepsilon$ & IT.,TK & •, & r997 &., 1.0 & מזץ,. & $\varepsilon$ & بلغاريا \\
\hline $1, \cdot \Lambda$. & & ס י, & r^१V & $\cdot, \cdots 7$ & $\cdot, \cdot 1 Y$ & 1 & تركيا \\
\hline V & OYT, rT & $117, r Y q$ & r^qV & $11, \cdot \vee q$ & $\varepsilon ., 110$ & 0 & تايو ان \\
\hline וT|, & $7, \vee 91$ & $\cdot, \cdot r$ & INH. & $\cdot, \cdots \varepsilon$ & $\cdot, \cdots 9$ & 1 & روسيا \\
\hline$\cdot,|1|$ & $r, Y \wedge)$ & $\cdot, \cdot r$. & س & $\cdot, \cdots r$ & $\cdot, \cdots \varepsilon$ & 1 & سنغافورة \\
\hline$q, \leqslant 1$. &., .70 & $\cdot, r r$ & rovr & r., & $\cdot, \cdots 7$ & 1 & سوريا \\
\hline$\cdot, \cdot \leq \Lambda$ & $r V \cdot, \wedge T \leq$ & טוr, & $18 \vee 9$ & $\cdot, \wedge$ & $\cdot, I V V$ & $\varepsilon$ & شيلي \\
\hline r., & $\varepsilon 0 \leqslant, Y \wedge V$ & $\cdot, \cdot \leq V$ & o & $\cdot, \cdots v$ & $\cdot, \cdot 10$ & r & فر لندا \\
\hline & & $\leqslant 0 T, 07 \mathrm{~V}$ & & $1 \ldots$ & 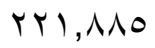 & & الجملة \\
\hline
\end{tabular}

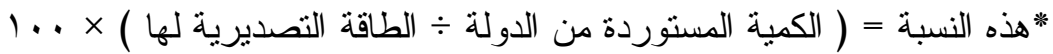

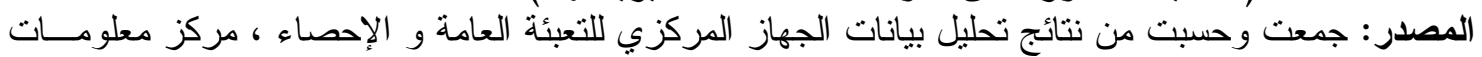

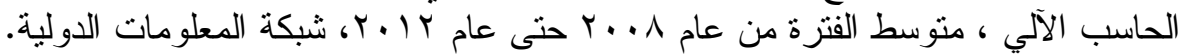

\section{r- التوزيع الجغرافي الحالي لواردات زيت فول الصويا :}

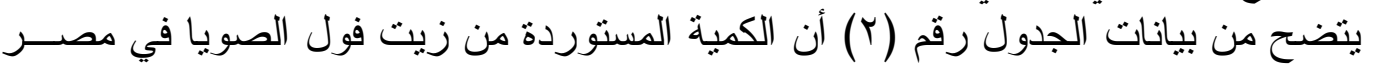

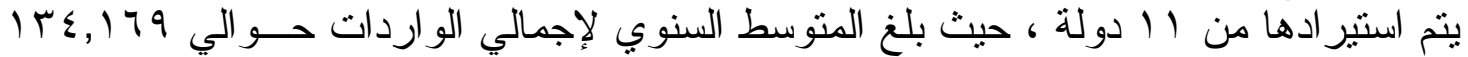

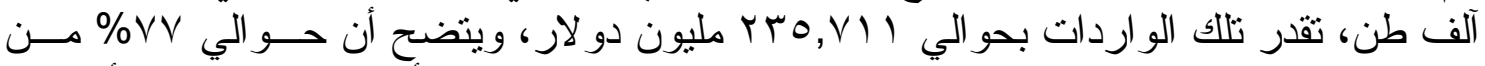

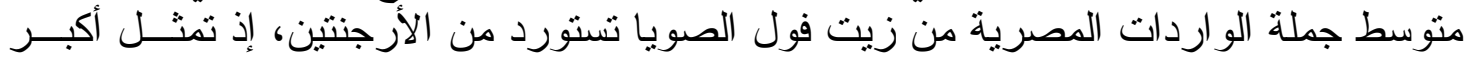

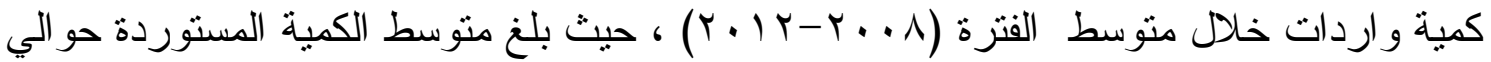

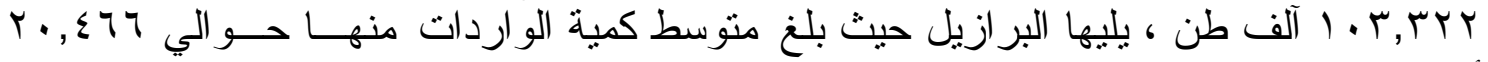

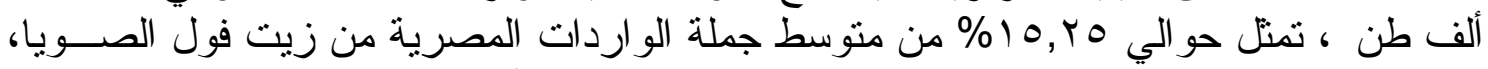

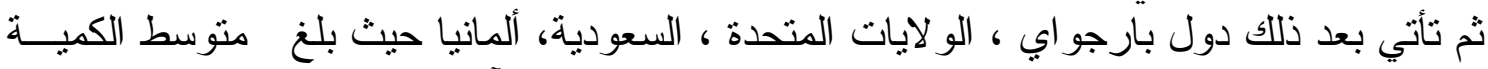

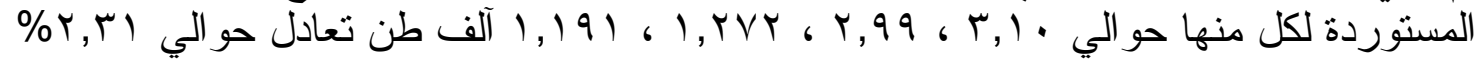

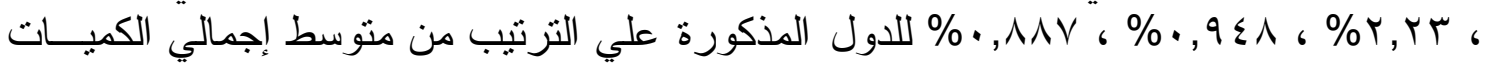

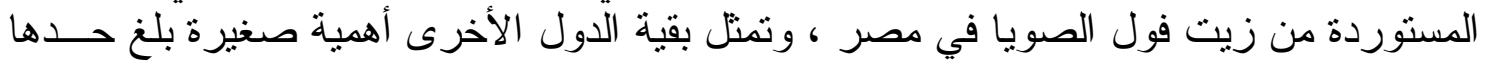




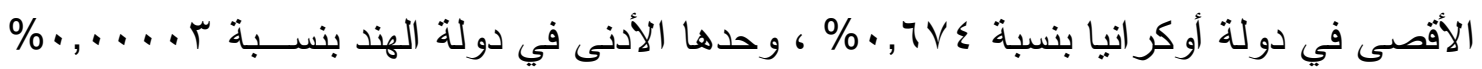

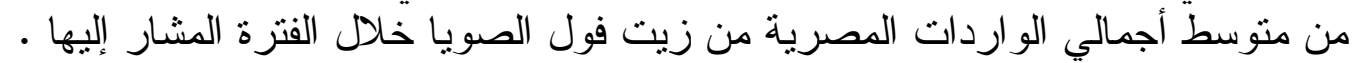

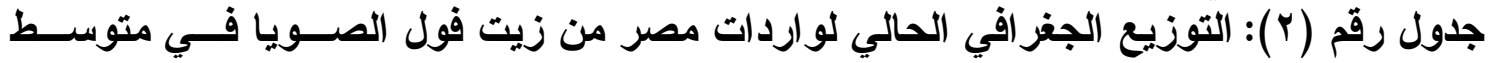

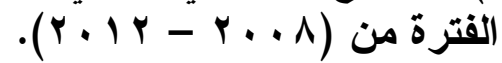

\begin{tabular}{|c|c|c|c|c|c|c|c|}
\hline \multicolumn{2}{|c|}{ الطاقة التصديرية } & \multirow{2}{*}{ مليون الاستير ادية } & \multirow{2}{*}{ دولار/طن السعر } & \multicolumn{2}{|c|}{ الكمية المستوردة } & \multirow{2}{*}{ السنوات } & \multirow[b]{2}{*}{ الدولة } \\
\hline$* \%$ & ألف طن & & & $\%$ & ألف طن & & \\
\hline$r, Y_{1}$. & $\leqslant 7 \vee \leqslant, 9 \wedge 9$ & INY,OVV & IVTV & $v \vee, \ldots q$ & I.r,TrY & 0 & الأرجنتين \\
\hline ס & $11 \cdot 4,779$ & ro, 174 & IVIN & $10, Y 0 \leqslant$ & $T_{\cdot}, \sum T T$ & $r$ & البر ازيل \\
\hline סטז, & $|r V|, q r q$ & $\varepsilon, Y T V$ & $1 \leqslant r q$ & Y,YYT & $r, q \wedge \vee$ & r & الو لايات المتحدة \\
\hline$\cdot, r \wedge 0$ & $r \cdot q, \varepsilon \leq \varepsilon$ & סזד, & TrV & $\cdot, \wedge \wedge \vee$ & 1,191 & $\varepsilon$ & ألمانيا \\
\hline$\cdot, \cdots 1$ & r,oYq & $\cdot, \ldots 19$ & $0 \leqslant \cdot r$ & $\cdot, \ldots r$ & $\cdot, \ldots \varepsilon$ & 1 & |الهند \\
\hline $1, r \cdot r$ & rMA,.01 & 7,0 \% & $r) \cdot 1$ & r, & $r, 1 \ldots$ & 1 & بارجو اي \\
\hline$\cdot, \cdot \Delta r$ & $\leqslant \neg \wedge, \vee 9 \varepsilon$ & $\cdot, \vee \vee q$ & $19 . \varepsilon$ & $\cdot, Y \wedge O$ & • & r & هو لندا \\
\hline س & $\cdot, Y \mu \Lambda$ & $\cdot, \cdots \wedge$ & $r \leq T \leq$ & $\cdot, \cdot r$ & $\cdot, \ldots r$ & 1 & سويسر | \\
\hline r,M & rA, rOV & $Y, O \cdot V$ & 1971 & $\cdot, 9 \leq \wedge$ & $1, r \vee r$ & r & السعودية \\
\hline r, १०r & $r \cdot, T \cdot V$ & $1,00 \mathrm{~V}$ & IVYT & $\cdot, T \vee \leqslant$ & $\cdot, 9 \cdot \leq$ & r & أوكر انيا \\
\hline$\cdot, \leq Y \wedge$ & $\mid r q, r \cdot \Lambda$ & $\cdot, \vee Y q$ & $1 \pi \leqslant 1$ & $\cdot, \varepsilon \cdot r$ & $\cdot, 0 \leqslant 1$ & 1 & ل كوسيا \\
\hline & & rro,VII & & $1 \ldots$ & $11 \varepsilon, 179$ & & الجملة \\
\hline
\end{tabular}

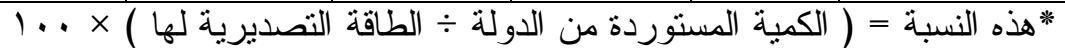

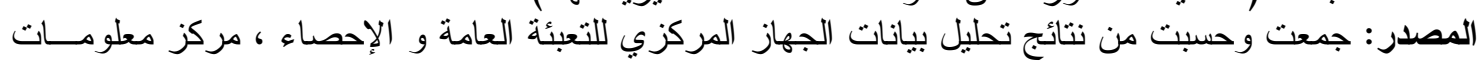

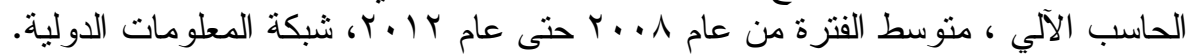

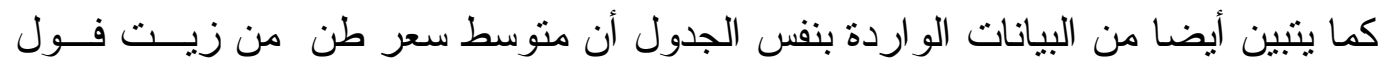

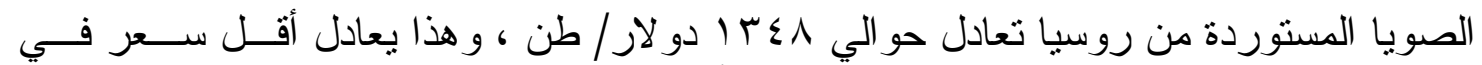

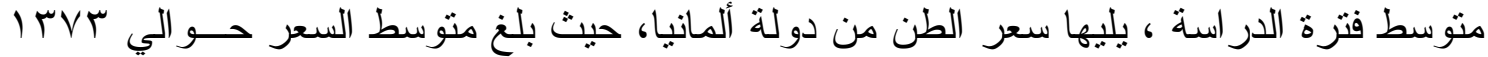

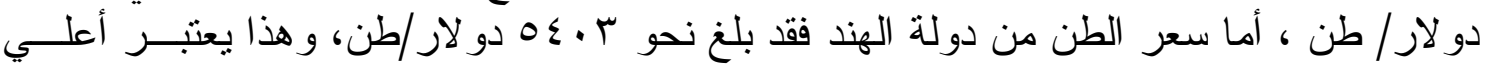
سعر في متوسط فترة الدر اسة. آما نسبة واردات مصر من دن زيت فول الصويا من الدول الدول المختلفة

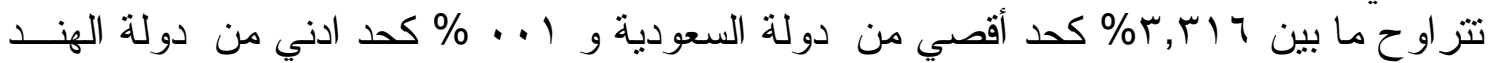

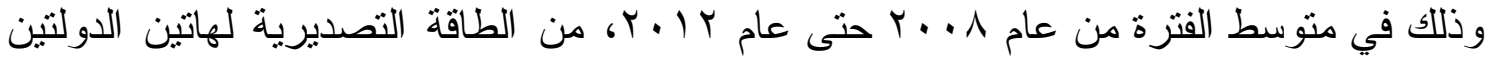
علي التزنيب.

\section{بَ- التوزيع الجغر افي الحالي لواردات زيت الأرة:}

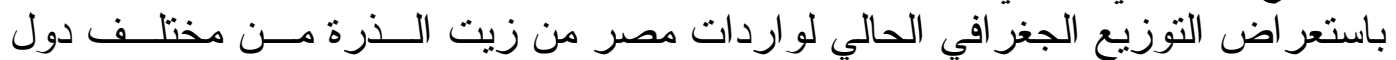

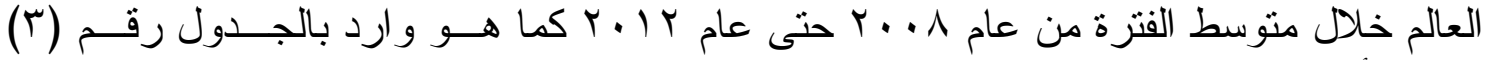

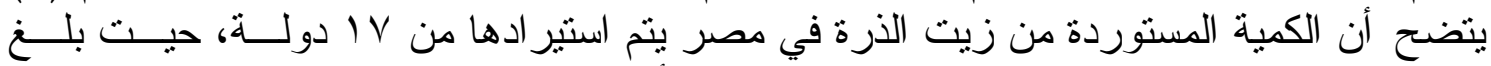

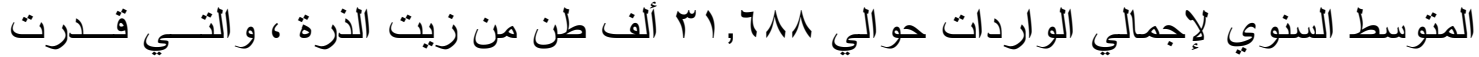

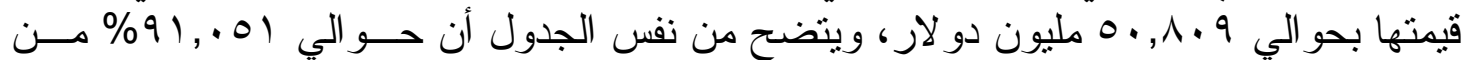

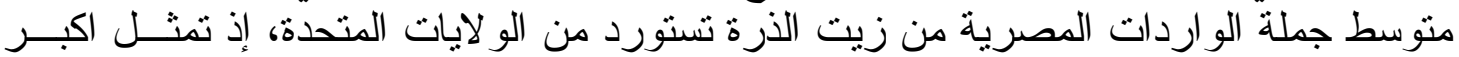

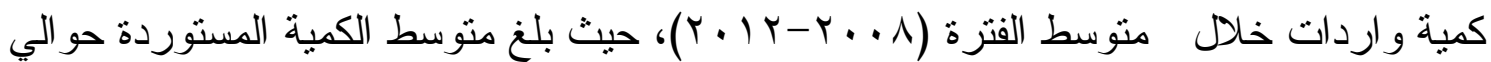

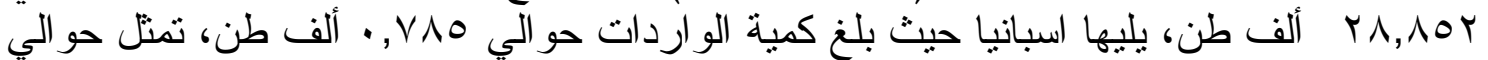
\% \% r \&VV

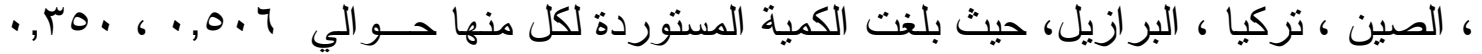

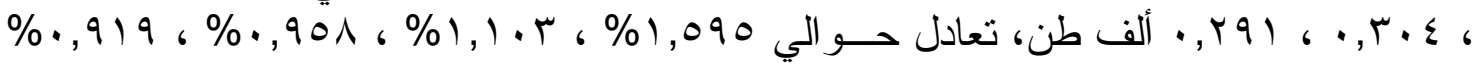

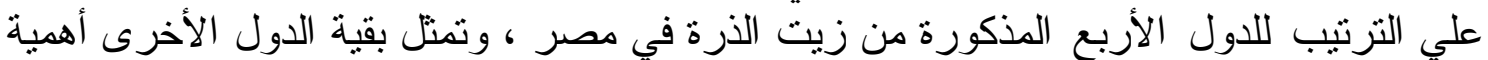

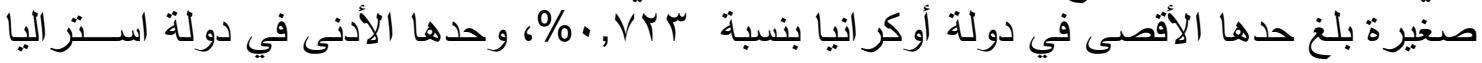


بنسبة ء . . . ., . من منوسط إجمالي الواردات المصرية من زيت الذرة خلال الفتـرة المشـــار

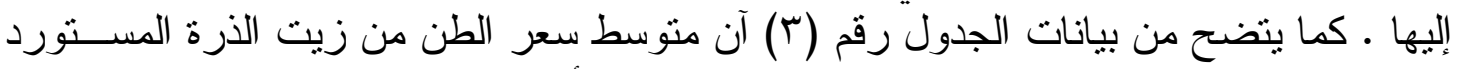

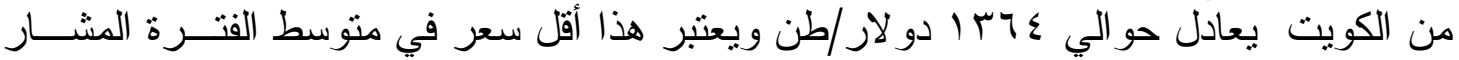

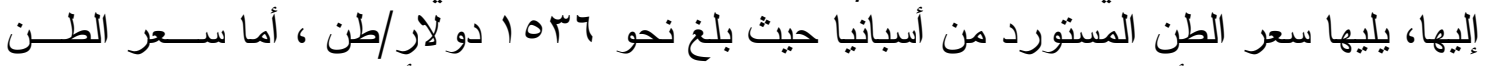

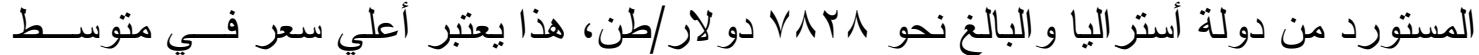

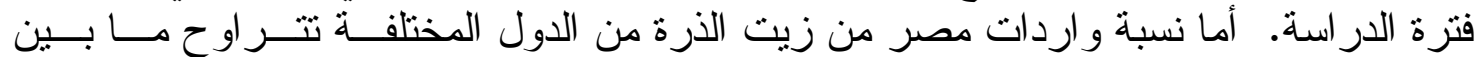

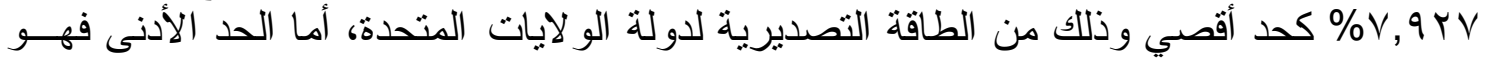

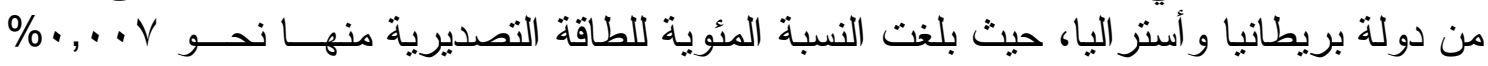
وذللك في متوسط الفترة المشار إليها سابقاً.

جدول رقم (ب): التوزيع الجغرافي الحالي لواردات مصر من زيت الأرة في متوسط الفترة من .$(r+1 r-r \cdot \Lambda)$

\begin{tabular}{|c|c|c|c|c|c|c|c|}
\hline \multicolumn{2}{|c|}{ الطاقة التصديرية } & \multirow{2}{*}{ مليون دالاتير ادية } & \multirow{2}{*}{ متوسط السعر } & \multicolumn{2}{|c|}{ الكمية المستوردة } & \multirow{2}{*}{ السنوات } & \multirow{2}{*}{ الدولة } \\
\hline$* \%$ & ألف طن & & & $\%$ & ألف طن & & \\
\hline$V, q Y V$ & & $\varepsilon 0,19 r$ & 1074 & $91, .01$ & YA,AOY & 0 & الو لايات المتحدة \\
\hline$r, 107$ & $r T, \varepsilon \leqslant V$ & $1,1 \wedge 1$ & סשדז & 1,090 &., 0.7 & r & أرجنتين \\
\hline$\cdot, Y Y T$ & $r r, \cdot \wedge r$ & $\cdot, r \cdot l$ & TVV & $\cdot, r Y q$ & $\cdot, \cdot V r$ & 0 & السعودية \\
\hline $1,9 \leqslant 1$ & 10,010 & $\cdot, 0 \wedge \Lambda$ & $19 \pi \mathrm{V}$ & $\cdot, 90 \wedge$ & $\cdot, r \cdot \varepsilon$ & 0 & تركيا \\
\hline$\cdot, \cdots V$ & $1, \vee \vee \wedge$ & $\cdot, \ldots r$ & r)91 & $\cdot, \ldots \varepsilon$ & $\cdot, \cdots 1$ & r & بريطانيا \\
\hline$\cdot, \Sigma \wedge \Sigma$ & rT, qTr & •, & MAV & דודו, & •.,117 & 0 & فرنسا \\
\hline$\cdot, \wedge \leq \vee$ & $\{1,(49)$ & $\cdot, T \vee V$ & $194 \mathrm{~V}$ & $1,1 \cdot r$ & • ro. & 1 & الصين \\
\hline$\vee, \vee \wedge \neg$ & 1,771 & - YYOO & IVYq & $\cdot$, . & • & 1 & | اليابان \\
\hline$\cdot, \leqslant 09$ & 9,107 & $\cdot, \cdot V T$ & IVE. & תזו, & $\cdot, \cdot \leq Y$ & 1 & الآمر ات \\
\hline$r, .90$ & $V, \varepsilon \cdot V$ & $\cdot, \varepsilon)$. & IVAV & $\cdot, V Y T$ & •, YYq & r & | أوكر انيا \\
\hline$\cdot, \wedge 90$ & Mr, $0 \leqslant \Lambda$ & $\cdot, 77 \varepsilon$ & TYA. & $\cdot, 919$ & $\cdot, r 91$ & 1 & البر ازيل \\
\hline$\cdot, \cdot 1 T$ & $r r, \cdot \varepsilon \varepsilon$ & $\cdot, \cdots 7$ & 1910 & $\cdot, \cdots 9$ & $\cdot, \cdots r$ & $r$ & إيطاليا \\
\hline$\cdot, \cdots \wedge$ & $7 r, 0 \cdot V$ & $\cdot, \cdot 1 \cdot$ & IAYA & $\cdot, ., 17$ & $\cdot, \ldots$ & 1 & بلجيكا \\
\hline$\cdot, \cdots V$ & $\cdot, 191$ & $\cdot, \cdots 11$ & VAYA & $\cdot, \ldots \varepsilon$ & $\cdot, \cdots$, & 1 & |ستر اليا \\
\hline$\cdot, \cdots 9$ & r & $\cdot, \cdots \varepsilon$ & ع & $\cdot, \cdots q$ & $\cdot, \ldots r$ & 1 & الكويت \\
\hline $0,7 \cdot 7$ & 11,991 & $1, r \cdot 0$ & 1047 & $Y, \leqslant \vee V$ & $\cdot, \vee \wedge \wedge$ & r & اسبانيا \\
\hline$\cdot, 9 \leqslant 1$ & ع & $\cdot, \cdots \wedge$ & $r \leqslant \Lambda$. & $\cdot, \cdot, \cdot$ & $\cdot, \ldots r$ & 1 & تايلاند \\
\hline & & $0 \cdot, 1 \cdot 9$ & & $1 \ldots$ & & & الجملة \\
\hline
\end{tabular}

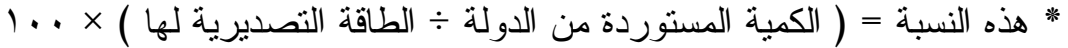

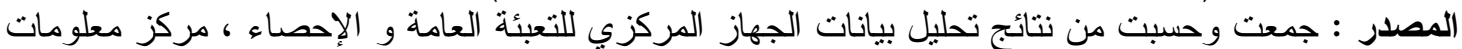

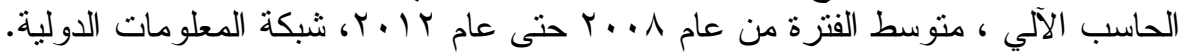

ثانيا: التوزيع الجغرافي المقترح (الأمثل) لواردات مصر من بعض الزيوت النباتية :

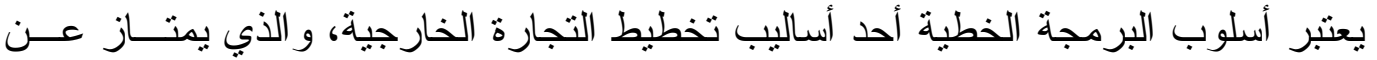

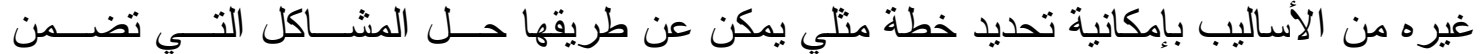
علاقات دالية خطية لعدة متغير ات ، ويتضمن هذا الأسلوب صياغة المشكلة موضع البحث فئ فئي

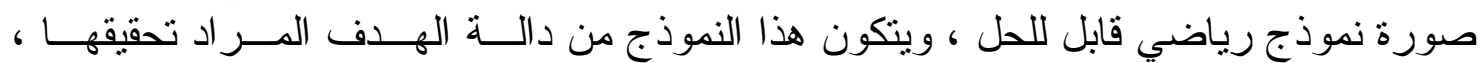

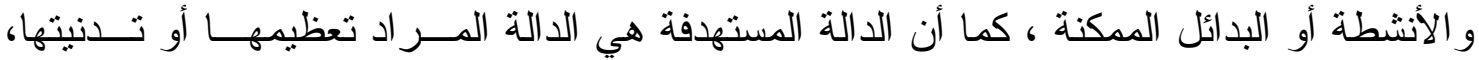




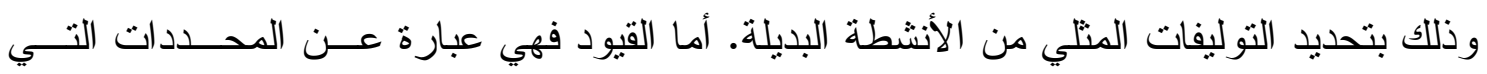

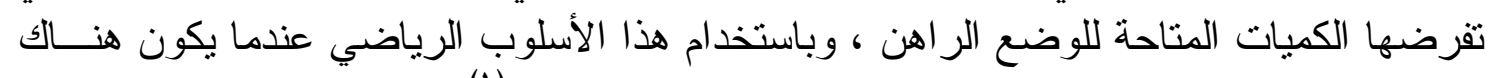

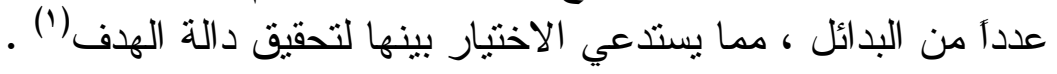

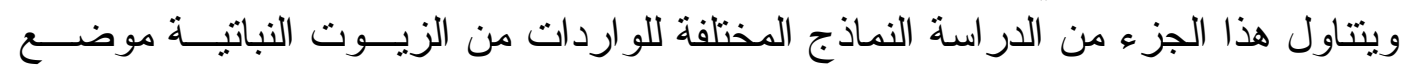

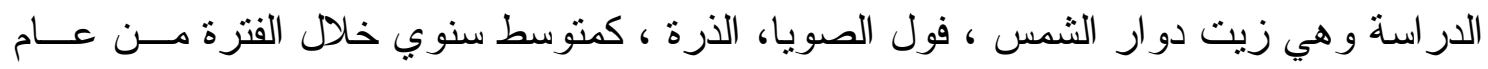

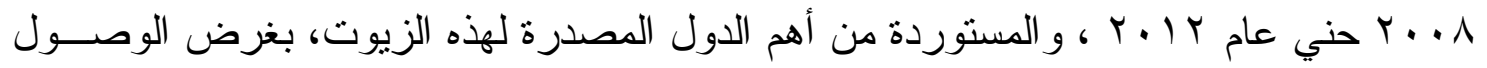

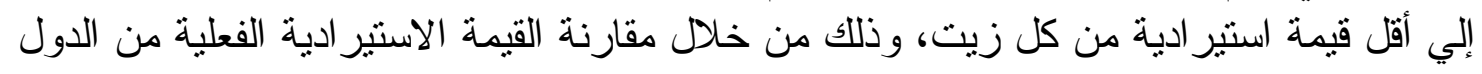

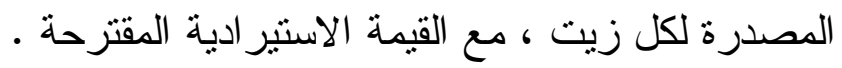

\section{توصيف نموذج البرمجة الخطية المستخدم في الصورة العامة:}

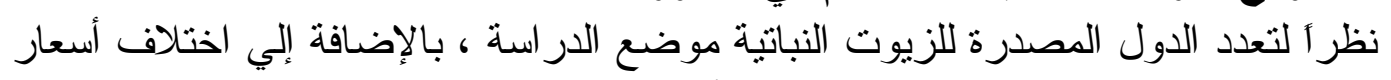

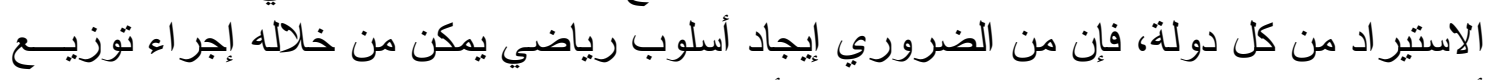

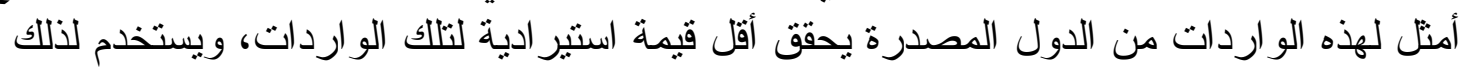

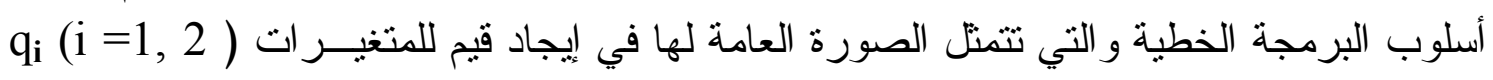

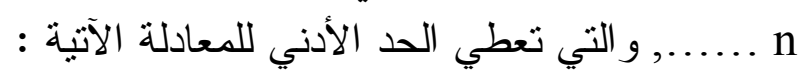

$$
\operatorname{Min} \mathrm{z}=\sum_{\mathrm{i}=1}^{\mathrm{n}} \mathrm{p}_{\mathrm{i}} \mathrm{q}_{\mathrm{i}}
$$

وتأخذ مصفوفة النموذج الصورة التالية:

$$
\begin{aligned}
& a_{11} q_{1}+a_{12} q_{2}+\ldots \ldots .+a_{1 n} q_{n} \geq X_{1} \\
& a_{21} q_{1}+a_{22} q_{2}+\ldots \ldots .+a_{2 n} q_{n} \geq X_{2} \\
& a_{31} q_{1}+a_{32} q_{2}+\ldots \ldots .+a_{3 n} q_{n} \geq X_{3}
\end{aligned}
$$

$$
a_{i 1} q_{1}+a_{i 2} q_{2}+\ldots . . .+a_{i n} q_{n} \geq X_{i} \quad \text { وذلك تحت القيود الآتية }
$$

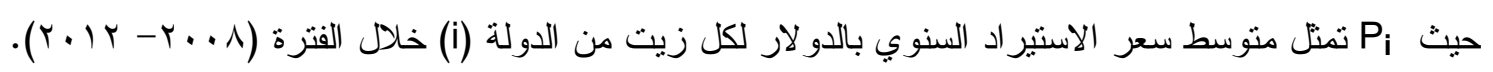

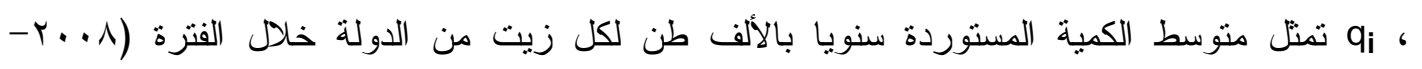

$$
\cdot(r \cdot)^{4}
$$

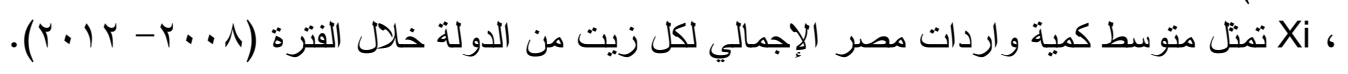

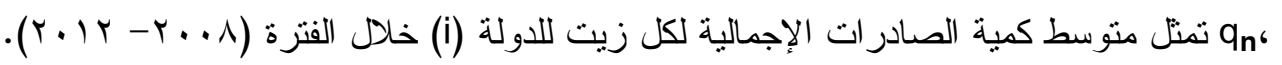

$$
\text { . a1 ، a2............ Am ، }
$$

\section{توصيف النموذج المستخدم في الار اسة:}

يتطلب أسلوب البرمجة الخطية عادة تحديد دالـــة الهــدف و الأنثــــة البديلـــة و القبـــود

$$
\text { المفروضة علي المشكلة موضع الدر اسة. }
$$

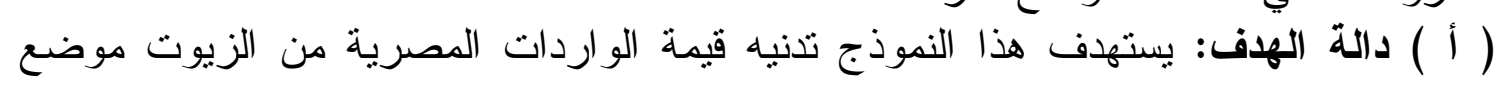

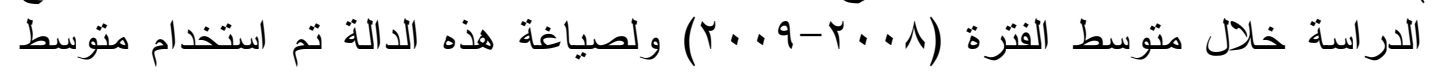

(1) عبدالوكيل ابر اهيم محمد (دكتور )، مني فخري جورجي (دكتور )، در اسة الإمكانيات التصديرية لمحصولي الفاصـــوليا

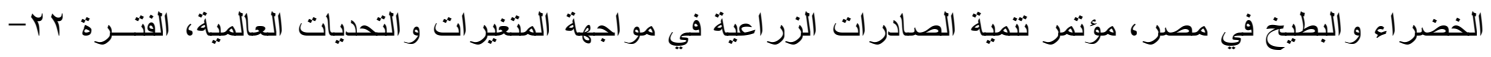

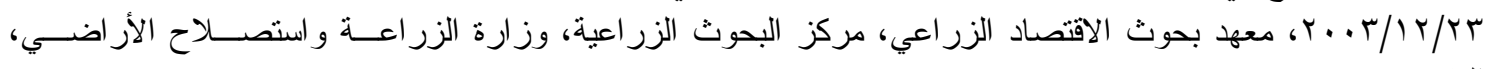


أسعار الاستير اد للطن من الزيوت موضع الدراسة خلال نفس الفترة ، وكنلك منوسط

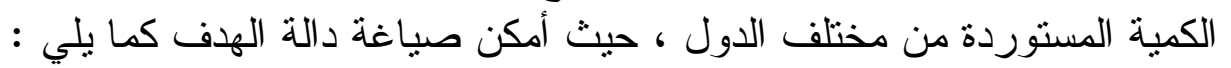

$$
\sum \mathrm{PQ}=\mathrm{P}_{1} \mathrm{Q}_{1}+\mathrm{P}_{2} \mathrm{Q}_{2}+\ldots \ldots .+\mathrm{P}_{\mathbf{n}} \mathrm{Q}_{\mathbf{n}}
$$

حيث SPQ إجمالي القيمة الاستير ادية من الزيوت المستهف تننيتها في ظل القيود المفروضة .

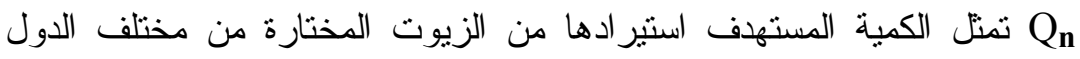
، $\mathrm{Q}_{3} \cdot \mathrm{Q}_{2}$ ' $\mathrm{Q}_{1}$

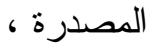

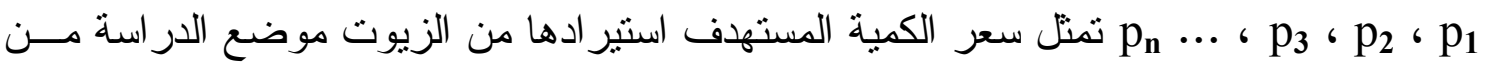
مختلف الدول المصدرة لها. (ب) الأنشطة البديلة: اعتبرت أهم الدول المصدرة للزيوت موضع الدر استة كأنشطة بديلة لهـــا

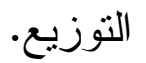

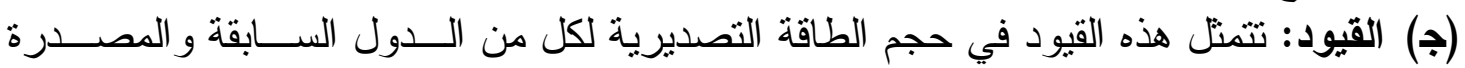

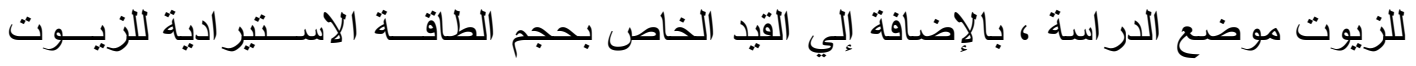

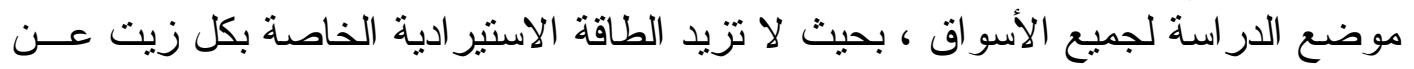

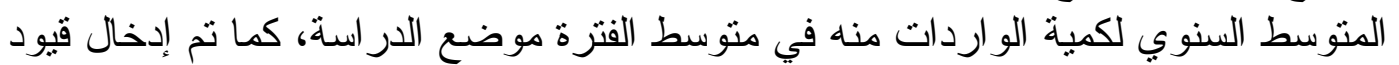

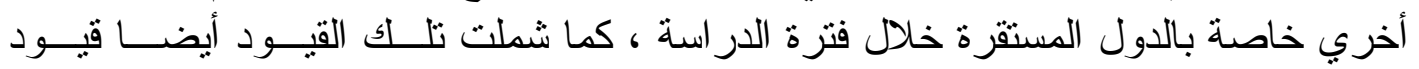

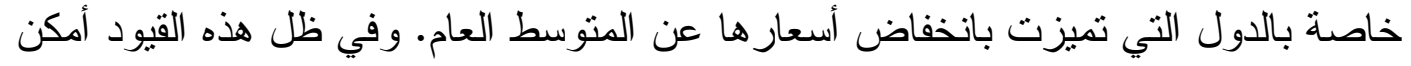

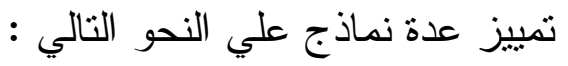

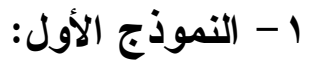

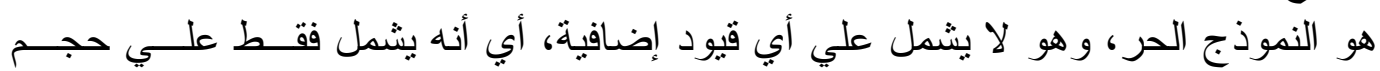

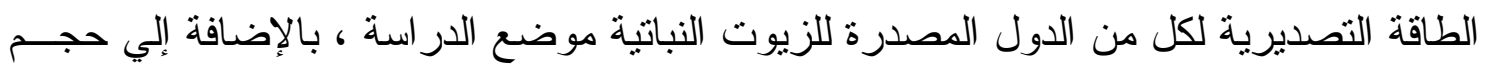

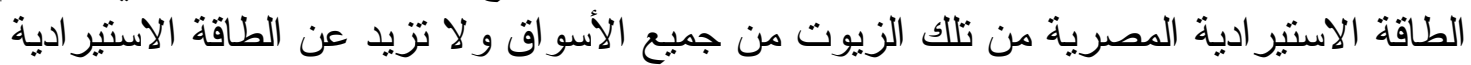

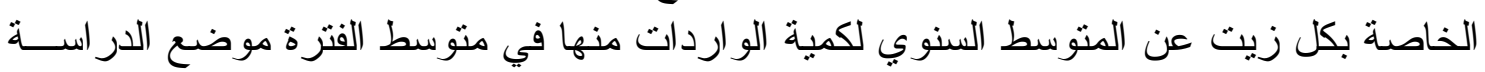

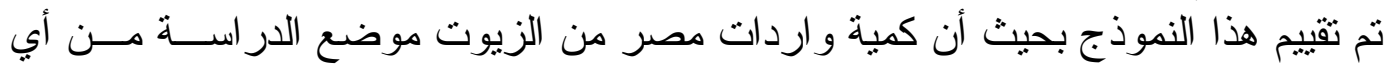

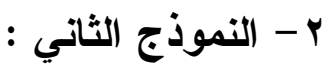

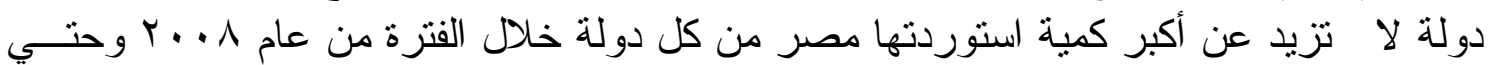

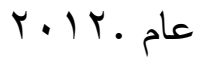

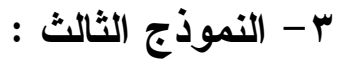

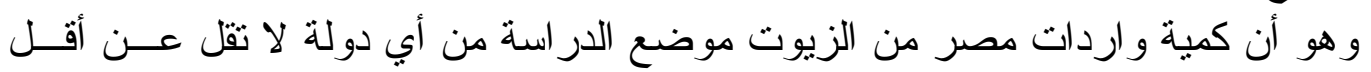

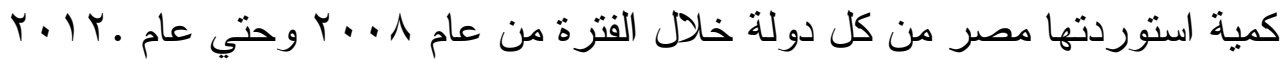

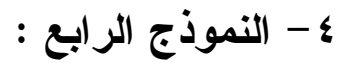

و هذا النموذج يشترط أن كمية واردات مصر من الزيوت من كل دولة لا لا تقل عن متوسط

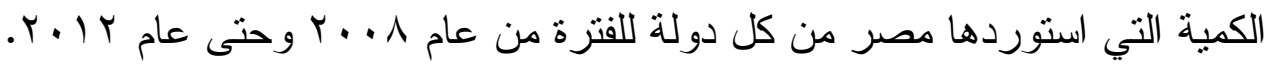

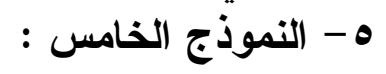

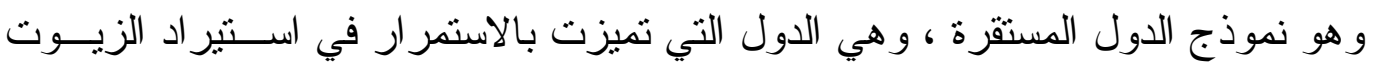

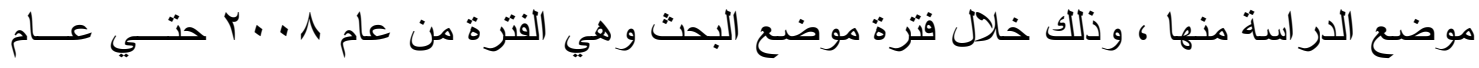

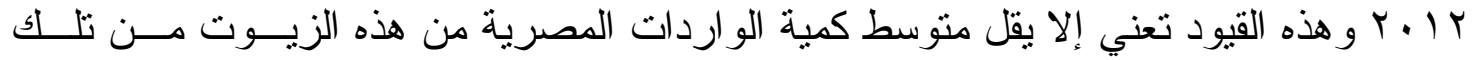

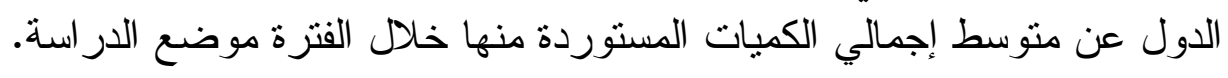




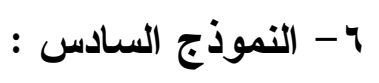

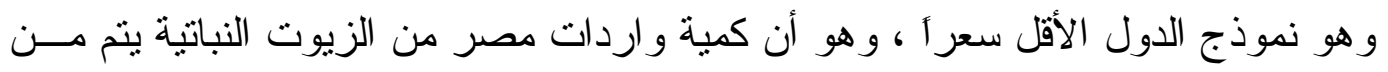

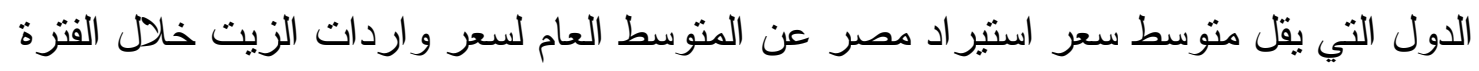

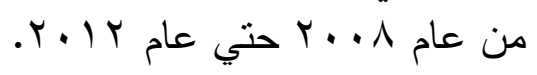


و وأمكن الحصول علي النتائج التالية للزيوت موضع الدر اسة:

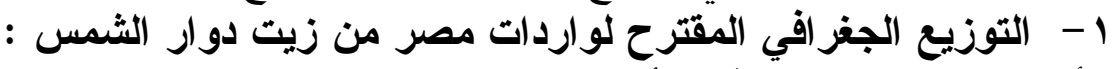
أ - نتائج تحليل النموذج الأول النئ (الحر):

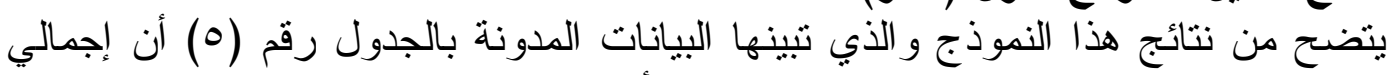

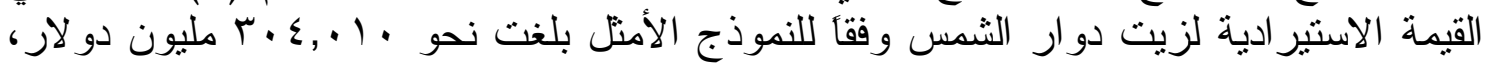

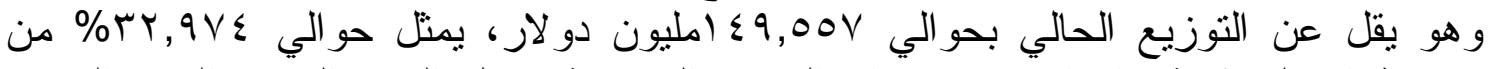

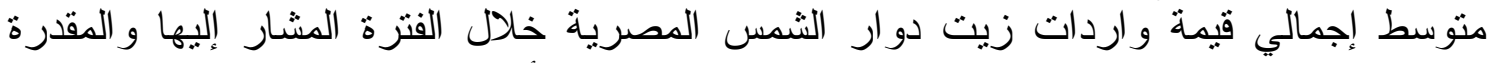

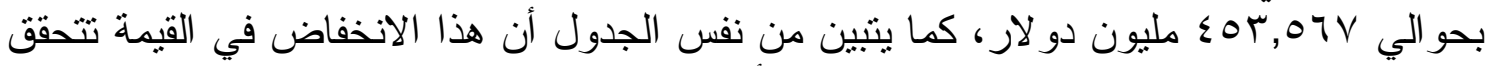

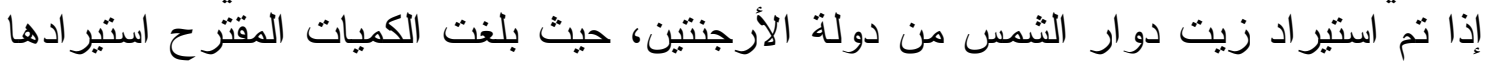

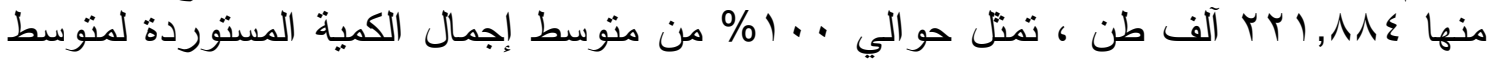

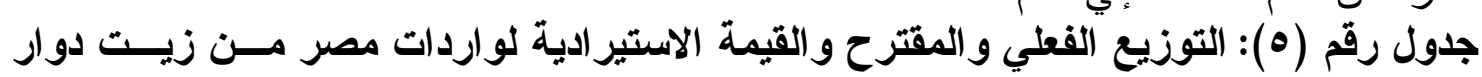

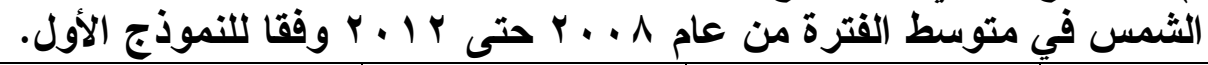

\begin{tabular}{|c|c|c|c|c|c|c|}
\hline \multicolumn{2}{|c|}{ القيمة الاستيرادية } & \multicolumn{2}{|c|}{ الكمية المقترحة } & \multicolumn{2}{|c|}{ الكمية المستوردة } & \multirow[t]{2}{*}{ الدولة المصدرة } \\
\hline المقترح & الحالي & $\%$ & آلف طن & $\%$ & آلف طن & \\
\hline$r \cdot \varepsilon, \cdot, \cdot$ & $\Lambda_{0}, .771$ & $1 \ldots$ & $Y Y,, \Lambda \Lambda \varepsilon$ & $Y \pi, r T V$ & $0 \wedge, \varepsilon \Psi V$ & أرجنتين \\
\hline$r \cdot \varepsilon, \cdot, \cdot$ & $\Lambda_{\cdot, \cdot, 741}$ & $1 \ldots$ & 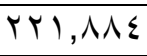 & $T \pi, r T V$ & $0 \wedge, \varepsilon r V$ & إجمالي الدول السابقة \\
\hline & EOT,OTV & $1 \ldots$ & 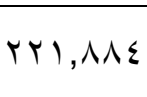 & $1 \ldots$ & 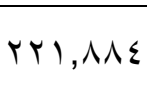 & إجميع الدولي الكمية المصنتوردة \\
\hline
\end{tabular}

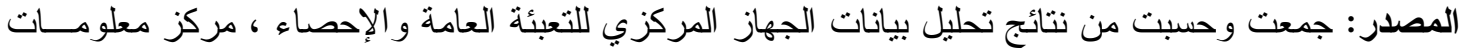

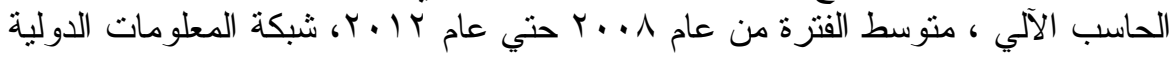

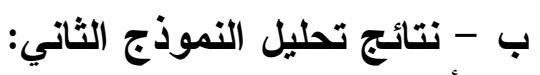

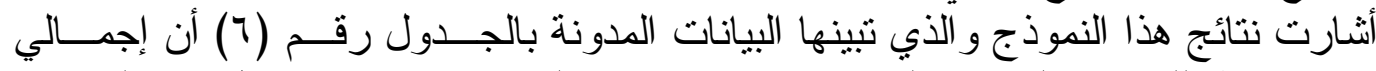

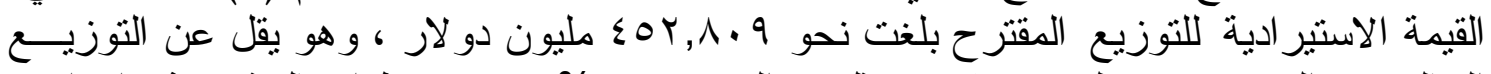

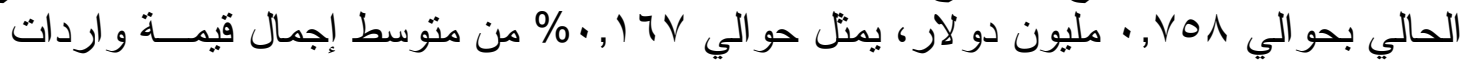

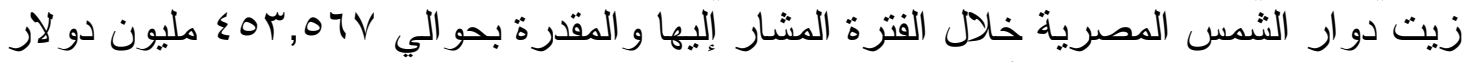

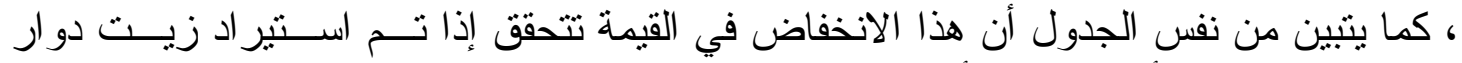

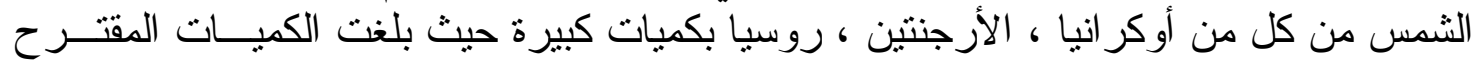

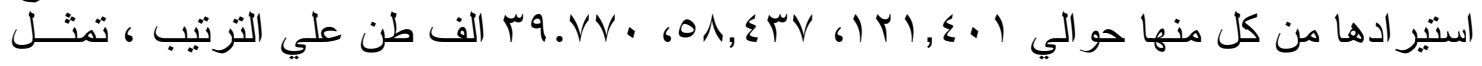

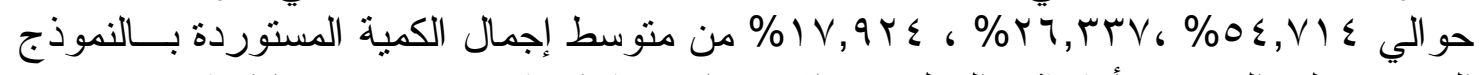

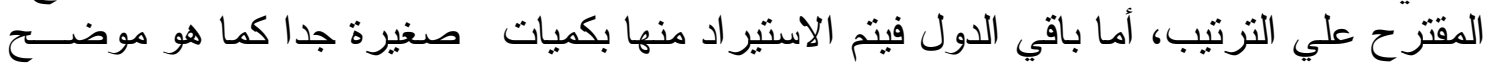
بالجدول. ج - نتائج تحليل النموذج الثالث:

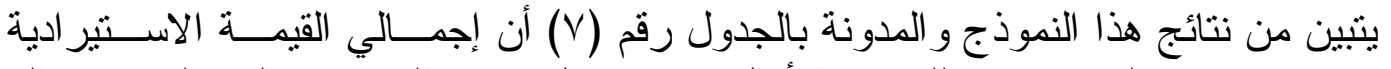

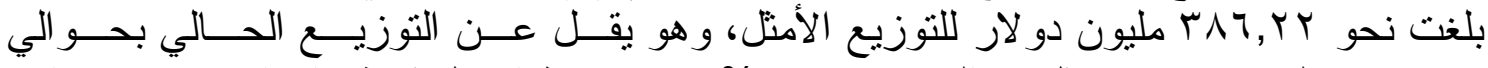

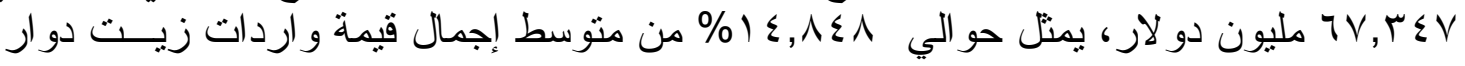

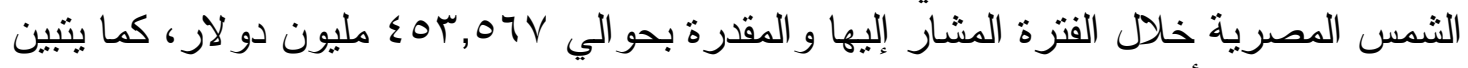

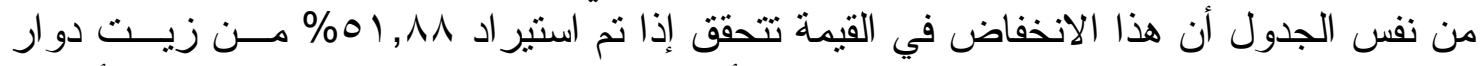

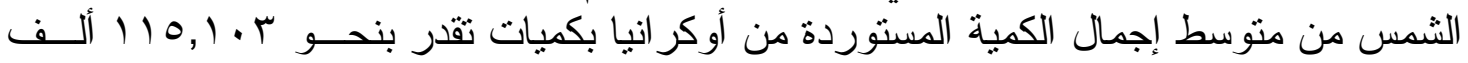

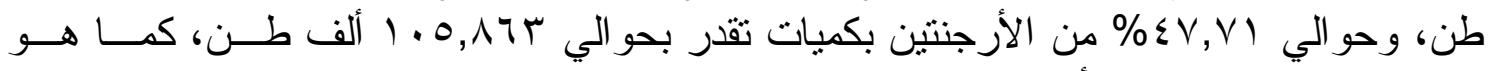
موضح بالنموذج المقترح أما باقي الدول فيتم الاستير اد منها بكميات صغيرة جدا كما هو هو موضح بالجدول. 
جدول رقم (†): التوزيع الفعلي والمقترح والقيمة الاستير ادية لواردات مصر مـنـ زيـــث دوار

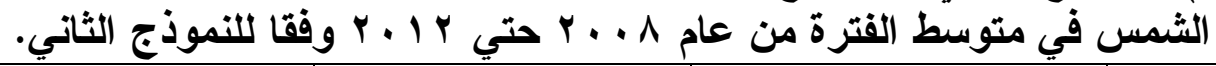

\begin{tabular}{|c|c|c|c|c|c|c|}
\hline \multicolumn{2}{|c|}{ القيمة الاستير ادية } & \multicolumn{2}{|c|}{ الكمية المقترحة } & \multicolumn{2}{|c|}{ الكمية المستوردة الفعلية } & \multirow[t]{2}{*}{ الاولة المصدرة } \\
\hline المقترح & الحالي & $\%$ & ألف طن & $\%$ & ألف طن & \\
\hline$\cdot, \cdot V Y$ & $\cdot, \cdot Y q$ & $\cdot, \cdot 1 \leq$ & $\cdot, \cdot T)$ & $\cdot, \cdots 7$ & $\cdot, \cdot 1 r$ & ل ل لإمار ات \\
\hline., .00 & $\cdot, \cdot 11$ & $\cdot, \cdot 1 \leq$ & $\cdot, \cdot r$. & $\cdot, \ldots r$ & $\cdot, \cdots 7$ & \\
\hline$\cdot, \cdot \leq 0$ & $\cdot, \cdots 9$ & •, & $\cdot, \cdot r q$ & $\cdot, \ldots r$ & $\cdot, \cdots 7$ & \\
\hline$\cdot, \ldots r$ & $\cdot, \cdots 1$ & $\cdot, \cdots 1$ & $\cdot, \ldots 1$ & $\cdot, \ldots 1$ & $\cdot, \cdots r$ & المكسيك \\
\hline$r, \wedge 00$ & $r, \cdot \wedge \varepsilon$ & $\cdot, \vee \vee q r$ & $1, \vee 09$ & (ז & $1, \varepsilon 1$ & الو لايات المتحدة \\
\hline., .01 & מr & $\cdot, \cdot 1 T$ & $\cdot, \cdot r$. & $\cdot, \ldots$ & $\cdot, \cdot 1 Y$ & اليونان \\
\hline $1 \cdot, \cdot 77$ & $1 \cdot, \cdot 77$ & rצ, rTV & O^, $\leqslant \Psi \vee$ & rq,rMV & $O \Lambda, \sum r V$ & 4 \\
\hline$\cdot$, ro & $\cdot, \cdot r$. &.,$\ldots$ & $\cdot, \cdot 11$ & $\cdot, \cdots \varepsilon$ & $\cdot, \cdots 9$ & مانيا \\
\hline YOY, $T \leq \Lambda$ & ror, $7 \leqslant \Lambda$ & $0 \leq, V) \leq$ & $|Y|, \varepsilon \cdot 1$ & $0 \leqslant, V) \leqslant$ & $\left|Y_{1}, \varepsilon \cdot 1\right|$ & أوكر انيا \\
\hline דו & $\cdot, \cdot 1 \leq 0$ & $\cdot, \cdot 1$ & $\cdot, \cdot Y r$ & $\cdot, \cdots \varepsilon$ & $\cdot, \cdots 9$ & بريطانيا \\
\hline$\cdot, r V$ & $\cdot, \cdots \vee \leqslant$ & $\cdot, \cdots 9$ & $\cdot, \cdot Y_{I}$ & $\cdot, \cdots r$ & $\cdot, \cdots \leq$ & غاريا \\
\hline$\cdot, I V V$ & •, & $\cdot, \cdot r \wedge$ & $\cdot, \cdot 71$ & $\cdot, \ldots 7$ & $\cdot, \cdot 1 r$ & ت ت ت ايو ان \\
\hline $110, Y Y A$ & $117, Y Y q$ & $1 V, 9 Y \leq$ & rq, $\vee \vee$. & $11, \cdot \vee 9$ & $\varepsilon \cdot, 110$ & ل روسيا \\
\hline$\cdot, \cdot 11$ & $\cdot, \cdot r$ & $\cdot, \ldots r$ & $\cdot, \cdots r$ & $\cdot, \cdots 1$ & $\cdot, \cdots 1$ & سنغافورة \\
\hline$\cdot, .99$ & $\cdot, \cdot r \cdot$ & $\cdot, \cdot$ YO & $\cdot, .00$ & $\cdot, \ldots$ & $\cdot, \cdot 11$ & سوريا \\
\hline • & • & $\cdot, 1 \ldots$ & $\cdot, Y Y I$ & $\cdot, \wedge$. & $\cdot, I V V$ & فرنسا \\
\hline$\sum 0 Y, \Lambda . q$ & $\leqslant 0 Y, 010$ & $1 \ldots$ & 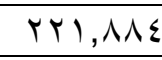 & $99, \wedge \wedge 1$ & YYI,T19 & إجمالى الدول السابقة \\
\hline$\leqslant O Y, \Lambda \cdot q$ & sor,orV & $1 \ldots$ & 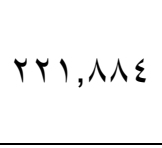 & $1 \ldots$ & Yrl,A^E & الجمالي الكمية \\
\hline
\end{tabular}

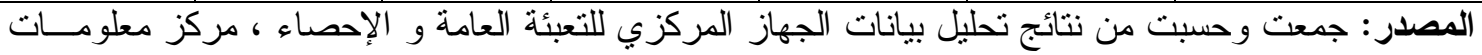

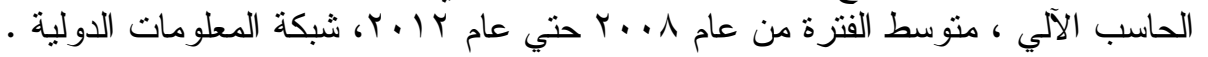

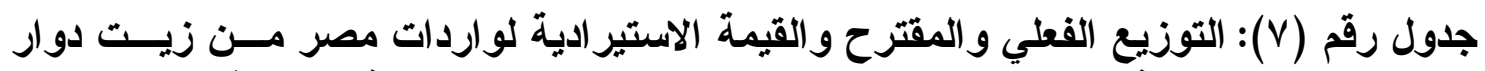

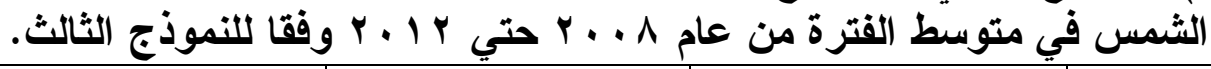

\begin{tabular}{|c|c|c|c|c|c|c|}
\hline \multicolumn{2}{|c|}{ القيمة الاستير ادية (مليون دولار) } & \multicolumn{2}{|c|}{ الكمية المقترحة } & \multicolumn{2}{|c|}{ الكمية المستوردة الفعلية } & \multirow{2}{*}{ الدولة المصدرة } \\
\hline المقترح & الحالي & $\%$ & ألف طن & $\%$ & ألف طن & \\
\hline$\cdot, .00$ & $\cdot, .11$ & $\cdot, \cdot Y_{T}$ & $\cdot, \cdot r$. & $\cdot, \cdot r$ & $\cdot, \cdots 7$ & الأردن \\
\hline$\cdot, \cdot \leq 0$ & $\cdot, \cdots 9$ & $\cdot$, , Yo & $\cdot, \cdot r q$ & $\cdot, \cdots r$ & $\cdot, \cdots 7$ & المجر \\
\hline$\cdot, \cdot 19$ & Tr & $\cdot, \cdot 4 q$ & $\cdot, \cdot \leqslant 0$ & $\cdot, \cdots$ & $\cdot, \cdot 1 Y$ & 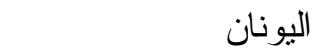 \\
\hline $1 \leqslant 0, \cdot \varepsilon V$ & $\Lambda \cdot, \cdot 77$ & $\varepsilon \vee, V)$ & 1.0,人тr & rד,rTV & 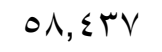 & أرجنتين \\
\hline$r r q, 0 \leqslant 1$ & YOY, $T \leq \Lambda$ & $01, \wedge \wedge$ & $110,1 \cdot r$ & $0 \leqslant, V) \leqslant$ & $\mid Y_{1}, \varepsilon \cdot 1$ & أوكر انيا \\
\hline., .09 & $\cdot, \cdot 10$ & $\cdot, \cdot M$ & & $\cdot, \cdots \varepsilon$ & $\cdot, \cdots \wedge q$ & بريطانيا \\
\hline$\cdot, \cdot r V$ & $\cdot, \cdots V$ & $\cdot, \cdot 11$ & $\cdot, \cdot r_{l}$ & $\cdot, \cdots r$ & $\cdot, \cdots \varepsilon$ & 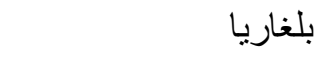 \\
\hline$\cdot, \cdot 11$ & $\cdot, \ldots r$ & $\cdot, \ldots$ & $\cdot, \ldots 7$ & $\cdot, \cdots 1$ & $\cdot, \cdots 1$ & سنغافورة \\
\hline$\cdot, .99$ & $\cdot, \cdot r \cdot$ & $\cdot, \cdot \leq V$ & $\cdot, .00$ & $\cdot, \ldots$ & $\cdot, \cdot 11$ & سوريا \\
\hline 1, rMV & $\cdot, 110$ & $\cdot, M \leq$ & $\cdot, 797$ & $\cdot, \wedge$. & $\cdot, I V V$ & فرنسا \\
\hline 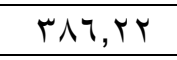 & TrT,117 & $1 \ldots$ & 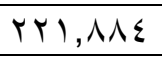 & $11,10 Y$ & $1 \wedge \cdot, \cdot 7 \varepsilon$ & إجمالى الدول السابقة \\
\hline r人t, r & sor,oTV & $1 \ldots$ & YYI,AヘE & $1 \ldots$ & 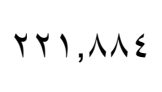 & لجميع الدولي الكمية المستوردة \\
\hline
\end{tabular}

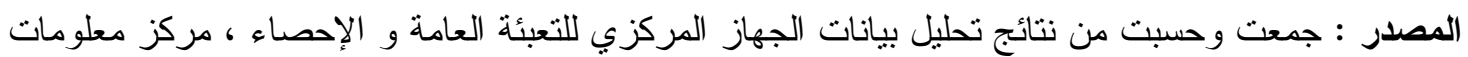

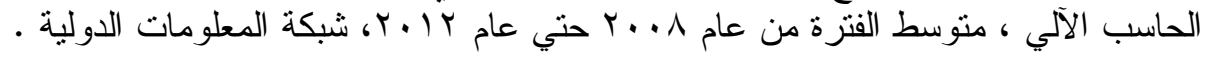




\section{د - نتائج تحليل النموذج الرابع}

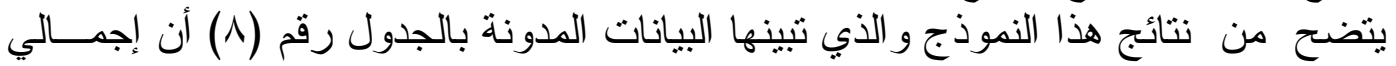

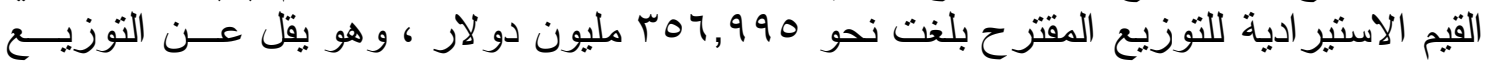

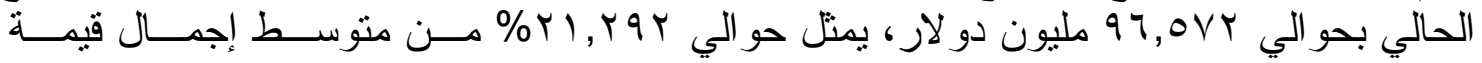

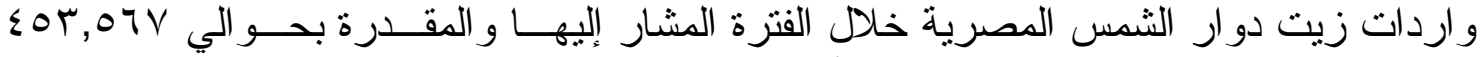

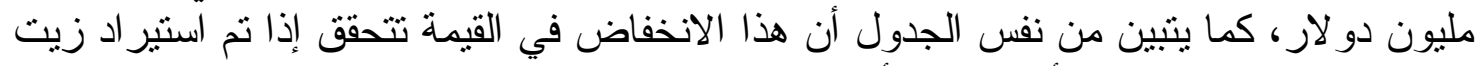

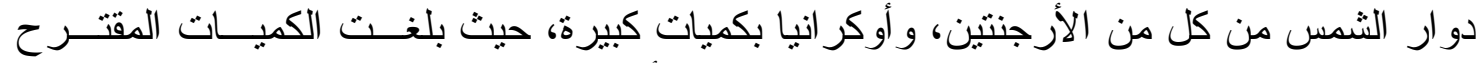

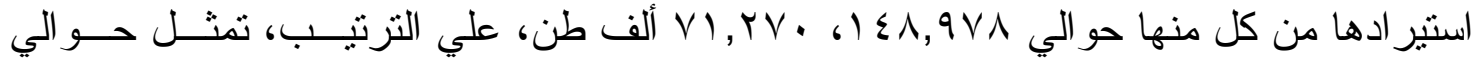

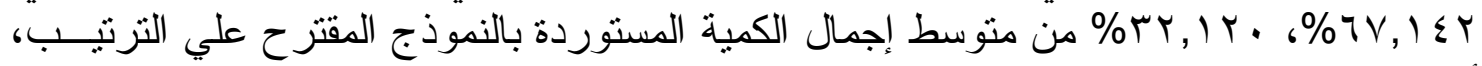

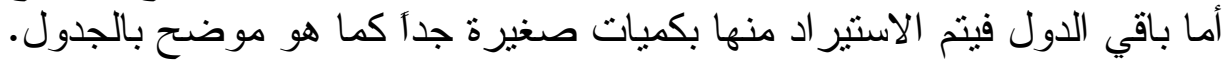

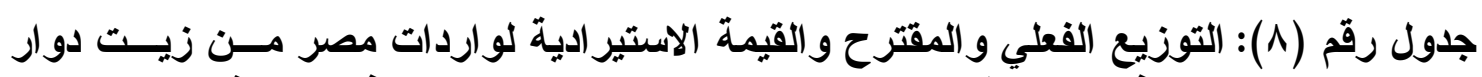

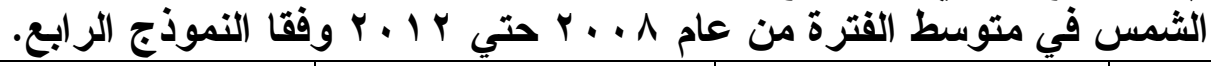

\begin{tabular}{|c|c|c|c|c|c|c|}
\hline \multicolumn{2}{|c|}{ القيمة الاستير ادية } & \multicolumn{2}{|c|}{ الكمية المقترحة } & \multicolumn{2}{|c|}{ الكمية المستوردة الفعلية } & \multirow[t]{2}{*}{ الدولة المصدرة } \\
\hline المقترح & الحالي & $\%$ & ألف طن & $\%$ & ألف طن & \\
\hline$\cdot, \cdot 7 \wedge$ & $\cdot,+r q$ & $\cdot, \cdot 1 T$ & $\cdot, \cdot r q$ & $\cdot, \ldots$ & $\cdot, \cdot 1 T$ & الإمار ات \\
\hline., .00 & $\cdot, \cdot 11$ & $\cdot, \cdot 1 \leqslant$ & •, . r. & ., & $\cdot, \cdots 7$ & الأردن \\
\hline$\cdot, 109$ & •, & $\cdot, \cdot r$ & $\cdot, \cdot \leq 0$ & $\cdot, \cdots \varepsilon$ & $\cdot, \cdots 9$ & الصين \\
\hline$\cdot, \cdots r$ &,$\ldots \ldots \varepsilon$ &,$\ldots \cdots 1$ & $\cdot, \cdots 1$ & $\cdot, \cdots \cdots$ & $\cdot, \ldots$, & الكويت \\
\hline$\cdot, \cdot \leq 0$ & $\cdot, \cdot 9$ & rו & $\cdot, r q$ & $\cdot, \cdot r$ & $\cdot, \cdot 7$ & المجر \\
\hline$\cdot, \cdot r$ & $\cdot, \cdots 1$ & $\cdot, \ldots 1$ & $\cdot, \cdots 1$ &,$\ldots \cdots q$ & $\cdot, \ldots r$ & المكسيك \\
\hline$\cdot$, Y77 & $r, \wedge \varepsilon$ &., 00 & $\cdot,|Y|$ & ع & $1, \varepsilon \cdot V$ & الولايات المتحدة \\
\hline$\cdot, \cdot T V \varepsilon$ & r & $\cdot, \cdots 7$ & $\cdot, \cdot 1 \leq$ & $\cdot, \cdots 0$ & $\cdot, \cdot 1 r$ & اليونان \\
\hline$\cdot, \cdot r q V$ & $\cdot, \cdot Y_{1}$ & $\cdot, \cdots 1$ & $\cdot, \cdots r$ & $\cdot, \cdots 1$ & $\cdot, \cdots 1$ & إيطاليا \\
\hline$r \cdot \varepsilon, I T$. & $\Lambda \cdot, \cdot 77$ & $T V, 1 \leq r$ & $1 \leqslant \Lambda, 9 \vee \wedge$ & VTr,Tr & $O \wedge, \Sigma T \vee$ & الأرجنتين \\
\hline$\cdot, \cdots v$ & $\cdot, \ldots 1$ & $\cdot, \ldots, 1$ & $\cdot, \cdot r$ &,$\ldots r$ & $\cdot, \ldots \varepsilon$ & أسبانيا \\
\hline$\cdot, \cdots 17$ & $\cdot, \cdot r$. &,$\ldots \cdots 1$ & $\cdot, \cdots 1$ & $\cdot, \cdots \varepsilon$ & $\cdot, \cdots 9$ & ألمانيا \\
\hline $\mid \leq \Lambda, r\} \mid$ & ror,, $7 \leq \Lambda$ & r & $V I, Y V$. & $0 \leq, V \mid \leq$ & $|Y|, \Sigma \cdot \mid$ & أوكر انيا \\
\hline$\cdot, \cdot 1 \leq$ & $\cdot, \cdot 10$ & $\cdot, \cdots \varepsilon$ & $\cdot, \cdots 9$ & $\cdot, \cdots \varepsilon$ & $\cdot, \cdots 9$ & بريطانيا \\
\hline 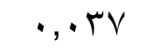 & $\cdot, \cdots V$ & $\cdot, \cdot 9$ & $\cdot, \cdot Y_{1}$ & $\cdot, \cdots r$ & $\cdot, \cdots \varepsilon$ & بلغاريا \\
\hline$\cdot, 1 \leq 7$ & $\cdot, 941$ & $\cdot, .17$ & $\cdot, r v$ & $\cdot, 1 \cdot 0$ & חזr, • & تز كيا \\
\hline$\cdot, I V V$ & ס ., & $\cdot, \cdot Y \Lambda$ & $\cdot, \cdot 71$ & $\cdot, \cdots 7$ & $\cdot, \cdot 1 Y$ & تايو ان \\
\hline T,YTr & $117, Y Y q$ & $\cdot, 0.1$ & $1,11 \%$ & $11, \cdot \vee 9$ & $\varepsilon \cdot, 110$ & روسيا \\
\hline$\cdot, .11$ & $\cdot, \cdot r$ & r & $\cdot, \cdots 7$ & $\cdot, \cdots \varepsilon$ & $\cdot, \cdots 9$ & سنغافورة \\
\hline$\cdot, .99$ & $\cdot, \cdot r \cdot$ & ., ro &., 00 & $\cdot, \cdot r$ & $\cdot, \cdots \leq$ & سوريا \\
\hline$\cdot, 11$ & •, & $\cdot, \cdot 1 \leqslant$ & (I., & $\cdot, \cdot r$ & $\cdot, \cdots 7$ & شيلي \\
\hline$\cdot, \cdot r_{T}$ & 0 & $\cdot, \cdot V$ & $\cdot, \cdot 10$ & $\cdot, \wedge$. & $\cdot, I V V$ & فرنساً \\
\hline., .07 & $\cdot, \cdot \leq V$ & $\cdot, \cdots 1$ & $\cdot, \cdot 1 \mathrm{~V}$ & $\cdot, \cdots V$ & $\cdot, .10$ & هو لندا \\
\hline 107,990 & sor, OTV & $1 \cdots$ & 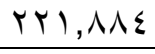 & $1 \cdots$ & 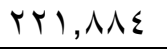 & إجمالي الدول السابقة \\
\hline 107,990 & sOr, OTV & $1 \ldots$ & 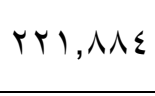 & $1 \cdots$ & YYI, AヘE & لجميع الدول المصية المستوردة \\
\hline
\end{tabular}

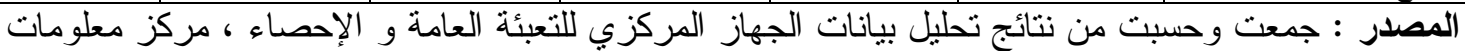

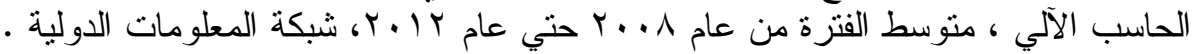




\section{هـ - نتائج تحليل النموذج الخامس:}

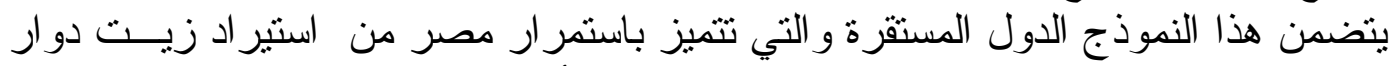

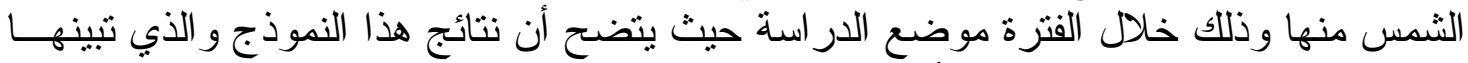

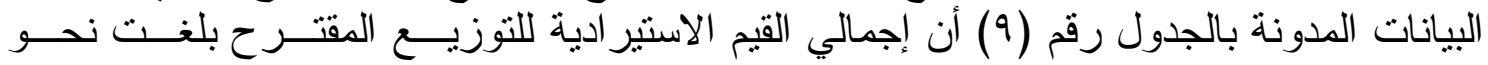

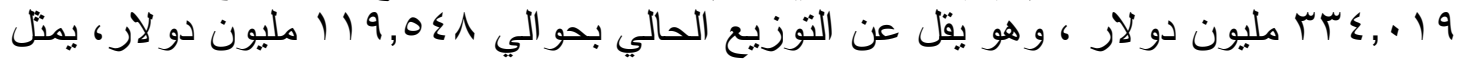

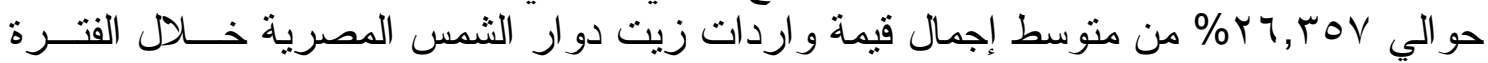

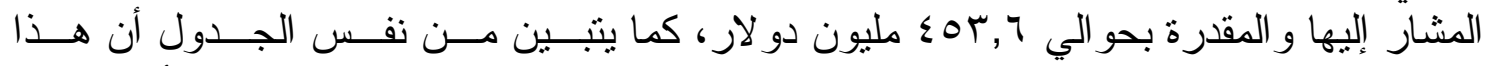

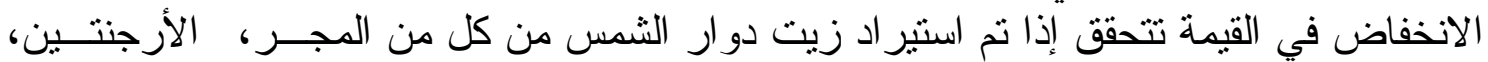

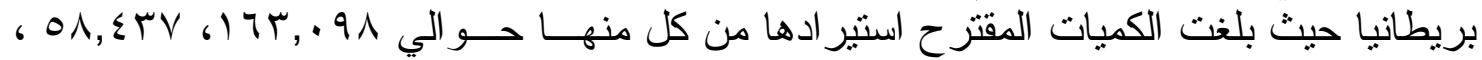

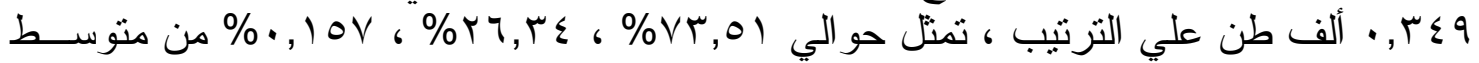

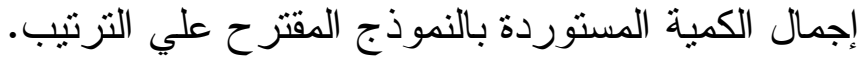

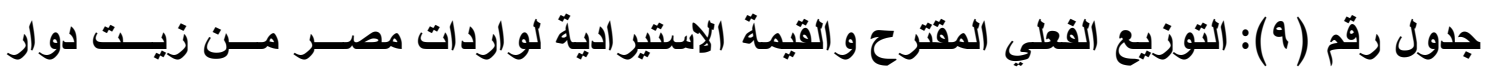

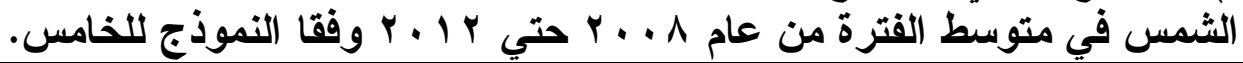

\begin{tabular}{|c|c|c|c|c|c|c|}
\hline \multicolumn{2}{|c|}{ 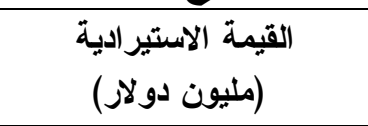 } & \multicolumn{2}{|c|}{ الكمية المقترحة } & \multicolumn{2}{|c|}{ الكمية المستوردة الفعلية } & \multirow[t]{2}{*}{ الاولة المصدرة } \\
\hline المقترح & الحالي & $\%$ & ألف طن & $\%$ & ألف طن & \\
\hline ror,rA. & $\cdot, \cdots 9$ & $V r, 01$ & $174, .91$ & $\cdot, \cdot r$ & $\cdot, \cdots 7$ & المجر \\
\hline $1 \cdot, \cdot 77$ & $1 \cdot, \cdot 77$ & $r \neg, \Gamma \varepsilon$ & 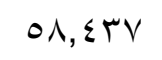 & V & $\Delta \wedge, \Sigma \Psi \vee$ & أرجنتين \\
\hline$\cdot, O V Y$ & $\cdot, \cdot 10$ & $\cdot, 10 \mathrm{~V}$ & $\cdot r \leq q$ & $\cdot, \cdots \varepsilon$ & $\cdot, \cdots 9$ & بريطانيا \\
\hline TrE, 19 & $1 \cdot, \cdot 9$. & $1 \ldots$ & 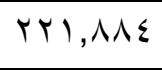 & $r \neg, r \leqslant r$ & OA, \&OY & إجمالي الدول السابقة \\
\hline TrE,. 19 & $\varepsilon 0 T, 0 T V$ & $1 \ldots$ & YYI, Aヘ & $1 \ldots$ & YYI,A^E & إجمالي الكمية المستوردة الدصدرة \\
\hline
\end{tabular}

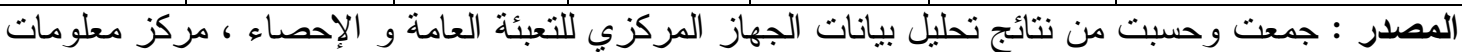

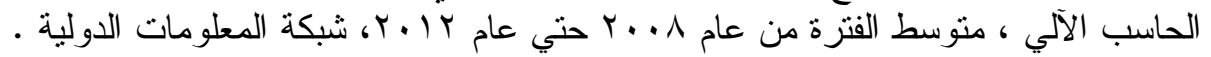

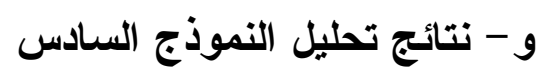

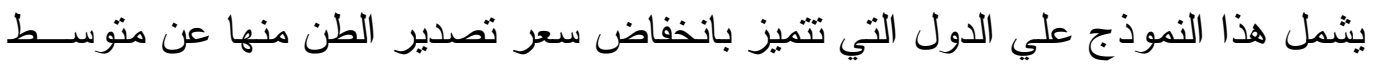

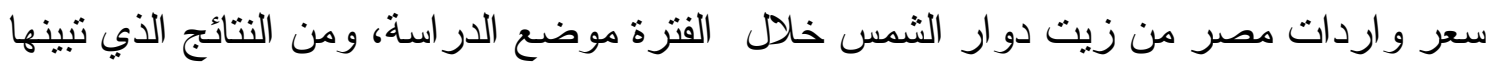

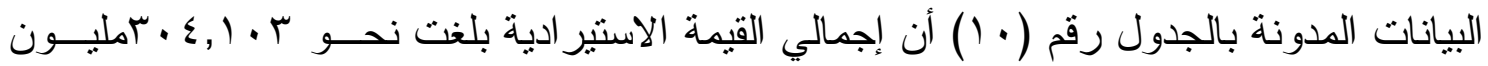

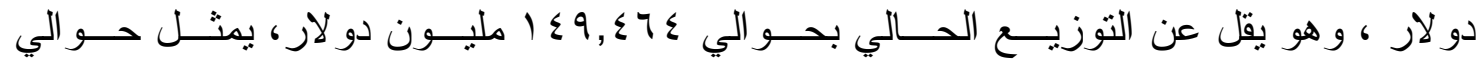

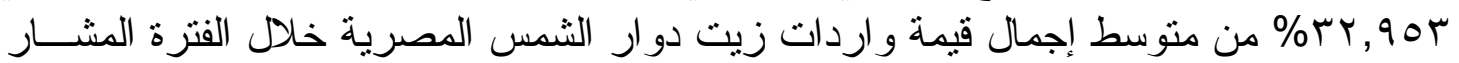

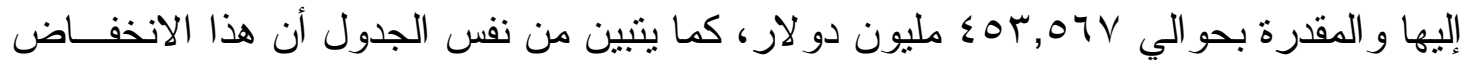

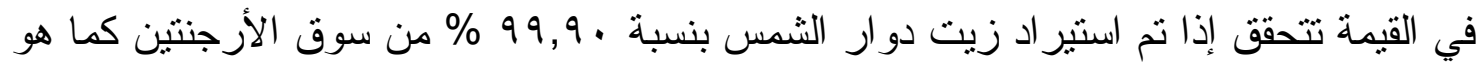

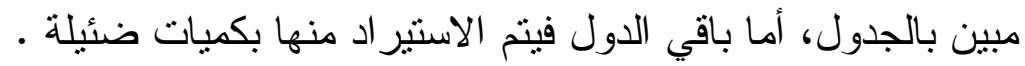

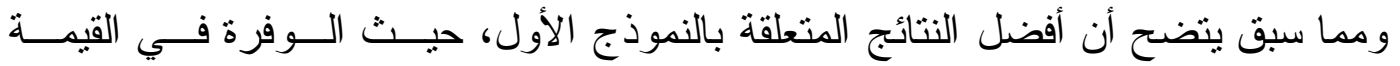

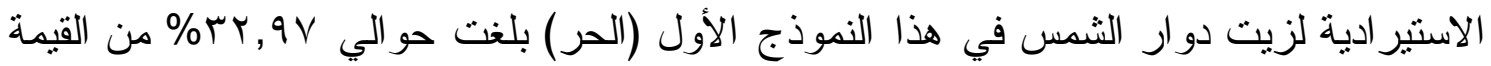

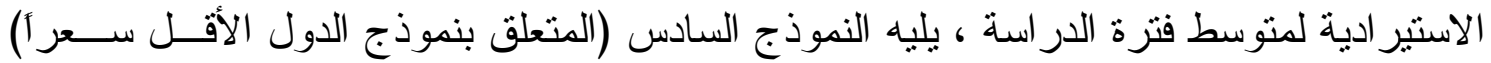

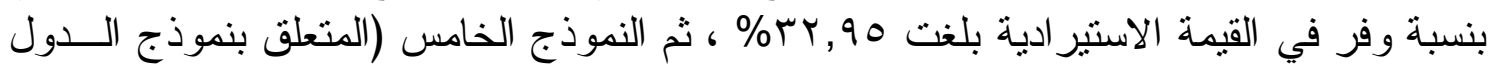

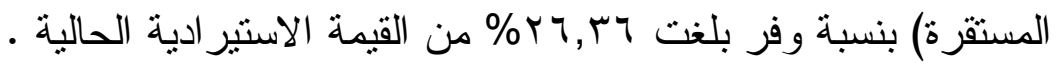


جدول رقم ( • 1):التوزيع الفعلي والمقترح والقيمة الاستير ادية لواردات مصر من زيــث دوار

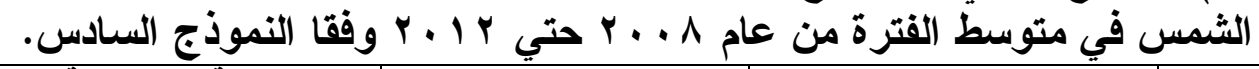

\begin{tabular}{|c|c|c|c|c|c|c|}
\hline \multicolumn{2}{|c|}{ القيمة الاستير ادية } & \multicolumn{2}{|c|}{ الكمية المقترحة } & \multicolumn{2}{|c|}{ الكمية المستوردة الفعلية } & \multirow[t]{2}{*}{ الاولة المصدرة } \\
\hline المقترح & الحالى & $\%$ & ألف طن & $\%$ & ألف طن & \\
\hline$\cdot, \cdot 11$ &., .11 & $\cdot, \cdots r$ & $\cdot, \cdots 7$ & $\cdot, \cdots r$ & $\cdot, \cdots 7$ & \\
\hline$\cdot, \cdot 1$ & $\cdot, \cdot 9$ & $\cdot, \cdots r$ & $\cdot, \cdots 7$ & $\cdot, \ldots r$ & $\cdot, \cdot 1 r$ & \\
\hline$\cdot, \cdot r T$ & $\cdot, \cdot r T$ & $\cdot, \cdots$ & $\cdot, \cdot 1 r$ & $\cdot, \cdots$ & $\cdot, \cdots 7$ & اليونان \\
\hline$r \cdot r, v \cdot$ & $1 \cdot, \cdot 77$ & $99, \wedge 9 \wedge$ & YMI,T01 & r & $0 \wedge, \varepsilon r \vee$ & \\
\hline$\cdot, \cdot 10$ & $\cdot, \cdot 10$ & $\cdot, \cdots \varepsilon$ & $\cdot, \cdots 9$ & $\cdot, \cdots \varepsilon$ & $\cdot, \cdots 9$ & ريطانيا \\
\hline$\cdot, \cdots v$ & $\cdot, \cdots v$ & $\cdot, \cdots r$ & $\cdot, \cdots \varepsilon$ & $\cdot, \cdot r$ & $\cdot, \cdots \varepsilon$ & بلغاريا \\
\hline$\cdot, \ldots r$ & $\cdot, \ldots r$ & $\cdot, \cdots 1$ & $\cdot, \cdots$ & $\cdot, \cdots \varepsilon$ & $\cdot, \cdots 9$ & سنغافورة \\
\hline$\cdot, \cdot r$. & $\cdot, \cdot r$. &.,$\ldots$ & $\cdot, \cdot 11$ & $\cdot, \cdots r$ & $\cdot, \cdots \varepsilon$ & بوريا \\
\hline$\cdot, r 10$ & $\cdot, \pi 10$ & $\cdot, \wedge$. & $\cdot, I V V$ & $\cdot, \wedge$ & $\cdot, I \vee V$ & فرنسا \\
\hline$r \cdot \varepsilon, 1 \cdot r$ & $\lambda \cdot, \leq 7 \Lambda$ & $1 \ldots$ & $r\{1, \wedge \wedge \varepsilon$ & 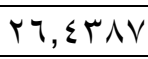 & $0 \Lambda, 74 \pi$ & إجمالى الدول السابقة \\
\hline$r \cdot \varepsilon, 1 \cdot r$ & sor, OTV & $1 \ldots$ & YYI,A^E & $1 \ldots$ & 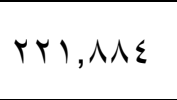 & لجميع الدول الكمية المستوردة \\
\hline
\end{tabular}

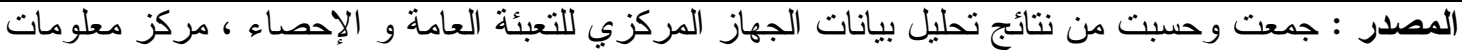

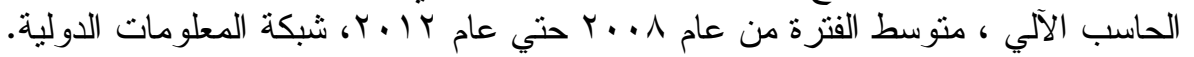

r - التوزيع الجغرافي المقترح لواردات مصر من زيت فول الصويطيا: أ - نتائج تحليل النموذج الجمي الأول (الحر):

يتضح من نتائج هذا النموذج و الذي تنينها البيانات المدونة بالجدول رقم (1 (1) أن إجمــالي

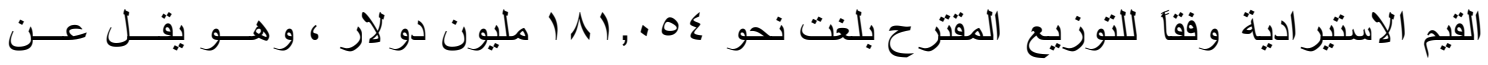

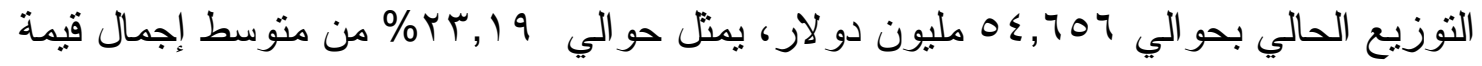

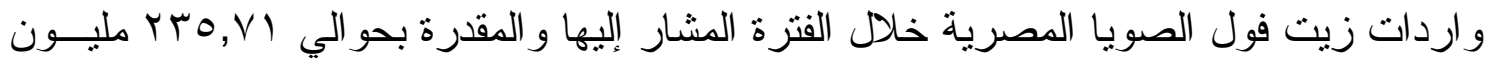

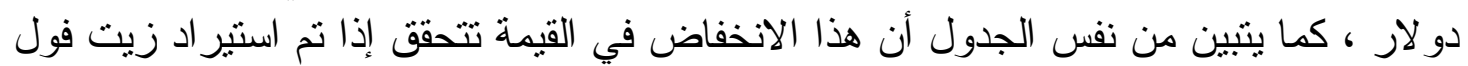

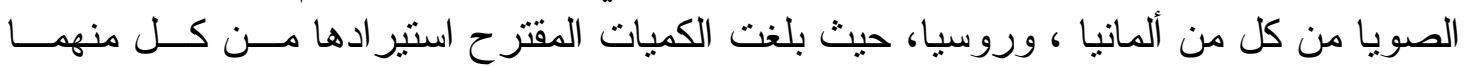

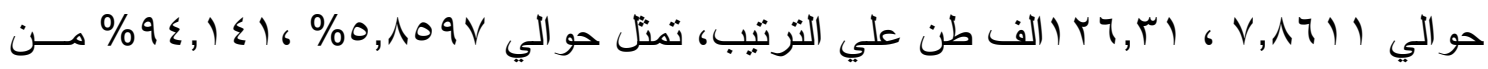
منوسط إجمال الكمية المستوردة بالنموذج المقترح عل علي الترنيب .

جدول رقم (11): التوزيع الفعلي والمقترح والقيمة الاستير ادية لواردات مصر من زيت فــول

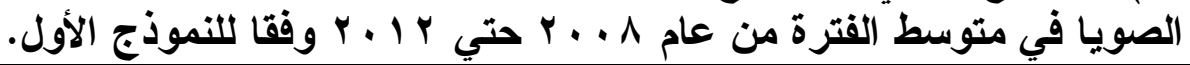

\begin{tabular}{|c|c|c|c|c|c|c|}
\hline \multicolumn{2}{|c|}{ القيمة الاستير ادية } & \multicolumn{2}{|c|}{ الكمية المقترحة } & \multicolumn{2}{|c|}{ الكمية المستوردة الفعلية } & \multirow[t]{2}{*}{ الدولة المصدرة } \\
\hline المقترح & الحالي & $\%$ & ألف طن & $\%$ & ألف طن & \\
\hline 1.,vqr & $1,7 r \leqslant 1$ & 0,109 & $V, \wedge 711$ & $\cdot, \wedge \wedge \vee 0$ & 1,191 & ألمانيا \\
\hline$|V \cdot, Y T|$ & $\cdot, \vee \vee Y q \mu$ & $9 \leq, 1 \leq 1$ & $|r q, r|$. & $\cdot, \varepsilon \cdot T r$ & $\cdot, 0 \leq 1$ & روسيا \\
\hline 111,00 & r, rצ & $1 \cdots, \cdots$ & $|r \leq| V \mid$, & $1, r q \cdot V$ & I,VMr & إجمالي الدول السابقة \\
\hline $111,0 \leqslant$ & $r M O, V)$ & $1 \ldots$ & $1 T \varepsilon, I V$ & $1 \ldots$ & $1 \pi \varepsilon, 179$ & إجمالي الكمية المستوردة الدصدرة \\
\hline
\end{tabular}

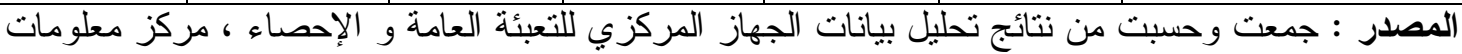

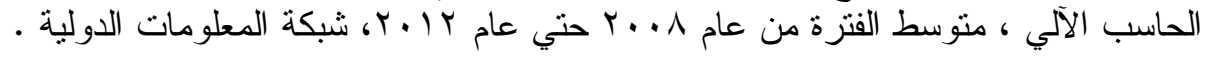




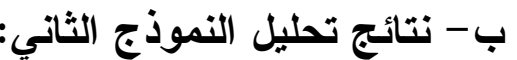

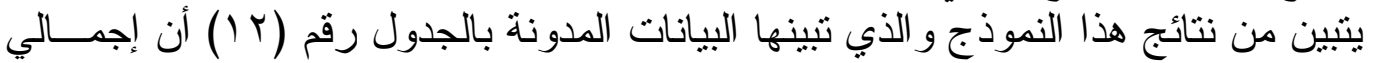

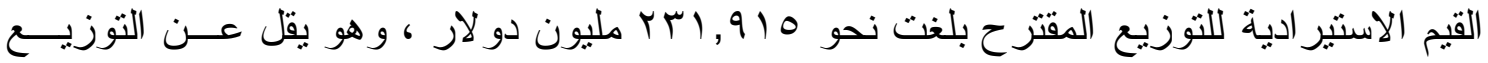

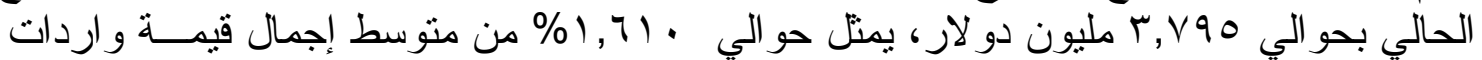

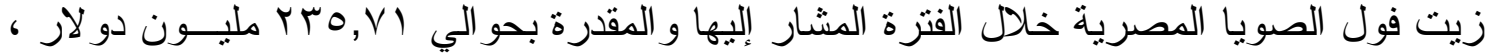

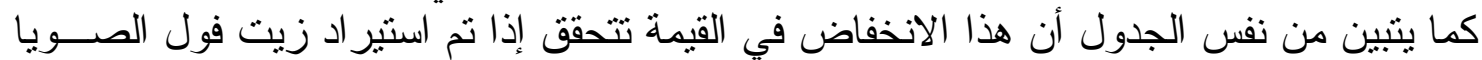

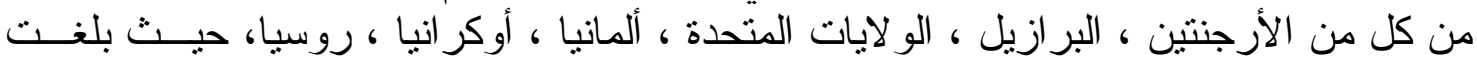

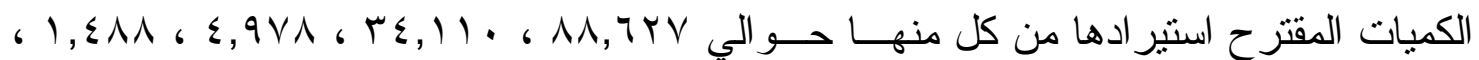

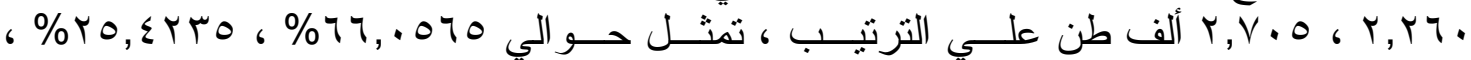

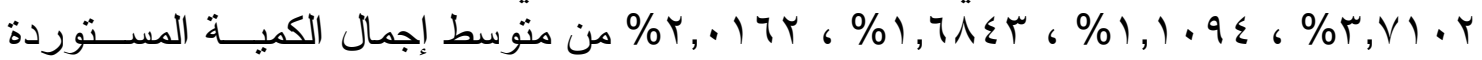
بالنموذج المقترح علي الترتيب.

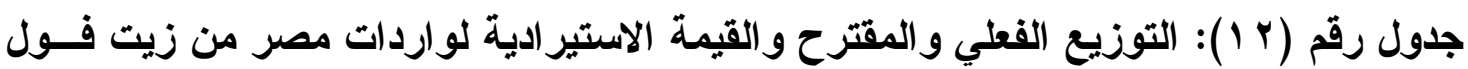

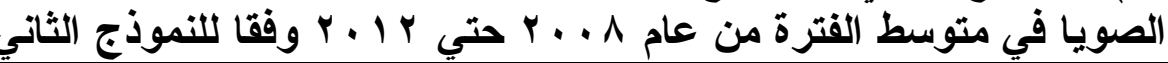

\begin{tabular}{|c|c|c|c|c|c|c|}
\hline \multicolumn{2}{|c|}{ القيمة الاستير ادية (مليون دولار) } & \multicolumn{2}{|c|}{ الكمية المقترحة } & \multicolumn{2}{|c|}{ الكمية المستوردة الفعلية } & \multirow{2}{*}{ الاولة المصدرة } \\
\hline المقترح & الحالي & $\%$ & ألف طن & $\%$ & ألف طن & \\
\hline $107,71 \cdot 7$ & $1 \wedge r, 0 \vee 79$ & $77, .070$ & $\Lambda \wedge, T Y \vee \backslash$ & $V \vee, \cdots \wedge \Lambda$ & I.T,TrY & \\
\hline $0 \wedge, 71 \cdot 1$ & ( & YO, & $r \varepsilon, 11 \cdot r$ & $10, Y 0 \leqslant 1$ & $r \cdot, \leqslant\rceil 7$ & \\
\hline$V, I M r$ & $\varepsilon, r T \vee r$ & $r, V) \cdot r$ & $\varepsilon, q \vee \vee q$ & Y,YYTI & r, qAV & الو لايات المتحدة \\
\hline ס & $1,7 r \leqslant \Lambda$ & $1,1.9 \varepsilon$ & $1, \varepsilon \wedge \wedge \leqslant$ & $\cdot, \wedge \wedge \vee 0$ & 1,191 & الد \\
\hline$r, \wedge q r r$ & 1,0079 & $1, T \wedge \leq r$ & $r, r \circ 9 \wedge$ & •, TVTV & $\cdot, 9 \cdot \varepsilon$ & كر انيا \\
\hline$r, 7 \leq 7 \leq$ & •, VYqR & $r, .17 r$ & $r, V \cdot 01$ & 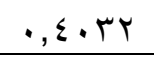 & $\cdot, 0 \leqslant 1$ & \\
\hline $4 r 1,910$ & rro, 9 r & $1 \cdots$ & $11 \varepsilon, 179$ & $97, \leqslant 04 \varepsilon$ & $\mid r q, \leq 11$ & جمالى الدول السابقة \\
\hline ol, וTr & rmo,vi & $1 \ldots$ & $17 \varepsilon, 179$ & $1 \ldots$ & $11 \varepsilon, 179$ & ميع الدول الكمية المستوردة \\
\hline
\end{tabular}

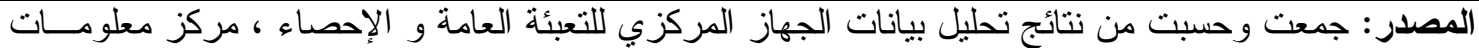

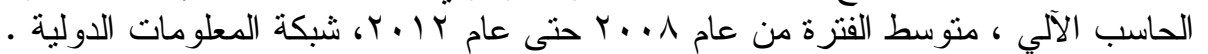

\section{ج- جنتائج تحليل النموذج الثالث:}

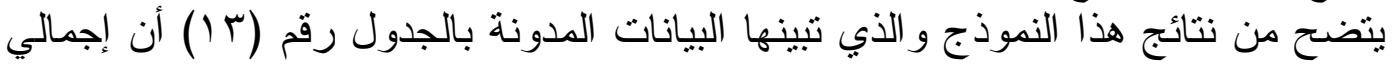

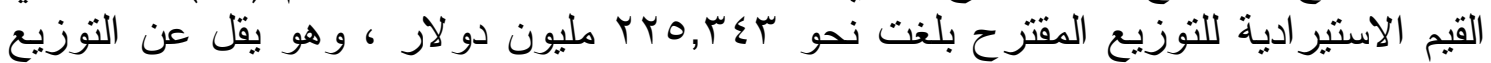

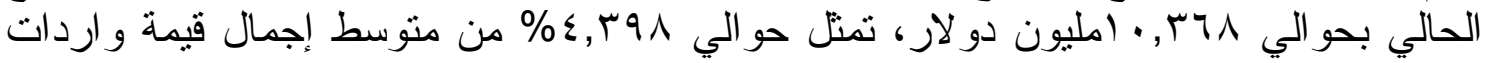

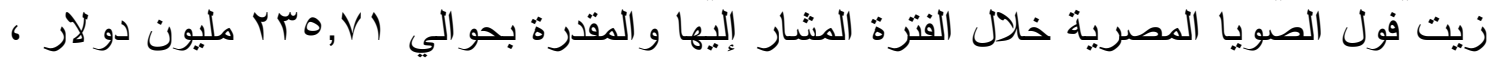

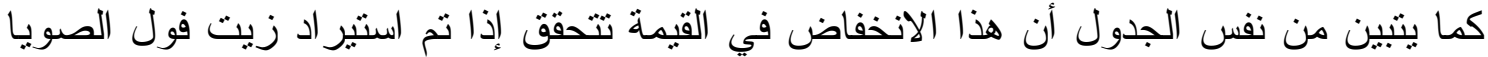

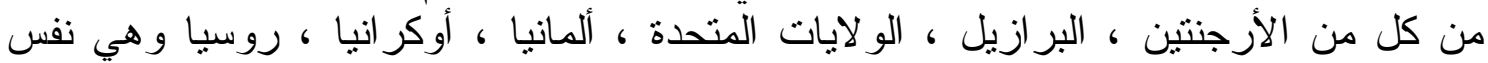

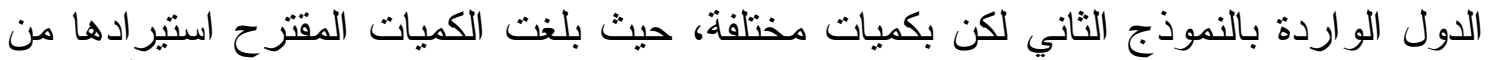

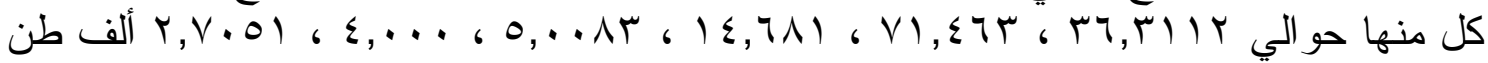

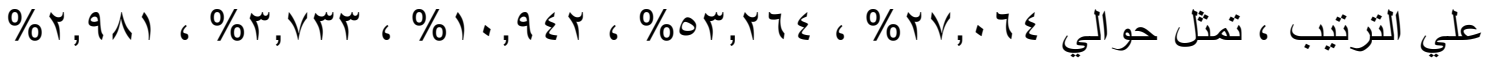

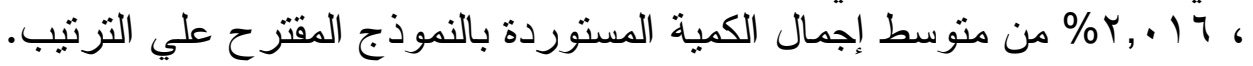

$$
\text { د - نتائج تحليل النموذج من الر ابع: }
$$

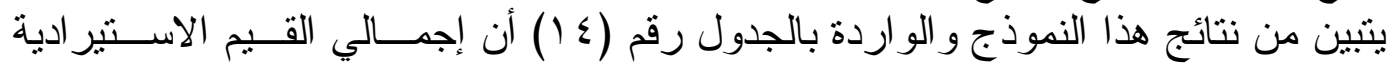

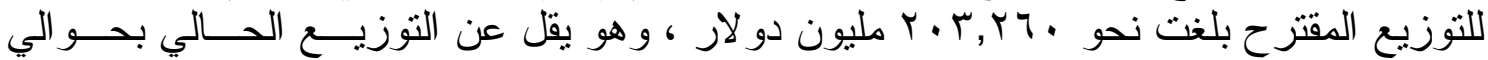

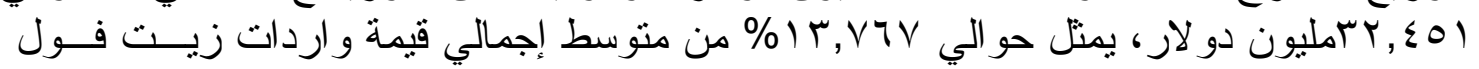

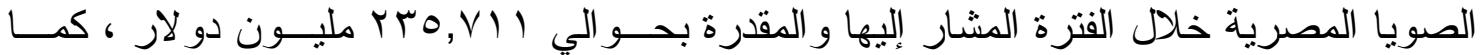

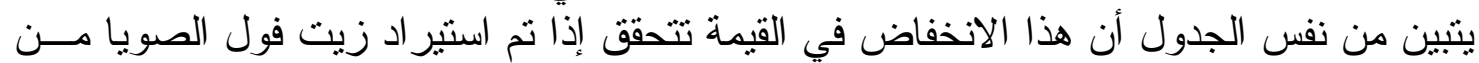

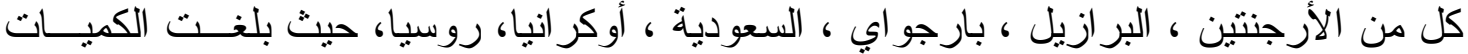




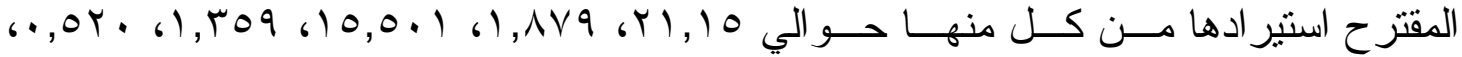

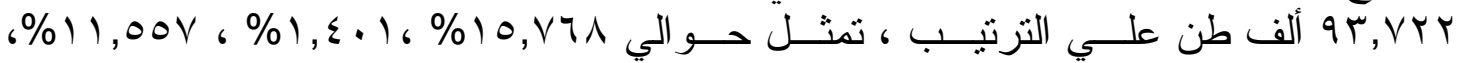

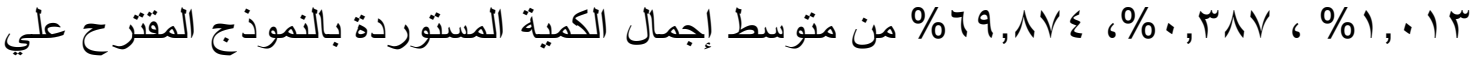
التزنيب.

جدول رقم (ب ا ): التوزيع الفعلي والمقترح والقيمة الاستير ادية لواردات مصر من زيت فــول

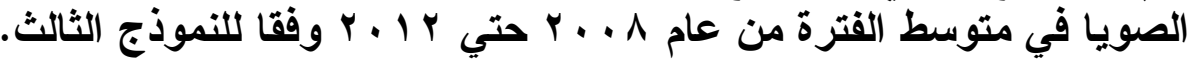

\begin{tabular}{|c|c|c|c|c|c|c|}
\hline \multicolumn{2}{|c|}{ (القيمة الاستيز ادية } & \multicolumn{2}{|c|}{ الكمية المقترحة } & \multicolumn{2}{|c|}{ الكمية المستوردة الفعلية } & \multirow[t]{2}{*}{ الاولة المصدرة } \\
\hline المقترح & 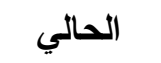 & $\%$ & ألف طن & $\%$ & ألف طن & \\
\hline $7 \varepsilon, 17 \leqslant V$ & $1 \wedge r, O V V$ & $r v, \cdot 7 \varepsilon$ & rוו & $\vee v, \cdots \wedge \wedge$ & Tr,r & |رجنتين \\
\hline$|r r, V q| \tau$ & ( & or, & VI, & $10, Y 0 \leqslant 1$ & $r \cdot, \leqslant \neg 7$ & 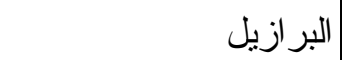 \\
\hline$r \cdot, q \vee 00$ & $\varepsilon, Y \neg \vee T$ & $1 \cdot, 9 \leqslant r$ & $|\varepsilon, 7 \wedge|$ & Y,YYYI & 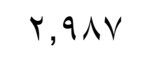 & الو لايات المتحدة \\
\hline$\Upsilon, \wedge \vee ० \wedge$ & $1,7 r \leq \Lambda$ & r & 0, . ט & $\cdot, \wedge \wedge \vee 0$ & 1,191 & \\
\hline$\nearrow, \wedge \wedge 9 \leq$ & 1,0079 & $r, q \wedge)$ & $\varepsilon$ & $\cdot, T \vee T V$ & $\cdot, 9 \cdot \varepsilon$ & 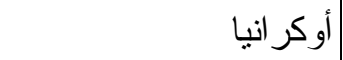 \\
\hline$\Gamma, \tau \leq \tau \leq$ & $\cdot, \vee \vee q q$ & $r, \cdot 17$ & $r, V .01$ & • & $\cdot, 0 \leqslant 1$ & \\
\hline$r \quad r 0, r \leqslant r$ & rYo,qMI & $1 \cdots$ & $1 T \varepsilon, 179$ & $97, \leqslant 0 T \leq$ & $\mid r q, \varepsilon 11$ & لالي الدول السابقة \\
\hline$r \quad r O, r \leq r$ & rro,VוI & $1 \ldots$ & $17 \varepsilon, 179$ & $1 \ldots$ & $17 \varepsilon, 179$ & إجمالي الكمية المستوردة المصدرة \\
\hline
\end{tabular}

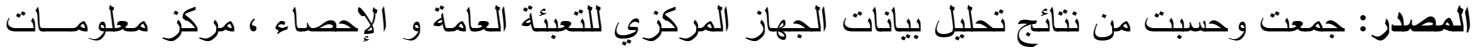

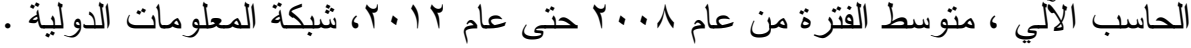

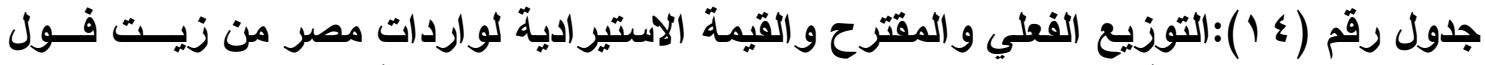

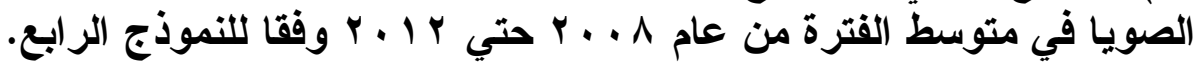

\begin{tabular}{|c|c|c|c|c|c|c|}
\hline \multicolumn{2}{|c|}{ القيمة الاستير ادية (مليون دولار) } & \multicolumn{2}{|c|}{ الكمية المقترحة } & \multicolumn{2}{|c|}{ الكمية المستوردة الفعلية } & \multirow{2}{*}{ الاولة المصدرة } \\
\hline المقترح & الحالي & $\%$ & ألف طن & $\%$ & ألف طن & \\
\hline rV,rVE & IAY,OVV & $10, \vee 7 \leq$ & 1,10 & $v V, \ldots q$ & 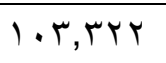 & نتنين \\
\hline r & ro, & $1, \varepsilon \cdots$ & $1, \wedge \vee q$ & 10, ros & $r \cdot, \leqslant \neg\rceil$ & 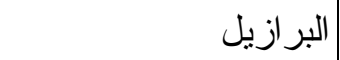 \\
\hline$\cdot, \cdot r \leq$ & $\varepsilon, Y T V$ & $\cdot, \cdot 1 r$ & $\cdot, \cdot 17$ & r, Y & $r, q \wedge \vee$ & 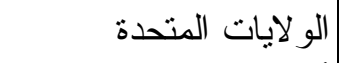 \\
\hline$\cdot, \cdots 7$ & 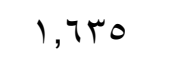 & $\cdot, \cdot r$ & $\cdot, \cdots \varepsilon$ & $\cdot, \wedge \wedge \vee$ & 1,191 & \\
\hline$\cdot, \cdots 1$ & $\cdot, \ldots 19$ & $\cdot, \cdots 1$ & $\cdot, \cdot r$ & $\cdot, \ldots$ & $\cdot, \ldots \varepsilon$ & \\
\hline r T, TVT & 7,oro & 11,001 & $10,0 \cdot 1$ & 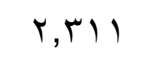 & 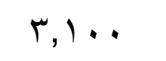 & \\
\hline$\cdot, \cdots 1$ & $\cdot, \vee \vee q$ & $\cdot, \cdot 1$ & $\cdot, \cdots 1$ & $\cdot, Y \wedge O$ & • & \\
\hline$\cdot, \cdot \leq r$ & $\cdot, \cdots \wedge$ & r & $\cdot, \cdot 1 \mathrm{~V}$ & •, & $\cdot, \cdot r$ & \\
\hline$r, \neg \vee \wedge r$ & $Y, 0 \cdot V$ & rו • & $1, r \circ 9$ & $\cdot, 9 \leq 1$ & $1, Y V Y$ & \\
\hline$\cdot, \wedge 90$ & $1,00 \mathrm{~V}$ & $\cdot, \Gamma \wedge V$ & •, Or. & $\cdot, 7 \vee \leqslant$ & $\cdot, 9 \cdot \varepsilon$ & \\
\hline דאז,דץ & $\cdot, \vee Y q$ & $79, \wedge \circ \leqslant$ & $q r, V Y r$ & س. & $\cdot, 0 \leqslant 1$ & \\
\hline$r \cdot r, r q$. & rrq, $\cdot(r$ & $1 \cdots$ & 115,179 & 97,091 & $11 \%, 179$ & لي الدول السابقة \\
\hline$r \cdot r, Y \tau$. & $r(0, V) l$ & $1 \ldots$ & $114 \varepsilon, 179$ & $1 \ldots$ & $1 T \varepsilon, 179$ & إجمالي الكمية المستوردة المصدرة \\
\hline
\end{tabular}

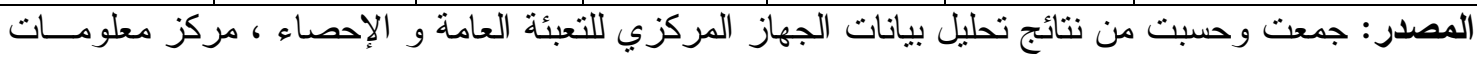

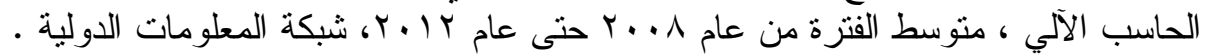


هـ - نتائج تحليل النموذج الخامس:

يتضح من نتائج هذا النموذج المدونة بالجدول رقم (0 (1) أن إجمالي القيمــة الاســتير ادية

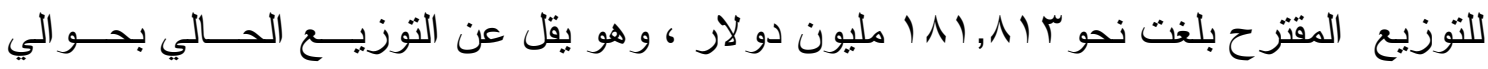

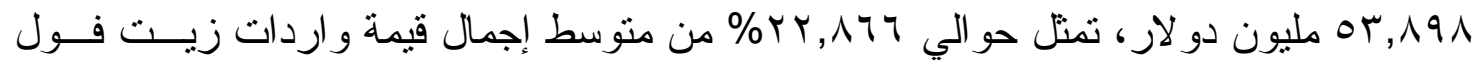

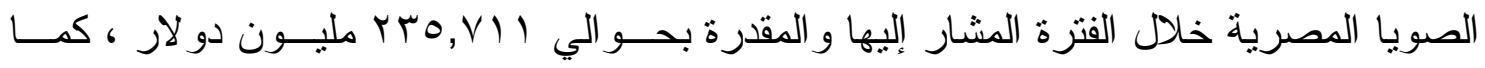

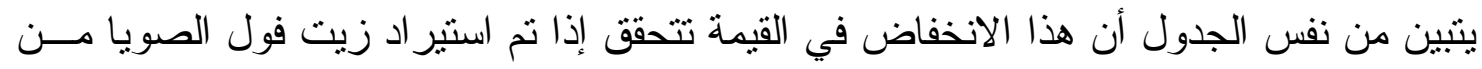

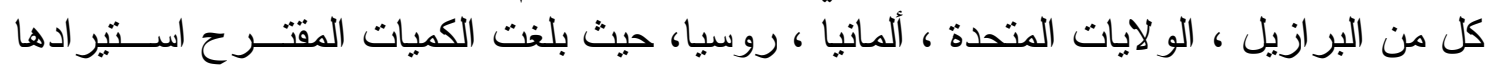

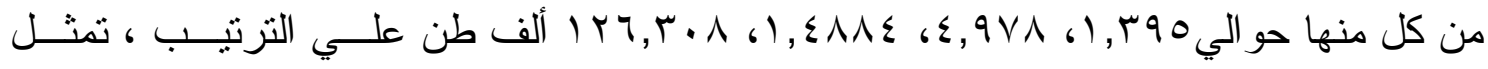

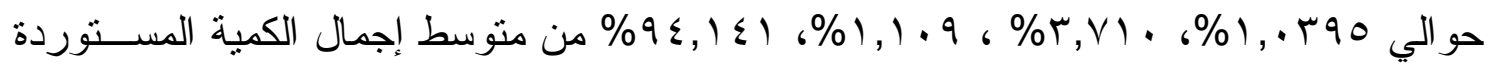
بالنموذج المقترح علي الترنيب.

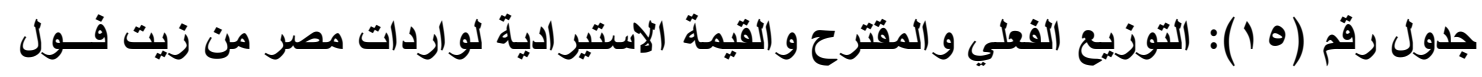

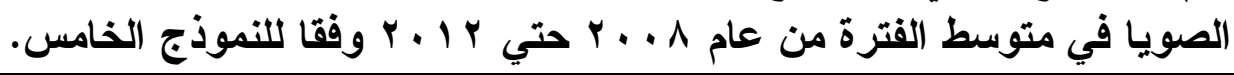

\begin{tabular}{|c|c|c|c|c|c|c|}
\hline \multicolumn{2}{|c|}{ القيمة الاستير ادية (مليون دولار) } & \multicolumn{2}{|c|}{ الكمية المقترحة } & \multicolumn{2}{|c|}{ الكمية المستوردة الفعلية } & \multirow{2}{*}{ الاولة المصدرة } \\
\hline المقترح & الحالي & $\%$ & ألف طن & $\%$ & ألف طن & \\
\hline r,r 970 & $r 0,1771$ & $1, .490$ & 1,490 & $10, Y 0 \leqslant$ & $\left.r_{\cdot}, \varepsilon 7\right\}$ & 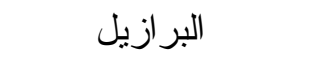 \\
\hline$V, 11 K r$ & $\varepsilon, Y T V T$ & $r, v)$. & $\varepsilon, 9 \vee \wedge$ & Y,YYT & 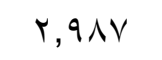 & الو لايات المتحدة \\
\hline$r, \cdot \varepsilon r_{0}$ & $1,7 \pi \leqslant 1$ & $1,1.9$ & $1, \varepsilon \wedge \wedge \varepsilon$ & $\cdot, \wedge \wedge \wedge$ & 1,191 & ألمانيا \\
\hline$|V \cdot, Y T|$ & •, & $9 \leqslant, 1 \leq 1$ & $\mid r q, r \cdot \Lambda$ & $\cdot, \varepsilon \cdot r$ & $\cdot, 0 \leq 1$ & 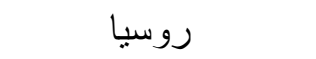 \\
\hline$|\wedge|, \lambda \mid r$ & $\varepsilon 1, \vee 9 \wedge$ & $1 \ldots$ & $1 \pi \varepsilon, 179$ & $|\wedge, \vee \vee \vee|$ & Y0,110 & إجمالي الدول السابقة \\
\hline$|\wedge|, \wedge \mid r$ & Yro,, 11 & $1 \ldots$ & $1 \pi \varepsilon, 179$ & $1 \ldots$ & $17 \varepsilon, 179$ & لجميع الدولي الكمية المستوردة \\
\hline
\end{tabular}

المصدر: جمعت وحسبت من نتائج تحليل بيانات الجهاز المركزي للتعبئة العامة و الإحصاء ، مركز معلومهـات

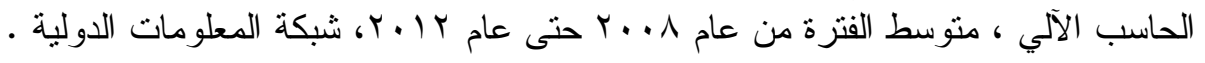

$$
\text { و - نتائج تحليل النموذج السادس: }
$$

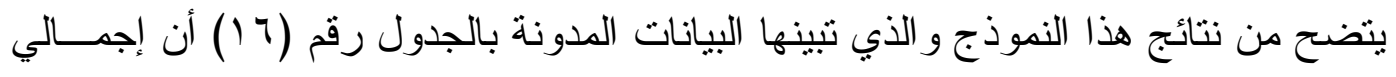

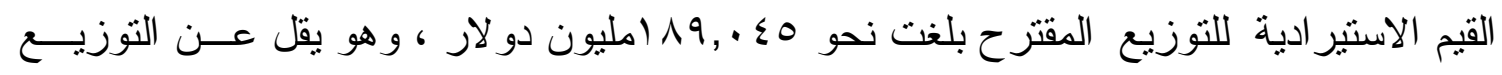

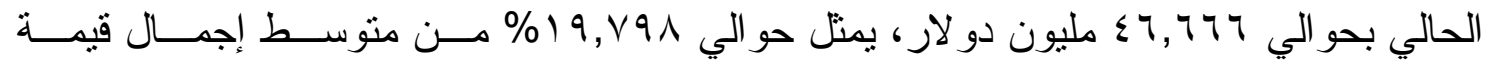

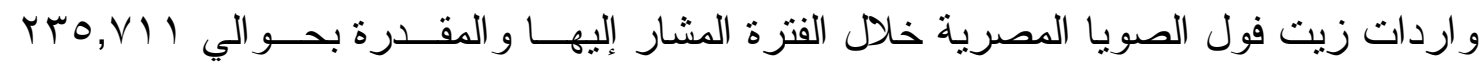

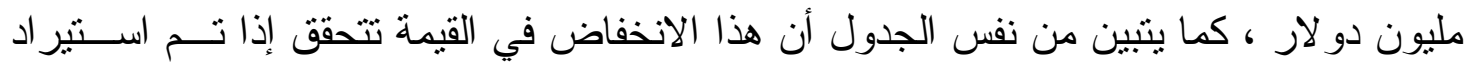

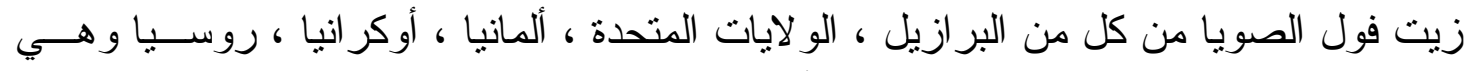

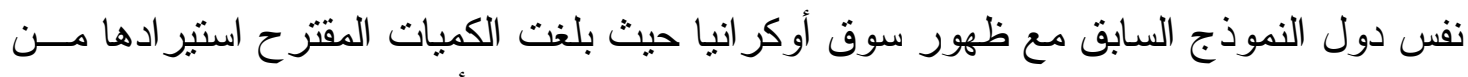

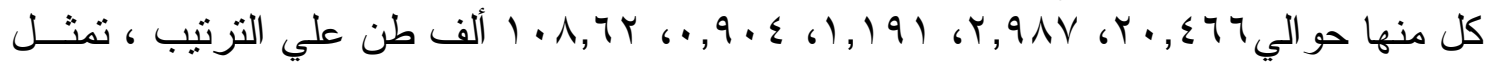

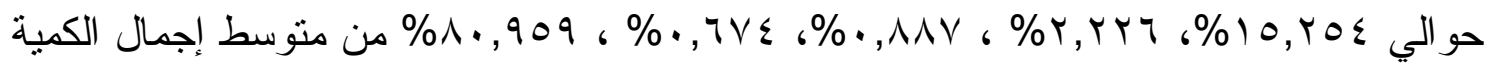

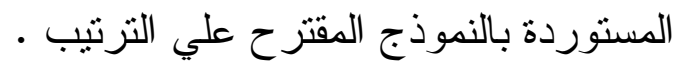


ومما سبق يتبين أن أفضل نتائج النماذج من حيث الوفرة في القيمة الاستير ادية لزيت فول

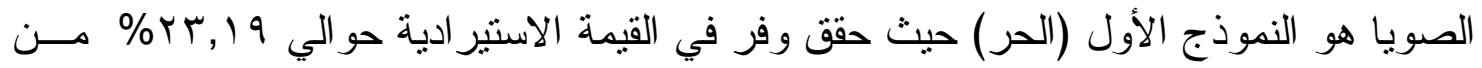

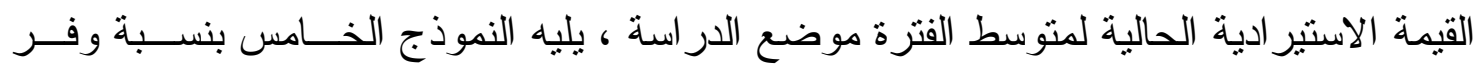

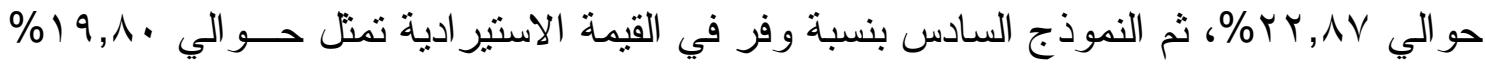

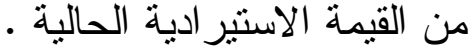




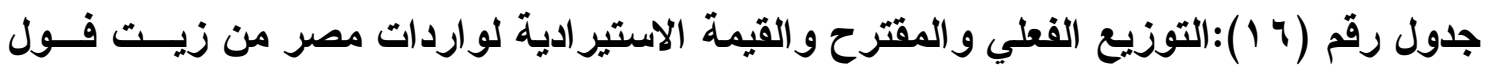

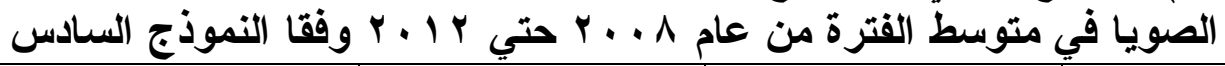

\begin{tabular}{|c|c|c|c|c|c|c|}
\hline \multicolumn{2}{|c|}{ القيمة الاستير ادية (مليون دولار) } & \multicolumn{2}{|c|}{ الكمية المقترحة } & \multicolumn{2}{|c|}{ الكمية المستوردة الفعلية } & \multirow{2}{*}{ الاولة المصدرة } \\
\hline المقترح & الحالي & $\%$ & ألف طن & $\%$ & ألف طن & \\
\hline$r 0,174$ & $r 0,177$ & $10, Y 0 \leqslant$ & Y., โ\ฯ & $10, Y 0 \leqslant$ & $r \cdot, \sum 77$ & \\
\hline$\varepsilon, Y T V$ & $\varepsilon, Y T V$ & Y, YYY & $\curlyvee, 9 \wedge \vee$ & Y,YYT & $r, 9 \wedge \vee$ & ليات المتحدة \\
\hline סחד, 1, & סחד, 1, & $\cdot, \wedge \wedge \vee$ & 1,191 & $\cdot, \wedge \wedge \wedge$ & 1,191 & \\
\hline $1,00 \mathrm{~V}$ & $1,00 \mathrm{~V}$ & $\cdot, 7 \vee \leq$ & $\cdot, 9 \cdot \varepsilon$ & $\cdot, T \vee \varepsilon$ & $\cdot, 9 \cdot \varepsilon$ & 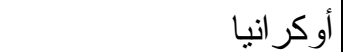 \\
\hline $1 \leq 7, \leq r$. & $\cdot, \vee \vee q$ & $1 \cdot, 909$ & $1 \cdot 1,7 r$ & $\cdot, \varepsilon \cdot \mu$ & $\cdot, 0 \leq 1$ & \\
\hline $1 \wedge 9, \cdot \leq 0$ & $\varepsilon r, r O \varepsilon$ & $1 \ldots$ & $1 \pi \varepsilon, 179$ & $19, \leqslant \leqslant 0$ & $r q, \cdot 19$ & مالي الدول السابقة \\
\hline $1 \wedge 9, \cdot \leq 0$ & ro, VII & $1 \ldots$ & $11 \varepsilon, 179$ & $1 \ldots$ & $1 \Gamma \varepsilon, 179$ & الدول المصدرة المستوردة \\
\hline
\end{tabular}

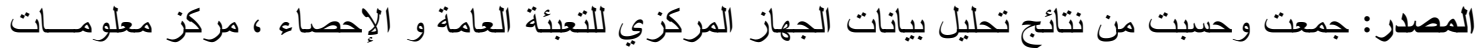

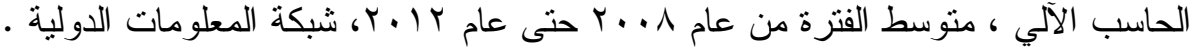

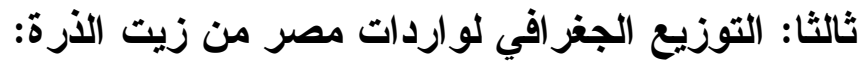

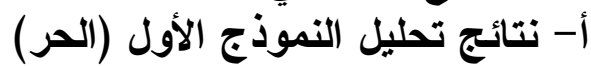

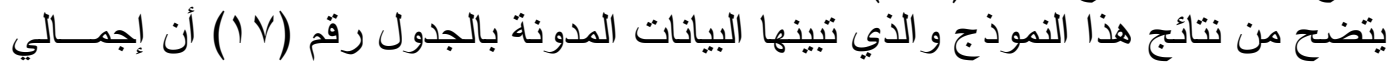

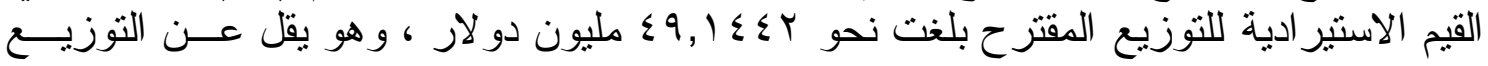

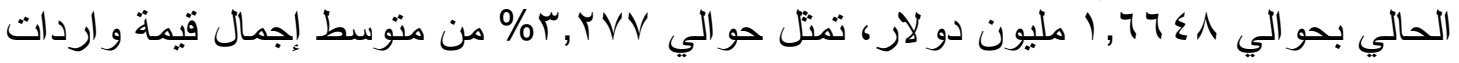

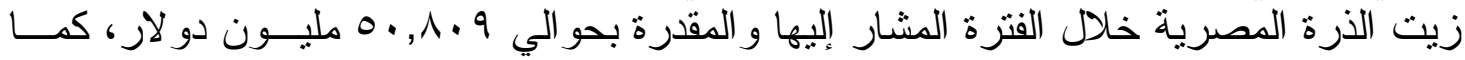

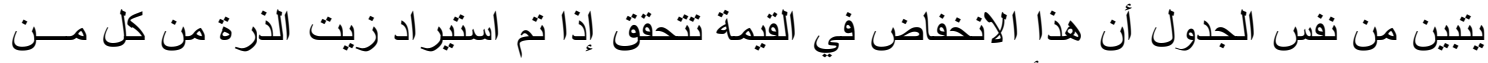

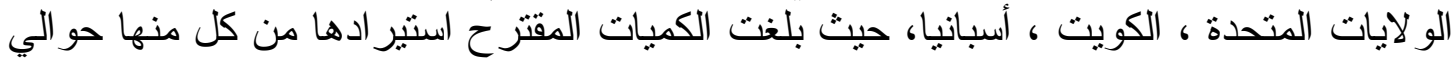

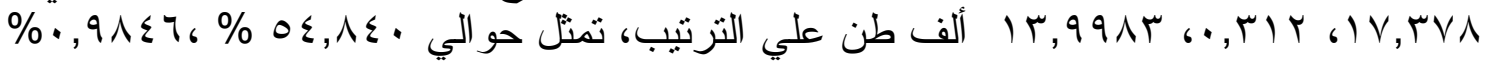

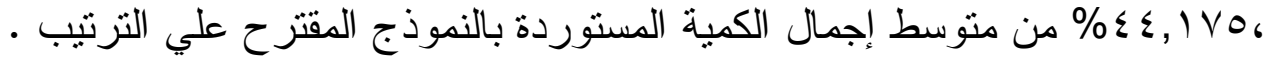

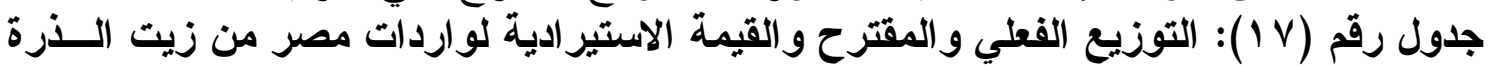

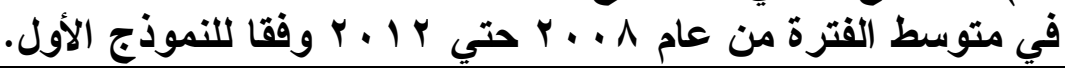

\begin{tabular}{|c|c|c|c|c|c|c|}
\hline \multicolumn{2}{|c|}{ القيمة الاستير ادية (مليون دولار) } & \multicolumn{2}{|c|}{ الكمية المقترحة } & \multicolumn{2}{|c|}{ الكمية المستوردة الفعلية } & \multirow{2}{*}{ الدولة المصدرة } \\
\hline المقترح & الحالي & $\%$ & ألف طن & $\%$ & ألف طن & \\
\hline TV,YY. & $\{0,19 Y$ & $0 \leqslant, \wedge \varepsilon$ & $I V, r \vee A$ & $91,0.0 . V$ & YA, AOYO & الو لايات المتحدة \\
\hline$\cdot, \leqslant Y 0$ & $\ldots \ldots \varepsilon$ & $\cdot, 9 \wedge 0$ & $\cdot, r) Y$ & $\cdot, \cdots 1$ & $\cdot, \ldots r$ & 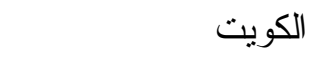 \\
\hline$r_{1}, \leqslant 99$ & $1, r \cdot 0$ & $\varepsilon \varepsilon, 1 \vee 0$ & 15,999 & $r, 乏 \vee V$ & $\cdot, \vee \wedge \leqslant \wedge$ & 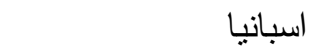 \\
\hline$\leq 9,1 \leq \leqslant$ & $\sum 7, r q \wedge$ & $1 \cdots$ & $r 1,7 \wedge 9$ & $9 T, 0 Y V$ & $r q, 7 r V r$ & إجمالي الدول السابقة \\
\hline$\leq 9,1 \leq \varepsilon$ & $0 \cdot, 1 \cdot 9$ & $1 \cdots$ & $4,7 \wedge 9$ & 1. & 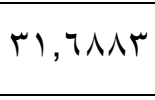 & إجميع الدولي الكمية المستوردة \\
\hline
\end{tabular}

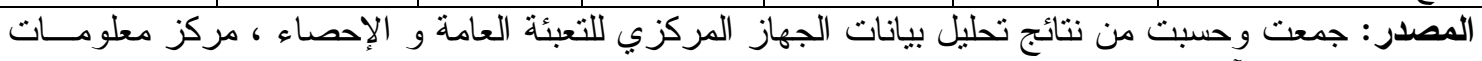

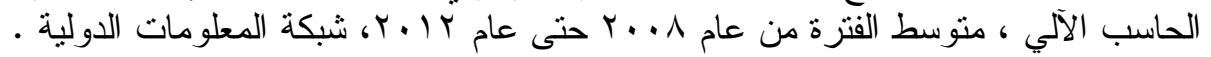

\section{ب- نتائج تحليل النموذج الثاني:}

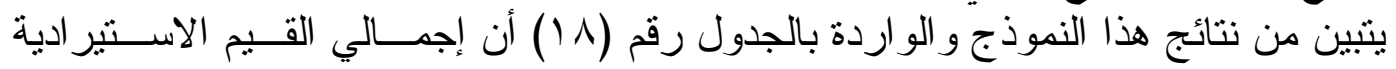

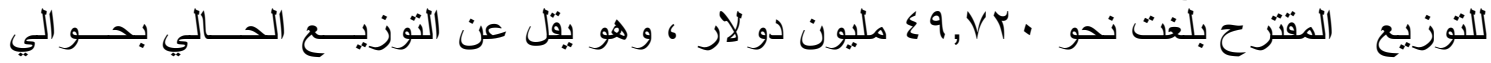

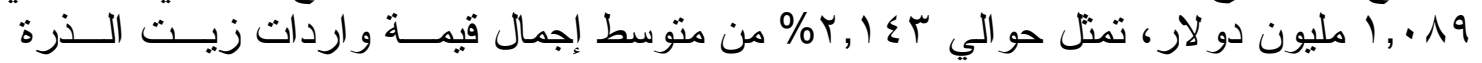

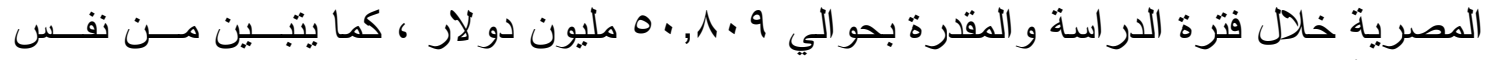

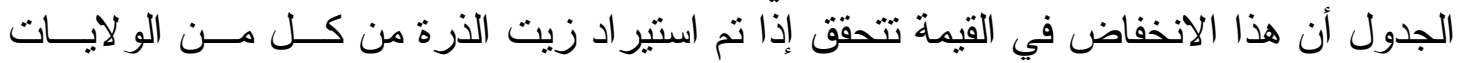

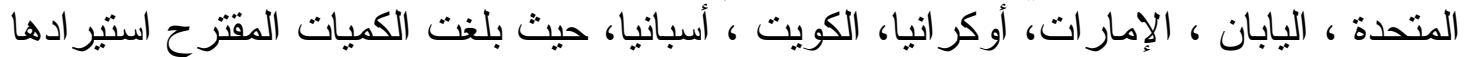

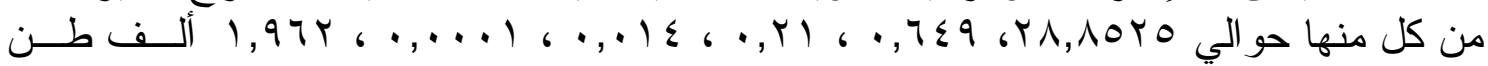




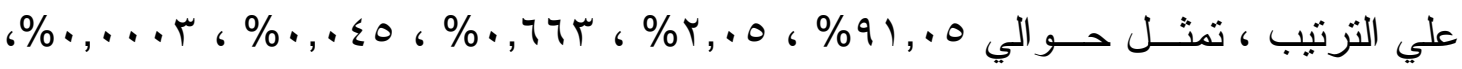

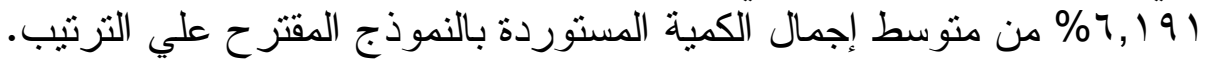
ج - نتائج تحليل النموذج الثالث:

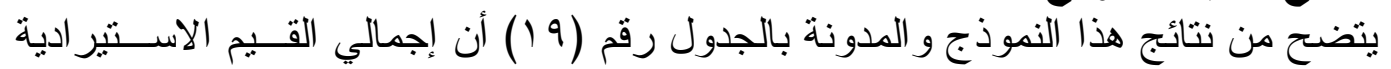

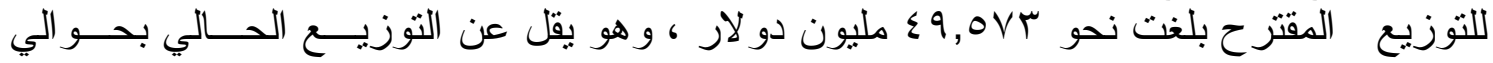

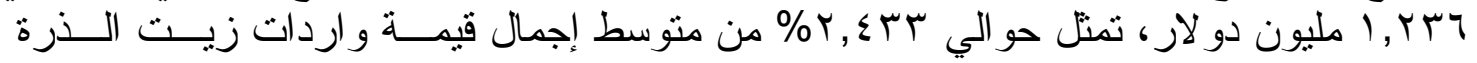

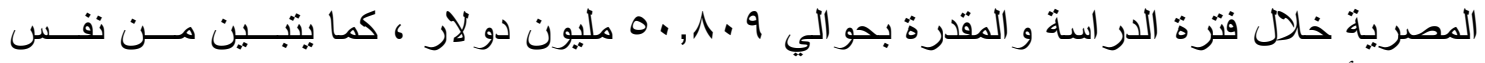

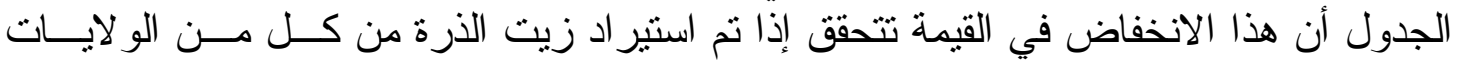

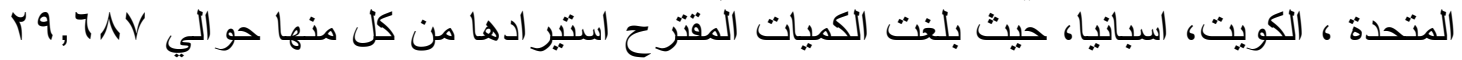

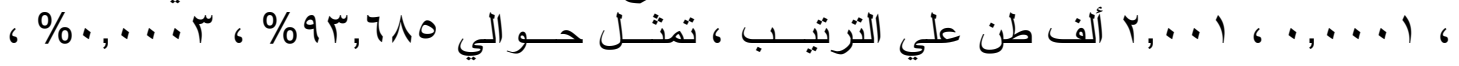

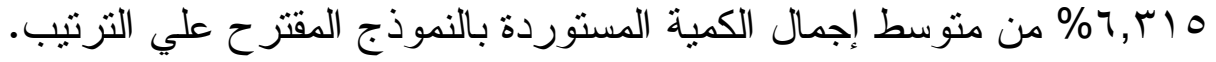

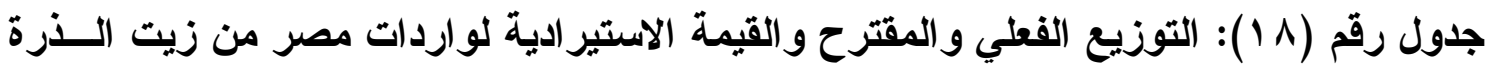

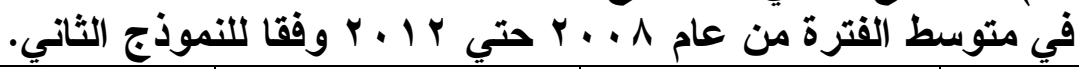

\begin{tabular}{|c|c|c|c|c|c|c|}
\hline \multicolumn{2}{|c|}{ القيمة الاستير اديةة } & \multicolumn{2}{|c|}{ الكمية المقترحة } & \multicolumn{2}{|c|}{ الكمية المستوردة } & \multirow[t]{2}{*}{ الاولة المصدرة } \\
\hline المقترح & الحالي & $\%$ & ألف طن & $\%$ & ألف طن & \\
\hline$\varepsilon 0,19 r$ & $\varepsilon 0,194$ & $91, .01$ & $r \wedge, \wedge \bullet r$ & $91, .01$ & $r \wedge, \wedge \odot r$ & الو لايات المتحدة \\
\hline $1,1 r r$ & $1 \cdot$, YYO & $r, \cdot \leq q$ & $\cdot, 7 \leq 9$ & $\cdot, \leqslant 1$ & $\cdot, 1 \mu$ & اليابان \\
\hline צד & $\cdot, \cdot V r$ & עד דו, • & $\cdot, Y_{1}$ & מ & $\cdot, \cdot \leq r$ & الإلمار ات \\
\hline •, , ro & $\cdot, \leqslant 1$. & $\cdot, \cdot \leq 0$ & $\cdot, \cdot 1 \varepsilon$ & •, VYr & $\cdot, r r q$ & أوكر انيا \\
\hline$\cdot, \cdots r$ & $\cdot, \ldots$ & $\cdot, \ldots r$ & $\cdot, \ldots$ & $\cdot, \ldots 1$ & $\cdot, \ldots r$ & الكويت \\
\hline$r, .1 r$ & $1, r \cdot O r$ & 7,191 & $1,97 \%$ & $Y, \leqslant \vee V$ & $\cdot, \vee \wedge \bullet$ & اسبانيا \\
\hline$\varepsilon q, \vee r$. & $\varepsilon v, 1,0$ & $1 \ldots$ & r & $q \varepsilon, V q \mu$ & $r \cdot, \cdot r \wedge \varepsilon$ & إجمالي الدول السابقة \\
\hline$\varepsilon q, \vee r$. & $0 \cdot, 1 \cdot 9$ & $1 \ldots$ & $\Psi_{1,7 \wedge \wedge \leq}$ & $1 \ldots$ & $P_{1,7 \wedge q}$ & إجمالي الكمية المستوردة \\
\hline
\end{tabular}

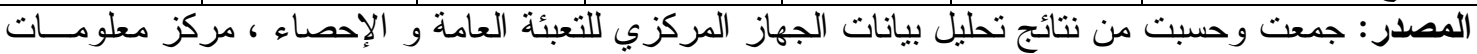

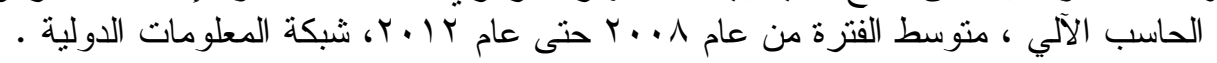

جدول رقم (9 1): التوزيع الفعلي والمقترح و القيمة الاستير ادية لواردات مصر من زيت الـــرة

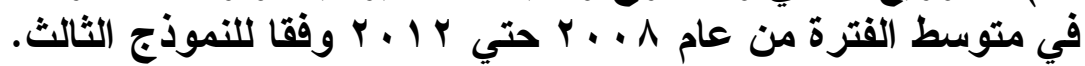

\begin{tabular}{|c|c|c|c|c|c|c|}
\hline \multicolumn{2}{|c|}{ القيمة الاستير ادية } & \multicolumn{2}{|c|}{ الكمية المقترحة } & \multicolumn{2}{|c|}{ الكمية المستيةوردة } & \multirow[t]{2}{*}{ الدولة المصدرة } \\
\hline المقترح & الحالي & $\%$ & ألف طن & $\%$ & ألف طن & \\
\hline$\leqslant 4,0 \ldots$ & $\leqslant 0,19 Y$ & $94,4 \wedge 0$ & rq, ४AV & $91, .01$ & 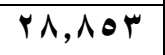 & الو لايات المتحدة \\
\hline$\cdot, \ldots r$ & $\ldots \ldots \varepsilon$ & $\cdot, \ldots r$ & $\cdot, \ldots 1$ & $\cdot, \ldots$, & $\cdot, \ldots, r$ & الكويت \\
\hline$r, \cdot v r$ & $1, r, 0$ & 7,410 & $r, \ldots$ & $r, \varepsilon \vee V$ & $\cdot, \vee \wedge \diamond$ & اسبانيا \\
\hline$\sum q, \diamond \vee r$ & $\leqslant q, r q \wedge$ & $1 \ldots$ & $r 1,7 \wedge \Lambda$ & $9 \%, O Y \wedge$ & $r 9,7 \% \wedge$ & إجمالي الدول السابقة \\
\hline$\{q, \diamond \vee r$ & $0 ., 1,9$ & 1. & 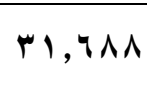 & . & $r, 7 \wedge \Lambda$ & 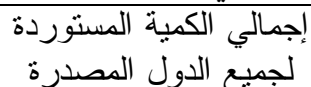 \\
\hline
\end{tabular}

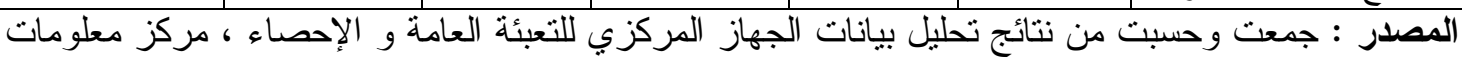

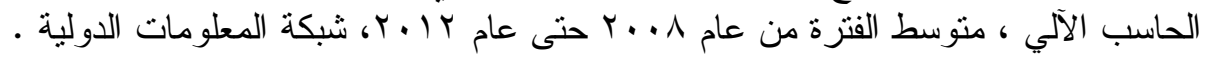

\section{د - نتائج تحليل النموذج الرابع:}

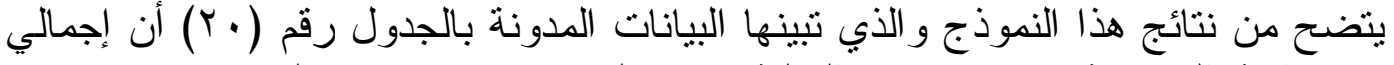

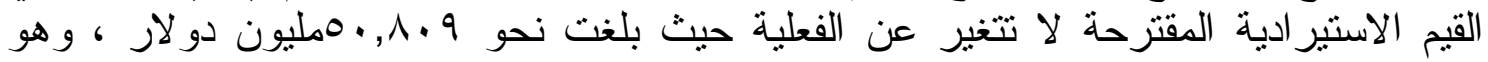

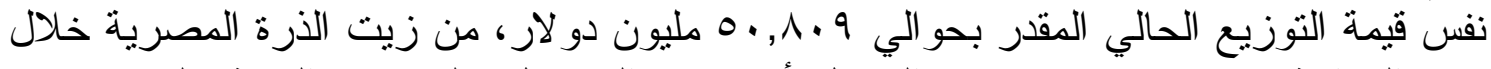

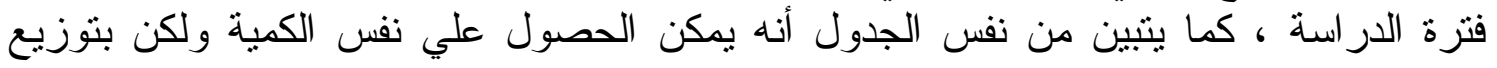


آخر علي النحو التالي : إذا تم استير اد معظم كميات زيت الذرة من كل من اسبانيا ، الولايات

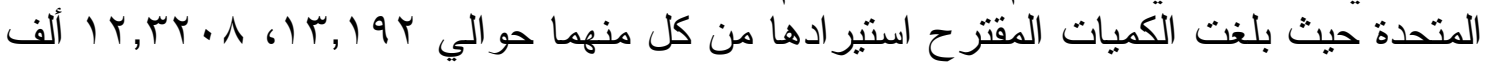

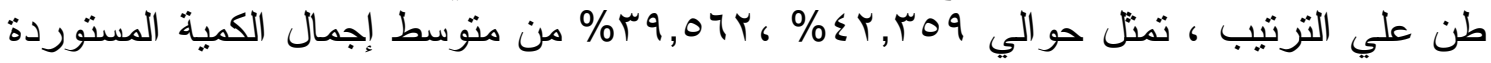

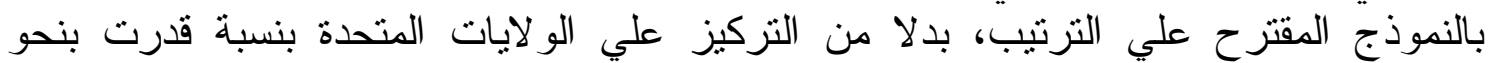

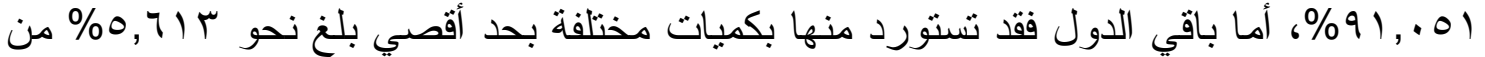

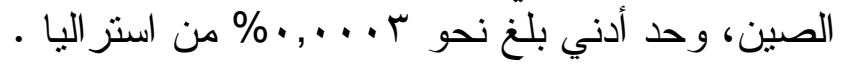

جدول رقم ( • r): التوزيع الفعلي والمقترح والقيمة الاستير ادية لواردات مصر من زيت الــــرة

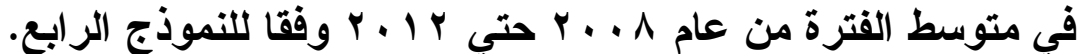

\begin{tabular}{|c|c|c|c|c|c|c|}
\hline مليون دولار) & القيمة الاستير | & ترحة & الكمية ال الكية & ردة الفعلية & الكمية المد & الادم لة المدر, \\
\hline المقترح & الحالي & $\%$ & ألف طن & $\%$ & ألف طن & المدوقي المصندرة \\
\hline $19, r 91$ & $\sum 0,194$ & $r 9,07 r$ & $M, r, A$ & $91, .01$ & 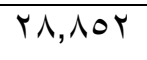 & الو لايات المتحدة \\
\hline $1, r \mu r$ & 1,111 & $1,79 \leq$ & . OYVV & 1,090 & .0 .7 & أرجنتين \\
\hline$\cdot, \cdot r q$ & $\cdot, Y \cdot 1$ & $\cdot, \cdot \leq 0$ & $\cdot, \cdot 149$ & •, YYq & •, & السعودية \\
\hline$\cdot, 107$ & $\cdot, 0 \wedge \Lambda$ & $\cdot, r O \Lambda$ & $\cdot, \cdot \wedge \cdot 0$ & $\cdot, 901$ & $\cdot, \Gamma \cdot \varepsilon$ & تزركيا \\
\hline$\cdot, \cdots \varepsilon$ & $\cdot, \cdots$ & $\cdot, \cdots 1$ & $\cdot, \cdots r$ & $\cdot, \ldots$ & $\cdot, \ldots$ & بريطانيا \\
\hline גזו, & ( & $\cdot, 1 q^{\prime}$ & •,,$E K r$ & מצד & $\cdot, 117$ & فرنسا \\
\hline r, ז人т & $\cdot, T \vee V$ & $0, \pi 1 T$ & $1, v \leq \wedge 1$ & $1,1 \cdot r$ & • r. & الصين \\
\hline Mr & •, Yro & $r, \cdot 10$ & $\cdot, 7 \leq 9 \leq$ & $\cdot, \leqslant)$. & $\cdot, 1 T$. & اليابان \\
\hline דודז, • & $\cdot, \cdot V T$ & $\cdot, 7 \vee 0$ & $\cdot, Y_{1} \cdot r$ & מזו, & $\cdot, \cdot \leq Y$ & الإمار ات \\
\hline$\cdot, 9 \vee 0$ & $\cdot, \leqslant 1$. & 1, Vor & $\cdot, 0 \leqslant 00$ & $\cdot, V Y T$ & $\cdot, r Y q$ & أوكر انيا \\
\hline T,MY & ( & $\varepsilon, T \vee V$ & $1, \leqslant 070$ & $\cdot, 919$ & $\cdot, Y 91$ & البر ازيل \\
\hline$\cdot, \cdot r$ & $\cdot, \cdots 7$ & $\cdot, \cdots \varepsilon$ & $\cdot, \ldots 1 r$ & $\cdot, \cdots 9$ & $\cdot, \cdots r$ & إيطاليا \\
\hline$\cdot, \cdot \leq \Lambda$ & $\cdot, \cdot 1 \cdot$ & $\cdot, \cdot \wedge \varepsilon$ & $\cdot, \cdot, Y 71$ & $\cdot, .17$ & $\cdot, \ldots$ & بلجيكا \\
\hline$\cdot, \ldots$ & $\cdot, \cdots 11$ & $\cdot, \ldots r$ & $\cdot, \cdots$, &,$\cdots \cdots \varepsilon$ & $\cdot, \cdots \cdots$ & استر اليا \\
\hline$\cdot, \leqslant Y \leqslant$ & $\cdot, \cdots \varepsilon$ & $1, \ldots r$ & $\cdot, M$ & $\cdot, \cdots \cdots$ & $\cdot, \ldots r$ & الكويت \\
\hline$r_{\cdot}, r_{T}$. & $1, r .0$ & $\varepsilon r, r \circ q$ & 14,194 & $r, \leqslant V V$ & $\cdot, \vee \vee \wedge$ & اسبانيا \\
\hline$\cdot, \cdot r q$ & $\cdot, \cdots \wedge$ & $\cdot, .01$ & $\cdot, .101$ & $\cdot, \cdot 1$. & $\cdot, \cdot, r$ & تايلاند \\
\hline $0 \cdot, 1 \cdot 9$ & $0 \cdot, 1 \cdot 9$ & $1 \ldots$ & $r, 7 \wedge \Lambda$ & $1 \ldots$ & $\Gamma, 7 \wedge \Lambda$ & إجمالي الدول السابقة \\
\hline $0 \cdot, 1 \cdot 9$ & $0 ., 1.9$ & $1 \cdots$ & $\Gamma, 7 \wedge \Lambda$ & $1 \cdots$ & $\Gamma, 7 \wedge \Lambda$ & المصدرة المدة لجه \\
\hline
\end{tabular}

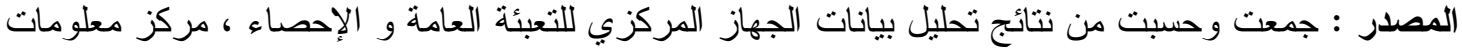

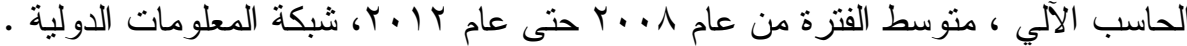

\section{هـ - نتائج تحليل النموذج الخامس:}

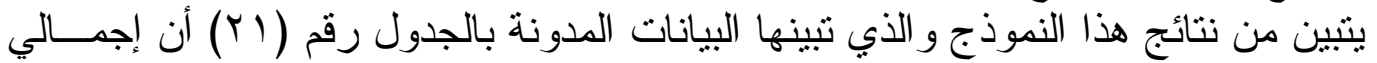

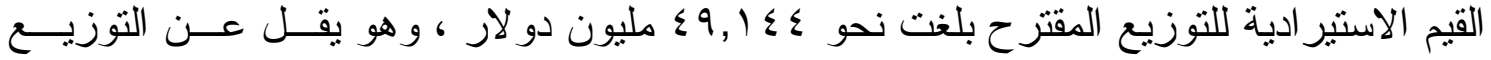

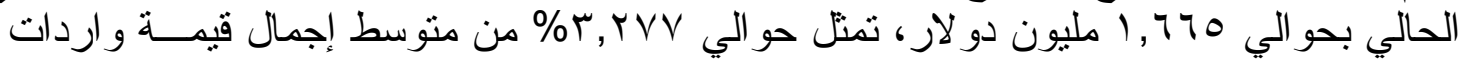
زيت الذرة المصرية خلال فترة الدر اسة و المقدرة بحو الي 9 • ^ر, ـ ه مليون دو لار ، كما يتبين من

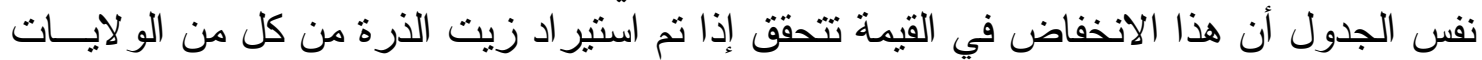

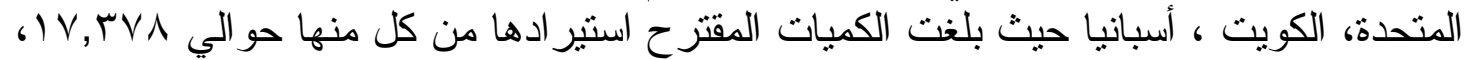

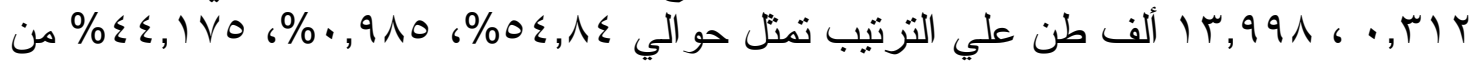

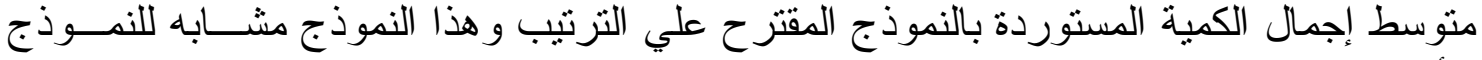
الأول (الحر). و - نتائج تحليل النموذج السادس: 
يوضح النموذج السادس المدون نتائجه بالجدول رقم (Yr) أن إجمالي القـيم الاســتير ادية

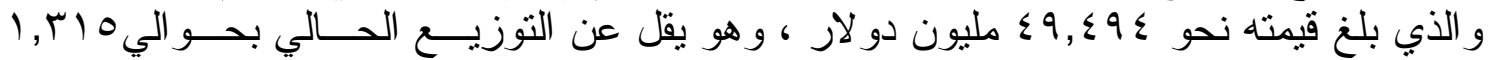

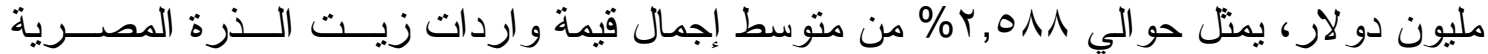

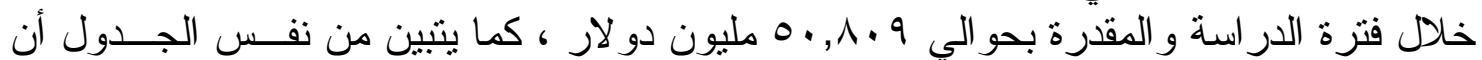
هذا الانخفاض في القيمة تتحقق إذا تم استير اد زيت الذرة من كل من الو لايات المتحدة ، الكويت

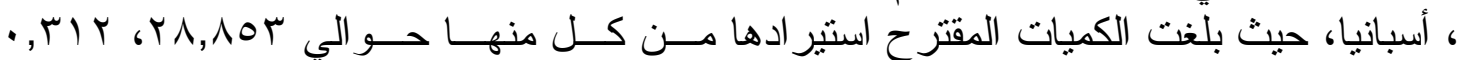

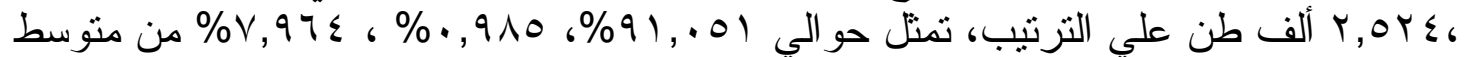

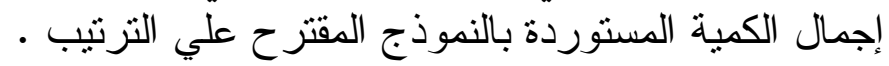

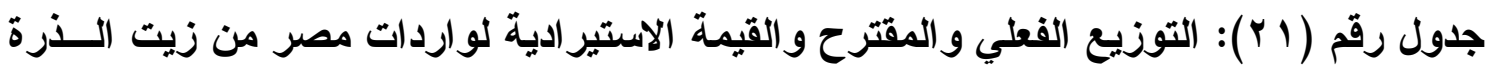

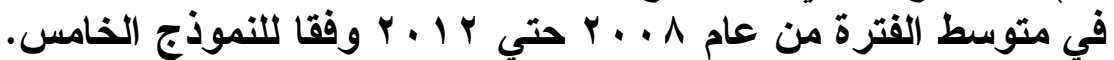

\begin{tabular}{|c|c|c|c|c|c|c|}
\hline \multicolumn{2}{|c|}{ القيمة الاستير ادية (مليون دولار) } & \multicolumn{2}{|c|}{ الكمية المقترحة } & \multicolumn{2}{|c|}{ الكمية المستوردة الفعلية } & \multirow{2}{*}{ الدولة المصدرة } \\
\hline المقترح & الحالي & $\%$ & ألف طن & $\%$ & ألف طن & \\
\hline TV,YY. & $\sum 0,19 Y$ & $0 \xi, \wedge \varepsilon$ & $I V, r \vee A$ & $91, .0 . v$ & YA,AOr & لايات المتحد \\
\hline$\cdot, \varepsilon Y_{0}$ & $\cdot, .479$ & $\cdot, 9 \wedge 0$ & $\cdot \operatorname{rir}$ & $\cdot, \cdots 1$ &,,$\ldots \varepsilon$ & الكويت \\
\hline$r_{1}, \varepsilon 99$ & $1, Y \cdot 0$ & $\varepsilon \varepsilon, 1 \vee 0$ & 14,991 & $r, \varepsilon V V$ & $\cdot, \vee \wedge \diamond$ & بانيا \\
\hline$\varepsilon 9,1 \leqslant \varepsilon$ & $\sum T, \varepsilon \Psi T$ & $1 \ldots$ & $\Gamma, 7 \wedge \wedge$ & $9 r, O r V$ & rq,7rA & مالي الدول السابقة \\
\hline १, $1 \leq \varepsilon$ & $0 ., \varepsilon \pi r$ & 1. & $\uparrow, 7 \wedge \wedge$ & $1 \ldots$ & $\top, \uparrow \wedge \Lambda$ & بلة المصدرة المستودة \\
\hline
\end{tabular}

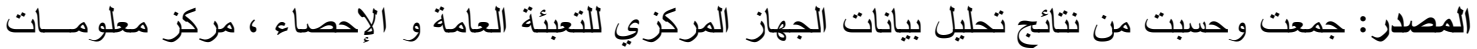

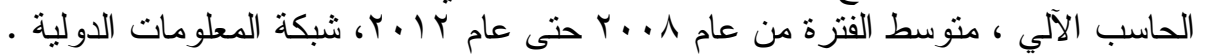

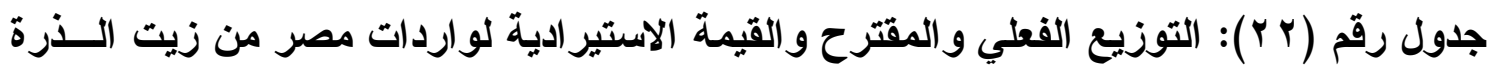

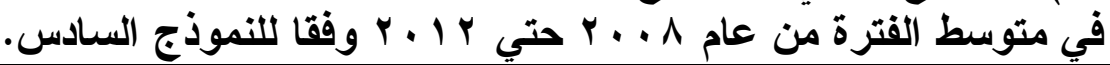

\begin{tabular}{|c|c|c|c|c|c|c|}
\hline \multicolumn{2}{|c|}{ القيمة الاستير ادية (مليون دولار) } & \multicolumn{2}{|c|}{ الكمية المقترحة } & \multicolumn{2}{|c|}{ الكمية المستوردة الفعلية } & \multirow{2}{*}{ الدولة المصدرة } \\
\hline المقترح & الحالي & $\%$ & ألف طن & $\%$ & ألف طن & \\
\hline$\varepsilon 0,19 \pi$ & $\sum 0,19 r$ & $91, .01$ & YA,AOY & $91, .01$ & YA,AOT & الو لايات المتحدة \\
\hline$\cdot, \varepsilon Y_{0}$ & $\cdot, \ldots \varepsilon$ & $\cdot, 9 \wedge 0$ & • & $\cdot, \ldots 1$ & $\cdot, \ldots r$ & 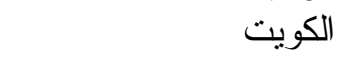 \\
\hline$\ulcorner, \wedge \vee \tau$ & $1, Y \cdot 0$ & $\vee, 97 \varepsilon$ & Y,OY $\varepsilon$ & $r, \varepsilon \vee V$ & $\cdot, \vee \vee \wedge$ & اسبانبا \\
\hline$\leq 9, \leqslant 9 \leqslant$ & $\varepsilon 7, \Gamma q \wedge$ & $1 \ldots$ & $r, 7 \wedge \lambda$ & $9 \mathrm{9T,OYA}$ & rq,7rᄉ & إجمالي الدول السابقة \\
\hline$\leqslant 9, \leqslant 9 \leqslant$ & $0 ., 1.9$ & $1 \ldots$ & $\mu_{1, \tau \wedge \Lambda}$ & $1 \ldots$ & $\mu_{\top, \uparrow \wedge \Lambda}$ & إجميع الدولي الكمية المستوردة \\
\hline
\end{tabular}

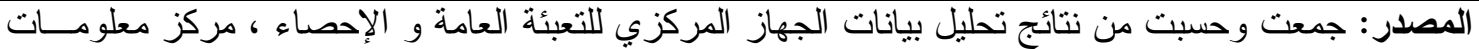

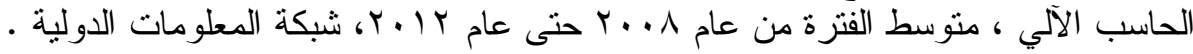

ومن النتائج السابقة يتضح أن أفضل النماذج من حيث الوفرة في القيمة الاستير ادية لزيت

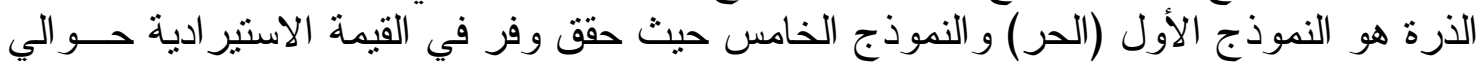

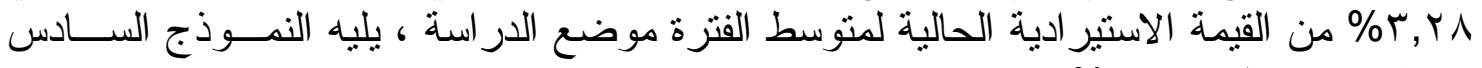

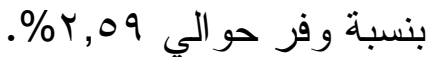

$$
\begin{aligned}
& \text { الملخص والتوصيات : }
\end{aligned}
$$

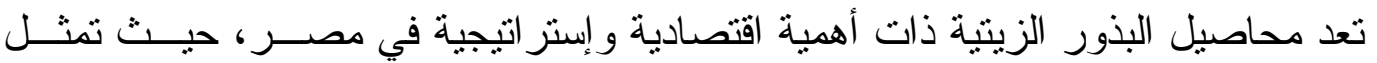

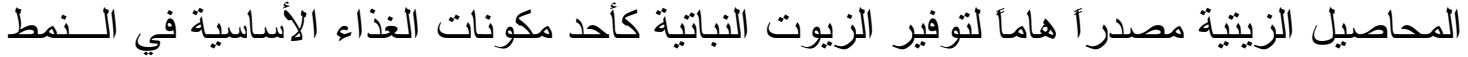

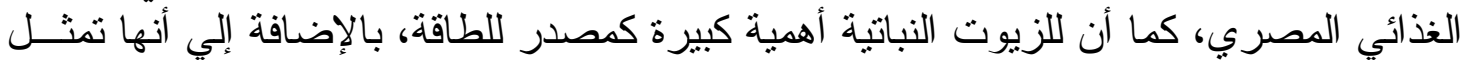

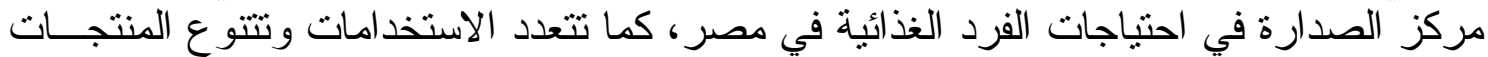

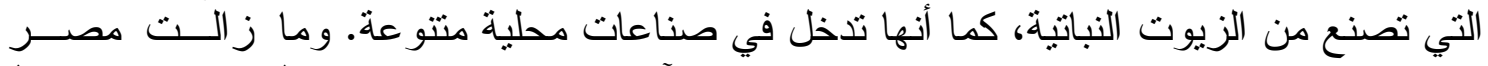

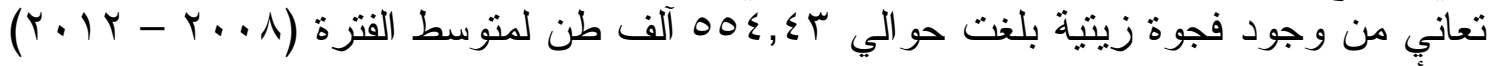

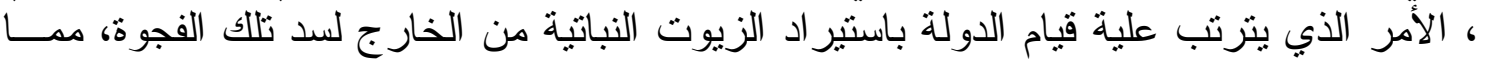




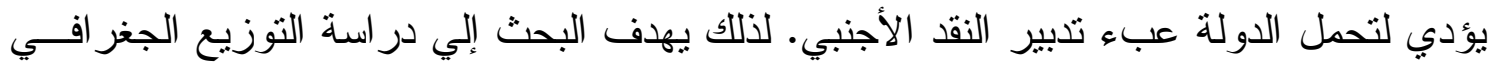

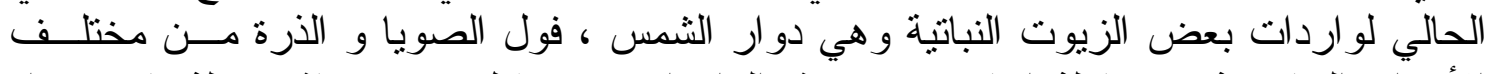

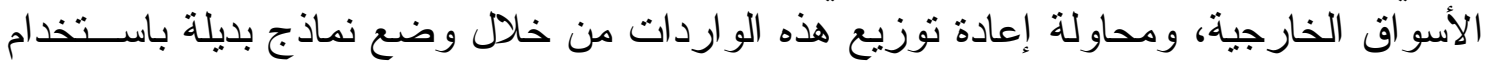
البرمجة الخطية لتننية قيمة استير ادها. 
وقد توصل البحث للنتائج التالية :

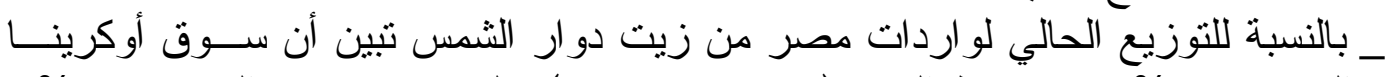

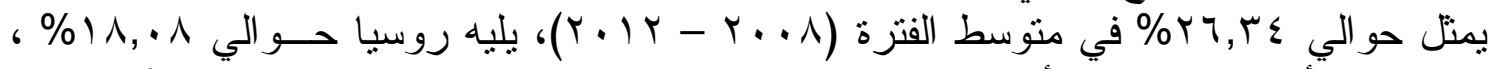

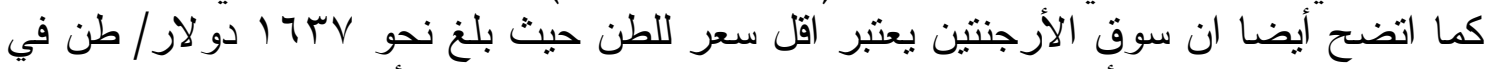

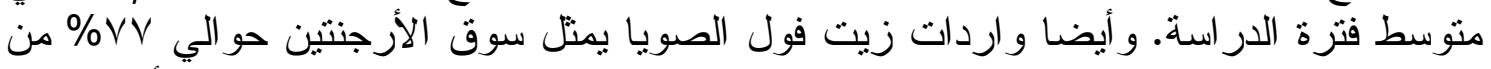

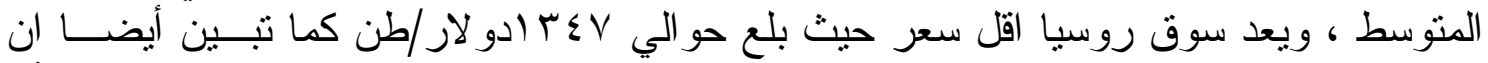

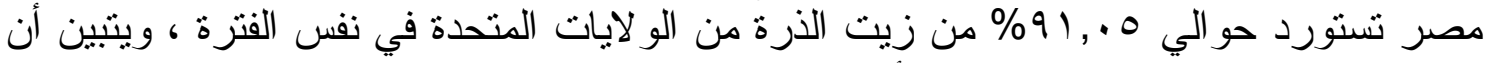

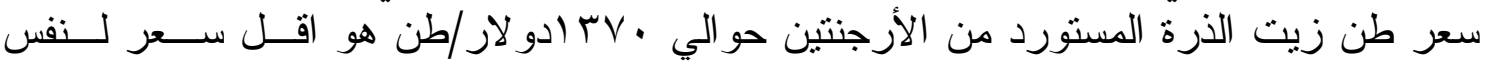
الفترة.

- ومن در اسـة التوزيع الجغر افي المقتر ح لواردات الزيوت موضـــع الدر اســـة باســـتخدام

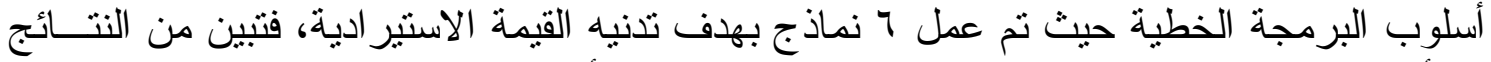

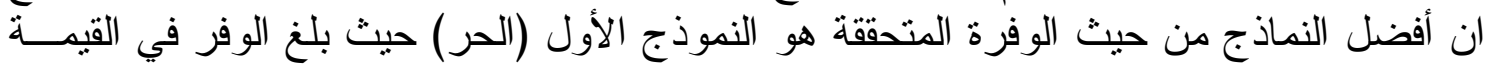

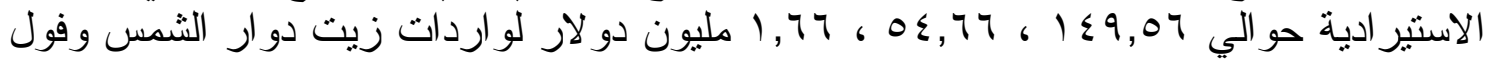

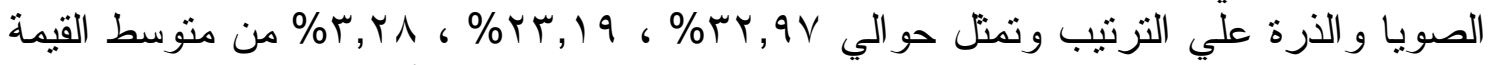

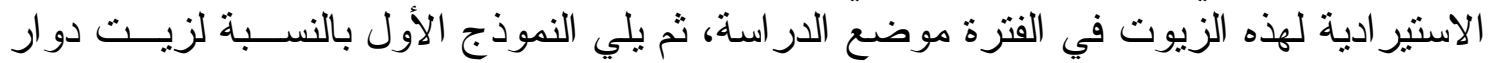

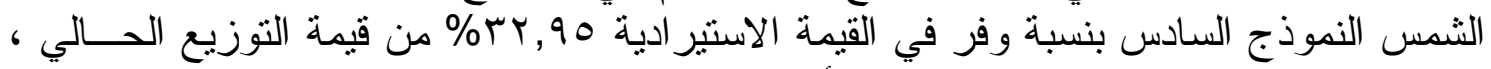

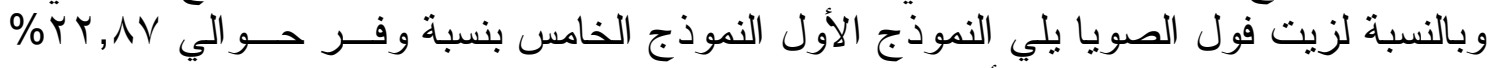

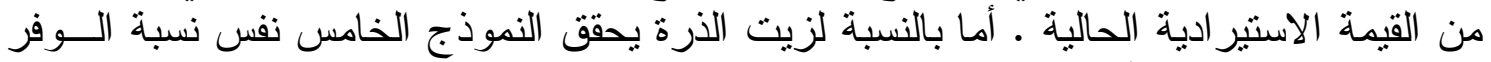

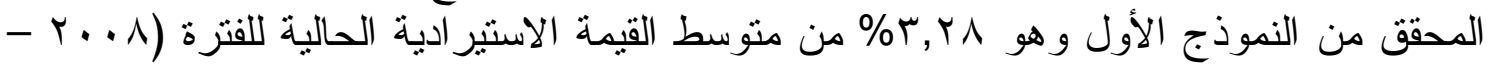
. $(r .14$

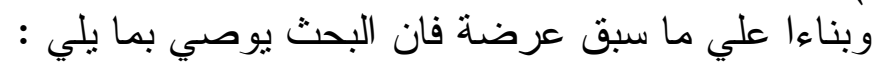

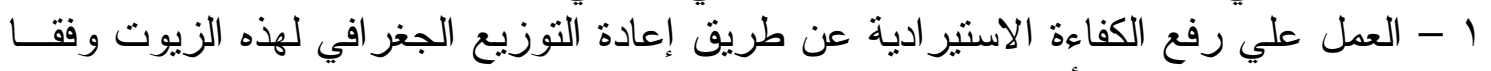

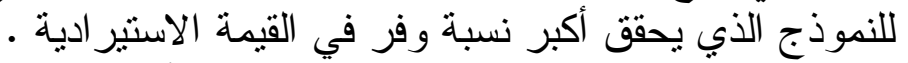

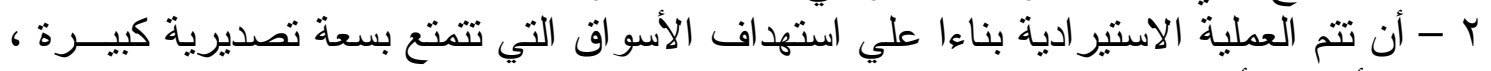

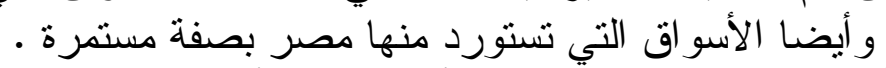

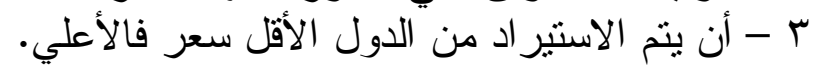
المر اجع : (انج) ا- الجهاز المركزي للتعبئة العامة و الإحصاء ، مركز معلومات الحاسب الآلي •

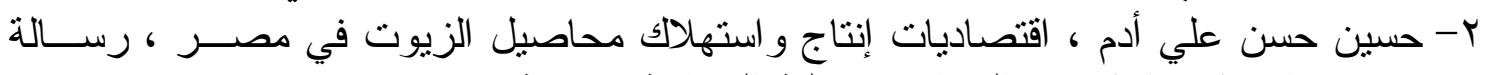

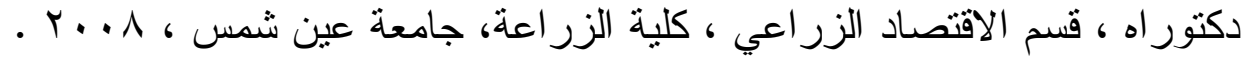

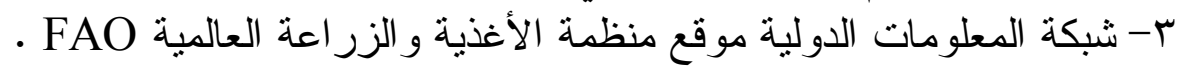

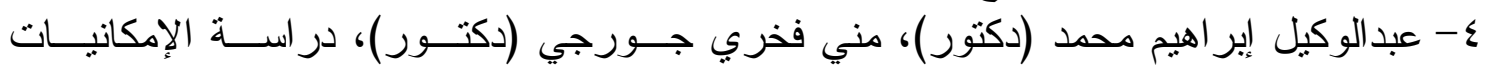

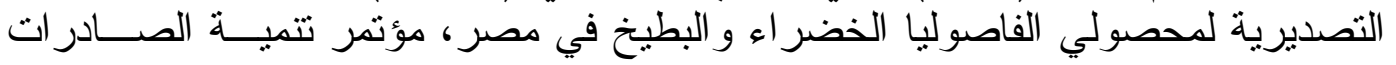

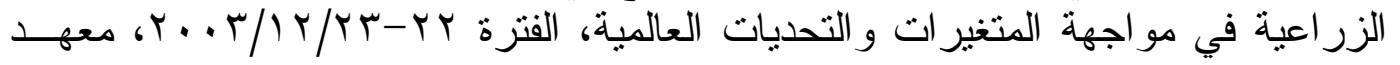

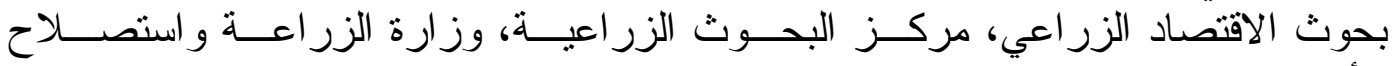

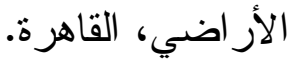
.www.aiu.edu/University -0 


\title{
The Current and Optimized Geographical Distribution for Egyptian Imports From Some Vegetable Oils
}

\author{
Magda, A.S. ; A. I. Mohamed ; A.H. El-Shimy and Y.A. Diab
}

Department of Agricultural Economics, Faculty of Agriculture, Assiut University

\section{Summary:}

The oilseed crops has an economical important and strategy in Egypt, where oil crops are represents an important source for the provision of vegetable oils as a basic food components in food style Egyptian, and vegetable oils of great importance as a source of energy as well as it represents the center of the food needs of the individual in Egypt as multiple uses and varied products that are made from vegetable oils, it is also involved in a variety of local industries.

And Egypt continues to suffer from an oily gap amounted to about 554.43 thousand tons for the average period (2008-2012), which would entail the State to import vegetable oils from abroad to fill the gap, leading to assume the state the burden of foreign exchnage management, so to study the distribution aims current geographical imports some oil, a sunflower, soybean and corn from various foreign markets, and try to re-distribute these imports through the development of alternative models using linear programming to balance the value imported.

The research found the following results:

- For the current distribution of imports from Egypt sunflower oil market show that Ukraine represents about $26.34 \%$ of the average of the period (20082012), followed by Russia about $18.08 \%$, also turned out to be Argentina' market is less price per tone at about 1637 dollars $77 \%$ on average, Russia's market is less price is at about US \$ 1348, also show that Egypt imports about $91.05 \%$ of the corn oil from the United States in the same period, showing that the price per ton of corn oil imported from Argentina about $\$ 1370$ and is the lowest price for the same period.

- It is proposed that the geographical distribution of oil imports into the study of the study using the linear programming method, where it was the work of 6 models with a view to minimization of import value and results show that the best models in terms of savings achieved is the first model where the free import value amounted to about 149.56, 54,66 , 1.66 million dollars for the import of sunflower oil, soybean and corn, respectively, representing approximately $32.97 \%, 23.19 \%, 3.28 \%$ of the average import value of these oils in the period under study.

Then follows the model states for sunflower oil sixth form by teams import value of $32.95 \%$ of the current distribution value, and for soybean oil following the first model, five model by providing approximately $22.87 \%$ of the current import value, as for corn oil attaining model fifth same percentage savings realized from the first model which is $3.28 \%$ of the current average import value for the period (2008-2012). 